\title{
UNA EVALUACIÓN DE LA EDUCACIÓN SUPERIOR: LA MIRADA DE LOS ESTUDIANTES
}

\author{
Loreto Cox \\ MIT - Centro de Estudios Públicos \\ Andrés Hernando \\ Centro de Estudios Públicos \\ Andrea Rebolledo \\ Universidad de Chile
}

\begin{abstract}
RESUMEN: El presente trabajo muestra los principales resultados de una evaluación de la educación superior chilena, desde el punto de vista de estudiantes y egresados en torno a su fecha de graduación. Entre los tópicos tratados se encuentran los criterios que utilizan los alumnos para elegir su institución y carrera y cómo evalúan a las mismas. Se analiza la relación entre la percepción de los estudiantes y el nivel de acreditación de la institución, las dificultades académicas que han enfrentado y las fuentes de financiamiento que han utilizado, junto con la evaluación del nivel de respeto percibido por
\end{abstract}

Loreto Cox. Economista y socióloga de la Pontificia Universidad Católica de Chile. Investigadora del Centro de Estudios Públicos (CEP) y candidata a doctora en el MIT. Email: 1cox@cepchile.cl.

Andrés Hernando. PhD en economía por Harvard University e ingeniero civil en computación y máster por la Universidad de Chile. Profesor en la Universidad Adolfo Ibáñez. Investigador del CEP. Email: ahernando@cepchile.cl.

Andrea Rebolledo. Economista y magíster en análisis económico por la Universidad de Chile. Actualmente estudia un máster en public administration en Harvard University. Email: andrea.paz.rebolledo@gmail.com. 
los alumnos hacia personas $\mathrm{u}$ opiniones diferentes en el ambiente de su institución. En base a los resultados, se presentan dos desafíos de política pública. El primero dice relación con el rol de la información de los estudiantes en sus elecciones. El segundo se relaciona con la importancia del nivel socioeconómico en las diferencias de percepción que tienen los estudiantes y cuál es el papel de las instituciones de educación superior en la reducción de estas diferencias.

PALABRAS ClAVE: educación superior; acreditación; percepción de estudiantes; dificultades académicas; percepción de respeto.

RECIBIDO: enero 2018; ACEPTADO: mayo 2018.

\title{
AN EVALUATION OF HIGHER EDUCATION: THE STUDENT VIEW
}

\begin{abstract}
The present study gives the main findings of an evaluation of Chilean higher education from the point of view of students shortly before or after graduation. The topics dealt with include the criteria used by students to choose their institution and course and the way they evaluate these. The study analyses the relationship between students' perceptions and institutions' level of accreditation, the academic difficulties students have encountered and the sources of financing they have used, and evaluates what they perceive to be the level of respect for different opinions and people in the institutional environment. Two public policy challenges arise from the results. The first concerns the role of students' information when they make their choices. The second concerns the influence of socioeconomic status on differences in students' perceptions and the role for higher education institutions in reducing these differences.
\end{abstract}

KEYwORDs: higher education, accreditation, student perceptions, academic difficulties, perceived respect.

RECEIVED: January 2018; ACCEPTED: May 2018.

\section{INTRODUCCIÓN}

E $\mathrm{n}$ los últimos años, se ha hablado mucho sobre educación superior en Chile. A principios de 2018, el Congreso aprobó la nueva ley de educación superior enviada por el gobierno de Michelle Bachelet, luego de un encendido debate que ha ocupado a menudo las páginas de nuestros medios de comunicación, concitando la opinión de rectores, expertos, líderes estudiantiles y políticos. Sin embargo, poco sabemos 
sobre cómo ven su experiencia en la educación superior los más de un millón doscientos mil estudiantes que forman parte de este sistema. El objetivo del presente estudio es precisamente ése: aportar al debate la visión de los propios estudiantes. Para ello, se realizó una encuesta en línea a 14.146 estudiantes de educación superior recién egresados o próximos a finalizar su carrera, provenientes de 49 instituciones de educación superior. Hasta donde sabemos, a la fecha no ha existido en Chile un esfuerzo, de esta magnitud, de recolección de datos concernientes a la visión que tienen los propios estudiantes de la educación superior.

Este trabajo presenta los principales resultados de la encuesta en relación con la experiencia en educación superior. Aquí se detallan, entre otras cosas, los criterios que utilizan los estudiantes para elegir su institución y carrera, y cómo las evalúan. Se analiza la relación entre la percepción de los estudiantes y el nivel de acreditación de la institución, las dificultades académicas que han enfrentado y las fuentes de financiamiento que han utilizado. También se estudia cómo varía el nivel de respeto percibido por los estudiantes hacia las personas u opiniones diferentes en el ambiente de su institución de educación superior.

En primer lugar, se establecen las características de este estudio, sus objetivos y diseño metodológico, para luego describir aspectos particulares de su elaboración, tales como los criterios de confidencialidad y algunas aclaraciones para leer los datos. Los capítulos 2 al 7 detallan los resultados para seis temas que consideramos relevantes de analizar. Cada sección es autocontenida, por lo que no es necesario leer este artículo en orden para entender los resultados de cada tema en particular.

Finalmente, el capítulo 8 presenta brevemente las conclusiones generales y algunas perspectivas de política pública a la luz de lo presentado anteriormente. En la versión digital de este artículo se agregan a estos capítulos un anexo con un glosario de las variables analizadas en este proyecto, el cuestionario de la encuesta y un análisis detallado de la representatividad de la muestra analizada.

\subsection{Estudio de educación superior}

Este estudio forma parte del proyecto académico "Educación superior en Chile: evaluación, expectativas y resultados", del Centro de Estudios Públicos. Éste es un trabajo pionero que aspira a ser una evalua- 
ción de la educación superior chilena que descanse en el punto de vista de los propios egresados y de su proceso de inserción laboral. Aquí no sólo se considera la dimensión económica de lo que hoy significa egresar de la educación superior, sino que también las dimensiones social y política. Creemos que este proyecto aportará antecedentes fundamentales para evaluar las virtudes y defectos de nuestro sistema terciario y para comprender de mejor forma los cambios sociales asociados a su masificación. Asimismo, este artículo aportará con evidencia empírica indispensable para ir mejorando nuestro sistema de educación superior.

Este proyecto tiene dos objetivos: 1) evaluar en profundidad la educación superior chilena desde la perspectiva de los propios estudiantes, en particular, de aquellos que están graduándose; y 2) caracterizar las expectativas laborales de los egresados de la educación superior. Este artículo se enfoca en los resultados relativos al primer objetivo, mientras que un trabajo complementario, en desarrollo, se enfoca en los del segundo. Se distingue por tipo de institución, tipo de carrera y tipo de estudiantes, con el fin de capturar la diversidad de nuestro sistema de educación superior.

\subsubsection{Diseño metodológico}

Una pieza clave del estudio consiste en la realización de una encuesta en línea que fue aplicada en dos momentos distintos a un grupo amplio de estudiantes cercanos al tiempo de su graduación. La primera ola, que se aplicó hacia fines de noviembre del año 2016, y en la cual se basa el presente análisis, consultó sobre cómo los estudiantes evalúan su paso por la educación superior, sobre sus expectativas laborales y sobre su visión del país. La segunda ola, que se realizó un año después a las mismas personas, preguntó sobre la inserción laboral efectiva de los egresados y, nuevamente, sobre su visión del país. La elaboración de ambos cuestionarios estuvo a cargo de un equipo académico experto ${ }^{1} \mathrm{y}$ bajo la supervisión de expertos internacionales. ${ }^{2}$ Ambos fueron también

${ }^{1}$ Este equipo involucró, junto a los autores de este artículo, a Harald Beyer y Ricardo González.

${ }^{2}$ En la supervisión internacional colaboraron Daniel Hidalgo, Carmen Le Foulon y Andrea Campbell. 
testeados previamente para asegurar su pertinencia. A continuación, se detallan diversos aspectos técnicos de dicha encuesta. ${ }^{3}$

\subsubsection{Diseño muestral}

El muestreo pretende acercarse, lo más posible, al universo de estudiantes próximos a graduarse de instituciones de educación superior, a fines de 2016 y en el primer semestre de 2017, para lo que se invitó a colaborar a todas las universidades del país, junto con todos los institutos profesionales (IP) y centros de formación técnica $(\mathrm{CFT})^{4}$ acreditados o de más de mil estudiantes, considerando el estado de acreditación y matrícula del año 2016.

Para la realización de la primera ola de encuestas se contó con la colaboración de 49 instituciones, las que corresponden aproximadamente al 72 por ciento de la matrícula total de educación superior del país para el año $2016 . .^{5}$

Las instituciones colaboradoras son bastante representativas del sistema como un todo, incluyendo 28 universidades, 9 IP y 12 CFT; en todos los casos, participaron instituciones de distintos tamaños y perfiles. Para efectos de definir a los estudiantes que calificaban en la muestra, se pidió a las instituciones que enviaran los correos a los estudiantes de pregrado o de magíster que:

- Terminaron sus requisitos de carrera o se graduaron durante 2016.

- Estaban en su último año de estudios de acuerdo a la malla académica de la carrera.

- Era de esperar que terminarían sus requisitos de carrera o se graduarían en el primer semestre de 2017.

Como resultado del diseño muestral de este proyecto, las opiniones aquí presentadas pertenecen sólo a estudiantes que están cercanos a

${ }^{3}$ La versión digital de este artículo contiene un anexo (sección 11.1) que presenta el cuestionario completo.

${ }^{4}$ Los IP y CFT son instituciones de carácter técnico-profesional, que entregan mayormente carreras de cuatro y dos años de duración, respectivamente.

${ }^{5}$ A modo de retribución por su colaboración, se les ofreció a las instituciones participantes del proyecto un informe confidencial con un análisis de los resultados del estudio para su propia institución, el cual puede ser de utilidad para su gestión y el que las instituciones podrán hacer público si así lo quisieran. 
terminar su carrera. Es decir, a estudiantes que lograron entrar a la educación superior, que lograron mantenerse y no desertar, y que ya llevan algunos años experimentando cómo funciona el sistema de educación superior, sus instituciones y carreras. Este factor debe considerarse al momento de evaluar los resultados de este estudio.

\subsubsection{Forma de contacto con los estudiantes}

Los estudiantes — próximos a graduarse o recién graduados de las instituciones colaboradoras - fueron contactados a través de sus instituciones de educación superior, mediante un correo electrónico que incluía un link a la encuesta en línea. Los encuestados fueron informados de que la encuesta formaría parte de este proyecto, y se solicitó su participación voluntaria. Como incentivo a la participación, se sortearon premios entre quienes contestaron la encuesta (cinco mini iPad 2, diez entradas a Lollapalooza 2017 y cuarenta giftcards por \$ 15.000). También pedimos a los participantes la autorización para volver a contactarlos directamente vía correo electrónico a fines del siguiente año (2017). Por supuesto, todos los participantes fueron libres de abandonar el estudio en cualquier momento del tiempo (no obstante, fue requisito completar la encuesta para participar del sorteo).

Además, hubo 6 instituciones que prefirieron colaborar anónimamente. Las instituciones colaboradoras del estudio fueron:

1) En CFT: Andrés Bello, Ceduc UCN, ENAC, Duoc UC, Inacap, Instituto Tecnológico de Chile - ITC, Manpower, San Agustín de Talca y Ucevalpo.

2) En IP: Agrario Adolfo Matthei, AIEP, Ciisa, Duoc UC, Escuela de Contadores Auditores de Santiago, Inacap e Instituto de Estudios Bancarios Guillermo Subercaseaux.

3) En universidades: Pontificia Universidad Católica de Chile, Pontificia Universidad Católica de Valparaíso, Universidad Adolfo Ibáñez, Universidad Andrés Bello, Universidad Autónoma de Chile, Universidad Católica de La Santísima Concepción, Universidad Católica de Temuco, Universidad Católica Silva Henríquez, Universidad de Chile, Universidad de Concepción, Universidad de La Frontera, Universidad de Las Américas, Universidad de Los Lagos, Universidad de Magallanes, Universidad de Santiago de Chile, Universidad de Valparaíso, 
Universidad del Desarrollo, Universidad Diego Portales, Universidad Finis Terrae, Universidad Gabriela Mistral, Universidad Mayor, Universidad Pedro de Valdivia, Universidad San Sebastián, Universidad Santo Tomás, Universidad Técnica Federico Santa María, Universidad Tecnológica de Chile Inacap y Universidad UCINF.

\subsection{Características de la muestra y tasa de respuesta}

Un análisis detallado de la representatividad de la muestra a nivel de instituciones e individuos se provee en el Anexo, sección 10.2, pero resumimos aquí sus principales resultados.

En términos de la composición de las instituciones que participaron de este estudio, vemos que la muestra es representativa a nivel país, con algunas excepciones. En particular, las universidades privadas están ligeramente sobre representadas ( 33 y 12 versus 23 y 6 por ciento para privadas y privadas del $\mathrm{Cruch}^{6}$ ), al igual que las instituciones con matrícula alta (45 versus 16 por ciento para instituciones con $15.001 \mathrm{a}$ 100.000 estudiantes) $^{7}$ y las instituciones con cinco o más años de acreditación $(22,12$ y 8 versus 13,5 y 3 por ciento para cinco, seis y siete años, respectivamente). Hay buena representatividad en términos de si la institución es de región o pertenece a la Región Metropolitana.

Al analizar la composición de los estudiantes de la muestra se obtiene que hay una sobre representación de los alumnos de universidades privadas (49 versus 30 por ciento), de instituciones con cinco años de acreditación ( 31 versus 18 por ciento) y de estudiantes provenientes de establecimientos particulares pagados (27 versus 13 por ciento), y una sub representación de los estudiantes de institutos profesionales (14 versus 31 por ciento), de instituciones con tres años de acreditación (11 versus 24 por ciento) y de estudiantes provenientes de establecimientos

${ }^{6}$ El Consejo de Rectores de las Universidades de Chile (Cruch) agrupa a las 25 universidades, tanto estatales como privadas, existentes antes de la reforma a la educación superior de 1981, más las dos universidades estatales creadas posteriormente. Las universidades del Cruch son a veces referidas como "tradicionales".

${ }^{7}$ Los tramos de estudiantes matriculados por institución se establecen de manera que el número de instituciones sea relativamente homogéneo entre cada grupo: 11 por ciento de las instituciones tiene entre 0 y 100 estudiantes; 25 por ciento tiene entre 101 y $1.000 ; 25$ por ciento tiene entre 1.001 y $5.000 ; 23$ por ciento tiene entre 5.001 y 15.000 , y 16 por ciento tiene entre 15.001 y 100.000 . 
municipales y particulares subvencionados (26 y 47 versus 32 y 56 por ciento). Nuevamente, hay buena representatividad a nivel regional, además de contar con buena representatividad por género y por cantidad de estudiantes matriculados en cada institución.

Tanto la composición de las instituciones como de los estudiantes sugiere que la muestra es razonablemente representativa de nuestro sistema de educación superior, no obstante hay algunos sesgos, en particular una sobre representación de estudiantes de universidades privadas y de instituciones grandes. Parte de estos sesgos podría deberse a que estamos comparando a estudiantes de último año o recién graduados con el universo de estudiantes (es decir, es posible que las tasas de deserción varíen entre estos grupos). Sin embargo, es importante tener en mente estos potenciales sesgos del estudio.

Por supuesto, no descartamos que puedan existir otras diferencias no observables entre el universo de estudiantes cercanos a graduarse y aquellos que contestaron nuestra encuesta; por ejemplo, un nivel diferente de motivación u optimismo, como sucede habitualmente en estudios de esta naturaleza.

No obstante, creemos que la distribución de características observables — que parece bastante representativa-, junto con el gran tamaño de la muestra hacen que la encuesta sea una fuente valiosa de información (información que, por lo demás, a la fecha, no existe para nuestro país).

La tasa de respuesta de este estudio se puede medir de dos maneras alternativas. La primera es en función de la cantidad de correos enviados a los estudiantes que cada institución reportó. Debido a la heterogeneidad de la calidad de esta primera medida,${ }^{8}$ se optó por una segunda, en función del total de matrícula de alumnos de primer año, según la información entregada por el Ministerio de Educación para el año 2016. Con esto, se intenta capturar el tamaño de una cohorte similar a la de los estudiantes considerados en esta encuesta. La tasa de respuesta promedio se encuentra en torno al 0,8 por ciento, con la primera medida,

840 de las 49 instituciones entregaron información sobre los correos enviados a sus estudiantes y, en algunos casos, la información reportada indicaba que se envió una cantidad de correos considerablemente superior a la matrícula total de la institución. 
y al 5,4 por ciento, con la segunda. Este segundo valor es semejante al obtenido en estudios similares, como Solís (2012). ${ }^{9}$

\subsubsection{Seguridad y confidencialidad}

La encuesta fue programada y aplicada en la plataforma Qualtrics (https://www.qualtrics.com/), la cual cumple con los más altos estándares tecnológicos y de seguridad. La información recopilada por la encuesta se encuentra resguardada con los mismos estándares de seguridad; será utilizada sólo para fines académicos y será analizada únicamente de forma agregada. Además, este proyecto es realizado bajo los estándares éticos del Massachusetts Institute of Technology (MIT) y cuenta con la aprobación del comité de ética de dicha universidad.

\section{2. ¿CÓMO ELIGEN LOS ESTUDIANTES SU INSTITUCIÓN Y CARRERA DE ESTUDIOS?}

La decisión de qué estudiar y dónde es una decisión importante, que probablemente marca el futuro de los estudiantes. ¿Cuáles son los factores más importantes en la toma de esta decisión? ¿Difieren por tipo de institución y por tipo de estudiante? Este capítulo explora estos temas.

Primero, se les preguntó a los estudiantes: “¿Cuáles de los siguientes factores fueron los más importantes al momento de elegir tu institución de educación superior?", pudiendo cada uno escoger a lo más tres opciones dentro de las que se listan en la tabla 1. En ella se muestran resultados para el total de la muestra y por tipo de institución. Cada fila muestra el número de veces que el factor fue mencionado sobre el total de respuestas en la categoría correspondiente a la columna, en porcentaje. ${ }^{10}$ Dado que los estudiantes podían contestar entre una y tres opciones, los totales por categoría suman más que cien por ciento

${ }^{9}$ Se debe hacer notar que Solís reporta una tasa de respuesta del orden del 40 por ciento, pero calculada sobre el total de emails abiertos, número que no tenemos en este estudio. Si se calcula sobre el total de emails enviados, su tasa de respuesta es del orden del 5 por ciento.

10 "Ests." corresponde a universidades estatales; "Privs.", a universidades privadas fuera del Cruch, y "Pr. Cruch", a universidades privadas del Cruch. 
y, además, pueden diferir por subgrupos. La última fila muestra el total de respuestas en la categoría en términos porcentuales, la que al dividir por cien nos da el promedio de razones elegidas por los estudiantes, por tipo de institución. Así, por ejemplo, encontramos que en los CFT los estudiantes entregaron en promedio 1,8 razones para elegir su institución, mientras que en las universidades privadas del Cruch el promedio asciende a 2,5. La estructura básica de esta tabla se mantiene a lo largo de este capítulo.

Tabla 1. FRECUENCIA DE MOTIVOS PARA ELEGIR LA INSTITUCIÓN, TOTAL Y POR TIPO DE INSTITUCIÓN (PORCENTAJE)

\begin{tabular}{lrrrrrr}
\hline & Total & \multicolumn{1}{c}{ CFT } & \multicolumn{1}{c}{ IP } & Ests. & Privs. & Pr. Cruch \\
\hline Su nivel académico y prestigioio & 58,3 & 46,9 & 52,7 & 72,3 & 50,1 & 84,3 \\
$\begin{array}{l}\text { Ops. laborales de los } \\
\text { egresados de la institución }\end{array}$ & 29,6 & 25,4 & 27,3 & 30,3 & 26,1 & 43,5 \\
$\begin{array}{l}\text { Su acreditación } \\
\text { Arancel y posibilidades de }\end{array}$ & 26,2 & 24,1 & 35,6 & 25,5 & 24,1 & 26,0 \\
financiamiento & 19,3 & 23,3 & 24,0 & 21,7 & 18,6 & 13,4 \\
$\begin{array}{l}\text { Orientación o áreas de } \\
\text { especialización en mi carrera }\end{array}$ & 18,2 & 12,9 & 14,6 & 17,8 & 19,1 & 21,4 \\
$\begin{array}{l}\text { Ubicación } \\
\text { Me la recomendaron }\end{array}$ & 17,7 & 20,0 & 19,4 & 21,5 & 14,3 & 22,7 \\
familiares o conocidos & 11,7 & 7,8 & 6,7 & 12,3 & 12,6 & 14,8 \\
$\begin{array}{l}\text { Era la mejor opción dado mi } \\
\text { puntaje }\end{array}$ & 11,2 & 0,9 & 1,1 & 12,8 & 15,0 & 13,0 \\
Horarios disponibles & 7,4 & 15,6 & 14,1 & 3,6 & 6,5 & 2,5 \\
El tipo de estudiantes & 4,4 & 0,4 & 0,8 & 12,2 & 3,5 & 7,2 \\
\hline Total & 204,0 & 177,3 & 196,3 & 230,0 & 189,9 & 248,8 \\
\hline
\end{tabular}

A nivel global, observamos que el factor más relevante, al momento de elegir la institución, es el nivel académico y el prestigio, seguido bastante más abajo por las oportunidades laborales de los egresados y la acreditación. Si consideramos que la acreditación busca ser una señal de calidad académica, pareciera que los estudiantes escogen su institución sobre todo pensando en factores académicos y laborales, y no tanto por restricciones como aranceles, ubicación u horarios. Los factores sociales, como las recomendaciones de familiares y amigos y el tipo de estudiantes son, en general, poco importantes en la decisión. 
En cuanto a las diferencias por tipo de institución, encontramos que en las instituciones técnicas (CFT e IP) los estudiantes atribuyen relativamente mayor relevancia a los aranceles y a los horarios disponibles; es decir, a factores que más bien restringen la decisión de dónde estudiar. A su vez, el mayor peso otorgado a los horarios es consistente con que más estudiantes de estas instituciones trabajan a la vez que estudian en comparación con los demás estudiantes de esta encuesta, o con que en promedio tienen más hijos. En cualquier caso, los factores académicos y laborales siguen siendo los principales para elegir las instituciones técnicas.

En las universidades estatales se da relativamente mayor peso al nivel académico y prestigio, así como al tipo de estudiantes y a la ubicación. En las privadas se da algo más de peso a que la institución "era la mejor opción dado mi puntaje", sugiriendo que la institución escogida no fue la primera prioridad. Finalmente, en las universidades privadas del Cruch el nivel académico tiene una incidencia altísima, así como las oportunidades laborales de los egresados, mientras que los aranceles influyen considerablemente menos. Factores sociales, como el tipo de estudiantes o que la institución fue recomendada por familiares o conocidos, son también más gravitantes en este tipo de instituciones.

Ahora, ¿en base a qué razones los estudiantes eligen su carrera de estudios? Realizamos el mismo análisis que en la tabla anterior para las respuestas a la pregunta: “¿Cuáles de los siguientes factores fueron los más importantes al momento de elegir tu carrera?", con las alternativas listadas en la tabla 2, para toda la muestra y por tipo de institución. Al igual que en el caso anterior, los estudiantes pudieron seleccionar hasta tres alternativas, por lo que los totales, por categoría, suman más que cien por ciento.

En el total de la muestra, la principal razón para elegir la carrera de estudios es la vocación, seguida por las oportunidades laborales de los egresados, el prestigio y los cursos. Restricciones tales como el arancel y posibilidades de financiamiento, la de la mejor opción dado el puntaje o los horarios resultan poco relevantes en esta decisión.

En cuanto a las diferencias por tipos de instituciones, observamos que en las instituciones técnicas la vocación es menos relevante que para la muestra total, al contrario de lo que sucede con las oportunidades laborales. De hecho, en los IP las oportunidades laborales superan 
a la vocación como la razón más importante. Esto es consistente con la idea de que las instituciones técnicas están más enfocadas a entregar herramientas prácticas para el mundo del trabajo. También vemos que en los CFT e IP los horarios influyen mucho más al momento de elegir carrera, lo que concuerda con que más estudiantes de estas instituciones trabajan a la vez o tienen hijos.

Tabla 2. FRECUENCIA DE MOTIVOS PARA ELEGIR LA CARRERA, TOTAL Y POR TIPO DE INSTITUCIÓN (PORCENTAJE)

\begin{tabular}{lrrrrrr}
\hline & Total & CFT & IP & Ests. & Privs. & Pr. Cruch \\
\hline Vocación & 52 & 46,8 & 46,5 & 49,6 & 53,7 & 56 \\
$\begin{array}{l}\text { Ops. laborales de los } \\
\text { egresados de la carrera }\end{array}$ & 42 & 44,4 & 48,3 & 38,2 & 41,7 & 38,7 \\
$\begin{array}{l}\text { Prestigio de la carrera } \\
\text { Sus asignaturas o cursos }\end{array}$ & 34,6 & 27,7 & 31,4 & 34 & 36,3 & 36,2 \\
$\begin{array}{l}\text { Su nivel académico } \\
\text { Me la recomendaron }\end{array}$ & 24,5 & 24,7 & 28,5 & 35,8 & 32,8 & 37,1 \\
familiares o conocidos & 10,8 & 10,2 & 10,4 & 10,4 & 11,2 & 10,9 \\
$\begin{array}{l}\text { Arancel y posibilidades de } \\
\text { financiamiento }\end{array}$ & 9,6 & 11,9 & 11,1 & 10 & 8,6 & 7,5 \\
$\begin{array}{l}\text { Era la mejor opción dado mi } \\
\text { puntaje }\end{array}$ & 6,6 & 1,2 & 1,6 & 13,7 & 6,2 & 10,4 \\
Horarios disponibles & 5,4 & 12,5 & 10,7 & 2,6 & 4,2 & 2,2 \\
\hline Total & 218,4 & 193,8 & 206,8 & 222,5 & 218,7 & 235,5 \\
\hline
\end{tabular}

En las instituciones estatales encontramos que, en cuanto a las razones para elegir carrera, la principal diferencia estriba en que se le atribuye mayor relevancia a "Era la mejor opción dado mi puntaje", sugiriendo que hay relativamente más estudiantes que no estudian en su carrera de mayor preferencia. En las instituciones privadas, las razones son muy similares a las del total de la muestra. Por último, en las privadas del Cruch, la vocación tiene relativamente más peso, mientras que las oportunidades laborales tienen menos. Las asignaturas y cursos, así como el nivel académico, también tienen mayor preponderancia en la elección de carrera en este tipo de instituciones.

Es importante tener en cuenta que observamos a estudiantes que ingresaron a la educación superior y que ya egresaron o están próximos a ello. Por esto, tanto en el caso de elección de institución como de ca- 
rrera, es posible que los estudiantes para los que las restricciones como aranceles, posibilidades de financiamiento son más relevantes no hayan ingresado a la educación superior, o bien hayan desertado. Así, estos resultados deben interpretarse como un cuadro más optimista que el que obtendríamos de observar a estudiantes tomando la decisión de qué y dónde estudiar.

\subsection{Elección de institución y características individuales}

Con el fin de evaluar cómo varían las razones para escoger institución, según las características individuales de los estudiantes, sin agobiarnos con tanta información, clasificamos las razones en las siguientes categorías:

- Razones académicas: Su nivel académico y prestigio; su acreditación; orientación o áreas de especialización en mi carrera.

- Razones laborales: Oportunidades laborales de los egresados de la institución.

- Razones sociales: Me la recomendaron familiares o conocidos; el tipo de estudiantes.

- Restricciones: Arancel y posibilidades de financiamiento; ubicación; horarios disponibles; era la mejor opción dado mi puntaje. Llamamos a estas razones "restricciones", pues, más que motivos de fondo, se asocian a elecciones determinadas por factores que, de alguna forma, restringen la decisión de dónde estudiar.

En cuanto a diferencias por sexo, los resultados no muestran disparidades relevantes respecto a cómo los estudiantes eligen su institución (por lo que no ha sido mostrado). La figura 1, en tanto, presenta los resultados por dependencia escolar del establecimiento de educación media. En todos los casos existe una clara tendencia entre egresados de establecimientos municipales, subvencionados y particulares pagados.

Las razones académicas, laborales y sociales son mencionadas en mayor medida por los estudiantes provenientes de establecimientos pagados. Llama especialmente la atención la preponderancia de razones sociales en este grupo, duplicando las menciones en el sector subvencionado. Por el contrario, las razones que corresponden más bien a restricciones predominan con más fuerza en los egresados de esta- 
blecimientos municipales, lo que es consistente con que tienen menos recursos económicos y académicos. En efecto, debido a que en promedio provienen de establecimientos escolares de menor calidad y tienen menor capital cultural en su entorno familiar, estos estudiantes tienden a obtener un menor puntaje PSU, restringiendo sus opciones de estudio. Además, dado que provienen de hogares con menor ingreso, deben compatibilizar sus estudios con el trabajo con mayor frecuencia. ${ }^{11}$

Figura 1. FRECUENCIA DE MOTIVOS PARA ELEGIR INSTITUCIÓN POR DEPENDENCIA ESCOLAR (PORCENTAJE)
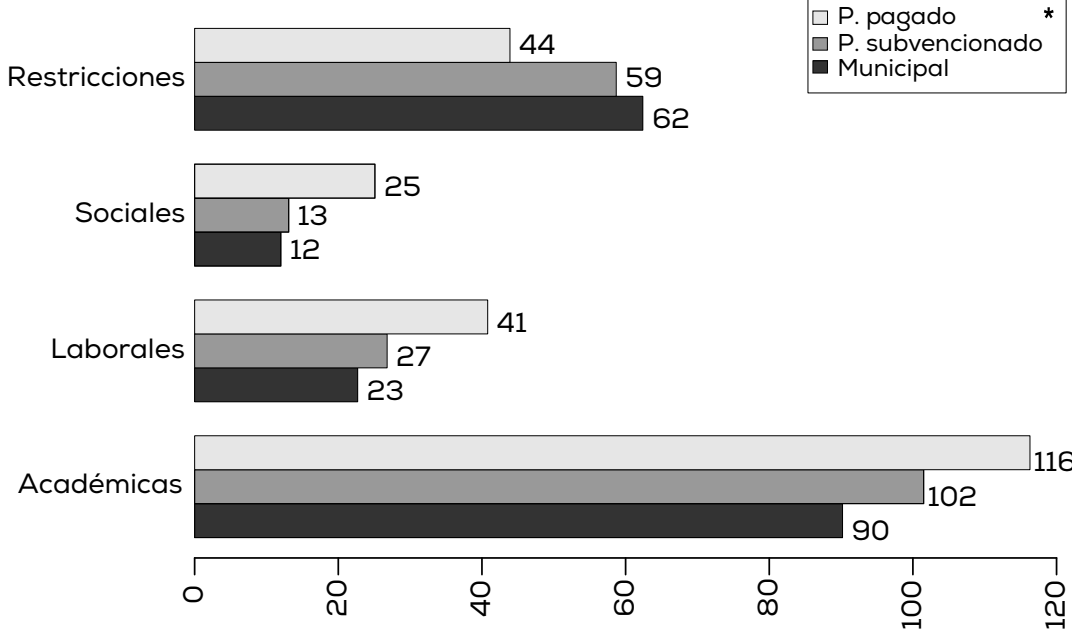

*Total de respuestas suma 226, 200 y 187\%, respectivamente

Al analizar los resultados, según si los estudiantes son o no primera generación en la educación superior, entendiendo que esta característica, al igual que la dependencia escolar, se correlaciona con el nivel socioeconómico, las conclusiones son similares al caso anterior (no mostrado): los estudiantes, cuyo padre o madre tiene educación superior, eligen su institución en mayor medida por razones académicas, laborales y sociales (para ellos éstas pesan 108, 34 y 20 versus 95, 23 y 10 por ciento para los estudiantes que son primera generación); mien-

${ }^{11}$ En la sección 5 se discute en profundidad que quienes financian sus estudios trabajando pertenecen a instituciones técnicas, provienen de establecimientos municipales o particulares subvencionados y tienen padres con un máximo nivel de educación igual o menor a media completa. 
tras que los estudiantes que son primera generación se ven obligados a elegir bajo más restricciones (62 versus 52 por ciento).

En suma, estos resultados, junto con los anteriores, sugieren un claro cuadro de desigualdad socioeconómica en la forma que los estudiantes eligen dónde realizar sus estudios superiores: los estudiantes de menor nivel socioeconómico, de acuerdo a nuestra definición de restricciones, escogen de manera más restringida. No obstante, cabe destacar que para los estudiantes de todos los grupos analizados las razones académicas de elección de institución priman por sobre las restricciones.

Figura 2. FRECUENCIA DE MOTIVOS PARA ELEGIR LA INSTITUCIÓN POR PRINCIPAL FUENTE DE FINANCIAMIENTO (PORCENTAJE)

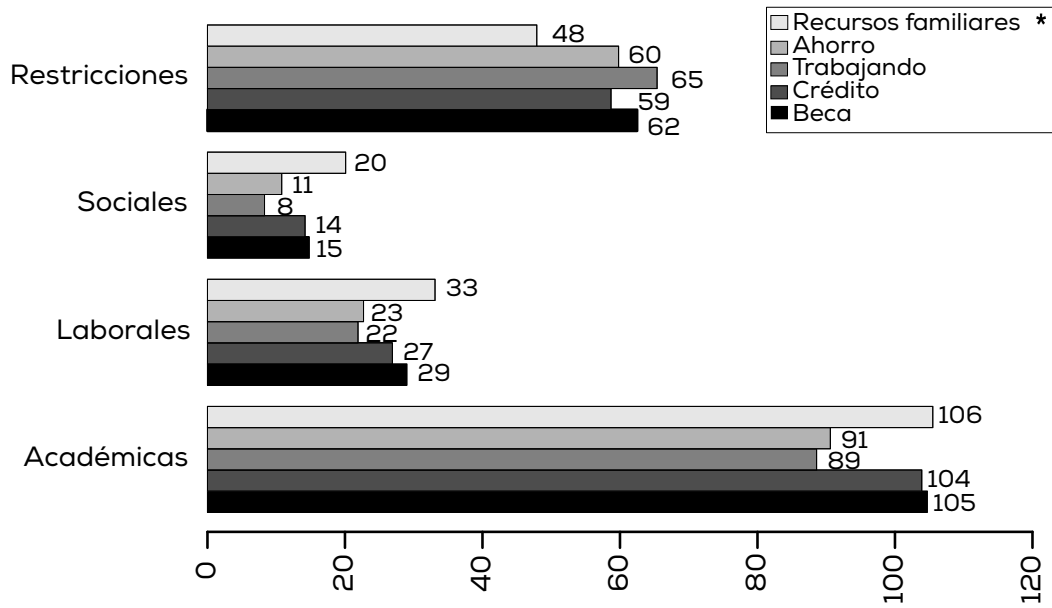

*Total de respuestas suma 207, 184, 184, 204 y $211 \%$, respectivamente

Al realizar el mismo análisis por principal fuente de financiamiento de los estudios superiores, mostrado en la figura 2, encontramos que las razones para escoger institución de los estudiantes que se financian mayormente con becas y con créditos son muy similares. Quienes se financian trabajando se preocupan menos de las razones académicas, laborales y sociales, y más de las restricciones, lo que, nuevamente, es consistente con los resultados anteriores. Los estudiantes que se financian con ahorros propios se comportan relativamente parecido a los que se financian trabajando, salvo porque eligen menos en función de las restricciones. Finalmente, los estudiantes que se financian con recursos 
familiares tienen un mayor foco en lo laboral, así como en las razones sociales, y escogen con menos restricciones.

\subsection{Elección de carrera y características individuales}

Analicemos ahora cómo influyen las variables individuales en la elección de carrera. Al igual que en el caso anterior, reducimos las razones a categorías:

- Razones académicas: Su nivel académico, su prestigio y sus asignaturas o cursos.

- Razones laborales: Oportunidades laborales de los egresados de la carrera.

- Recomendaciones: Me la recomendaron familiares o conocidos. Vocación

- Restricciones: Arancel y posibilidades de financiamiento; horarios disponibles; era la mejor opción dado mi puntaje.

En este caso, exploramos las razones para escoger carrera, clasificadas de esta forma, según área de conocimiento de la misma (tabla 3). ${ }^{12}$ Las razones académicas son especialmente fuertes en las áreas de humanidades, derecho y ciencias básicas, y especialmente poco relevantes en educación y salud. Las laborales, en tanto, sobresalen en el área de administración y comercio, tecnología y derecho, y son más débiles en las humanidades y en arte y arquitectura. Las humanidades, las ciencias básicas y educación son las áreas donde menos se mencionan las recomendaciones de familiares y amigos como motivo para elegir carrera. En tanto, la vocación tiene un peso similar en casi todas las áreas, salvo porque pesa especialmente poco en administración y comercio, tecnología y derecho. Por último, el área que es relativamente más escogida bajo restricciones, es educación, seguida por humanidades.

La figura 3 muestra los resultados de las razones para elegir carrera por sexo. Al contrario de lo que sucedía en la elección de institución, donde no se observaban diferencias relevantes, aquí encontramos que los hombres otorgan mayor relevancia a las razones académicas y labo-

12 Debido al gran número de áreas, presentamos la tabla con filas y columnas invertidas, a diferencia del resto de las tablas de este capítulo. 
rales, mientras que las mujeres priorizan la vocación en mayor medida. Además, las mujeres parecieran elegir carrera ligeramente menos influenciadas por las restricciones.

Tabla 3. FRECUENCIA DE MOTIVOS PARA ELEGIR CARRERA POR ÁREA DE CONOCIMIENTO (PORCENTAJE)

\begin{tabular}{lcccccc}
\hline & $\begin{array}{c}\text { Acadé- } \\
\text { micas }\end{array}$ & $\begin{array}{c}\text { Labo- } \\
\text { rales }\end{array}$ & $\begin{array}{c}\text { Recomen- } \\
\text { daciones }\end{array}$ & Vocación & $\begin{array}{c}\text { Restric- } \\
\text { ciones }\end{array}$ & Total \\
\hline $\begin{array}{l}\text { Administración y } \\
\text { comercio }\end{array}$ & 96,2 & 57,1 & 12,6 & 34,7 & 22,1 & 222,7 \\
Agropecuaria & 86,3 & 20,6 & 11,4 & 66,7 & 16,2 & 201,2 \\
Arte y arquitectura & 92,4 & 14,5 & 9,5 & 68,3 & 16,9 & 201,6 \\
Ciencias básicas & 111,3 & 17,6 & 5,9 & 70,1 & 22,2 & 227,1 \\
Ciencias sociales & 98,5 & 22,0 & 9,8 & 64,5 & 20,2 & 215,0 \\
Derecho & 115,7 & 44,1 & 11,5 & 45,5 & 17,8 & 234,6 \\
Educación & 73,0 & 26,0 & 7,6 & 67,6 & 25,7 & 199,9 \\
Humanidades & 122,5 & 10,8 & 3,9 & 66,7 & 24,5 & 228,4 \\
Salud & 78,7 & 36,9 & 10,1 & 69,1 & 20,6 & 215,4 \\
Tecnología & 93,3 & 52,8 & 11,8 & 43,2 & 22,3 & 223,4 \\
\hline
\end{tabular}

Figura 3. FRECUENCIA DE MOTIVOS PARA ELEGIR CARRERA, TOTAL Y POR GÉNERO (PORCENTAJE)
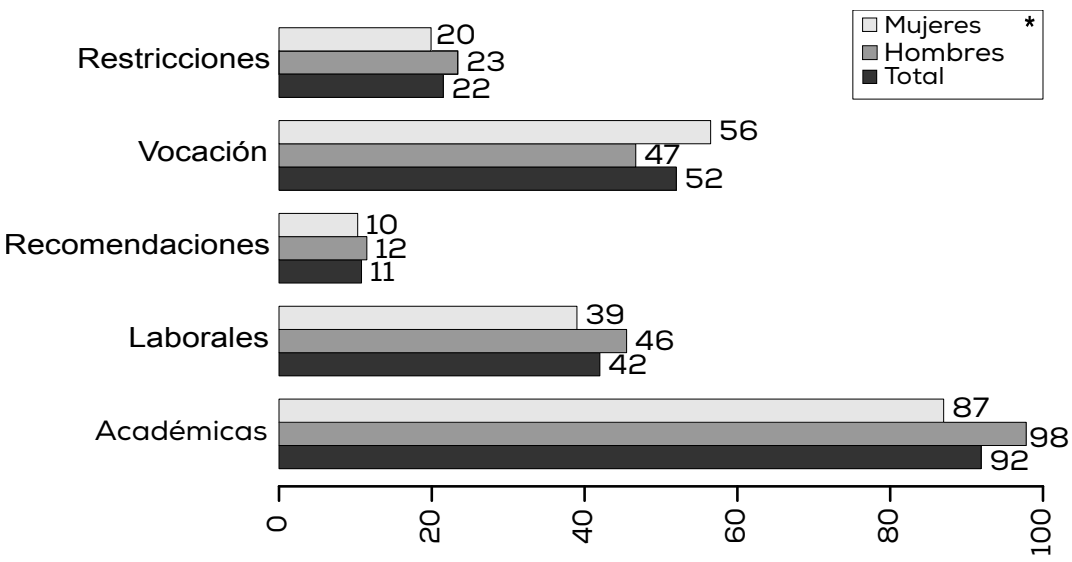

*Total de respuestas suma 213,225 y $218 \%$, respectivamente 
La figura 4 muestra los resultados por dependencia escolar. Similar al caso de la elección de institución, los egresados de colegios particulares pagados otorgan mayor prioridad a las razones académicas y laborales, y eligen bajo menos restricciones. También mencionan, con mayor frecuencia, las recomendaciones de familiares y conocidos que el resto de los estudiantes, mientras que la vocación tiene un peso parecido por dependencia.

Figura 4. FRECUENCIA DE MOTIVOS PARA ELEGIR CARRERA POR DEPENDENCIA ESCOLAR (PORCENTAJE)
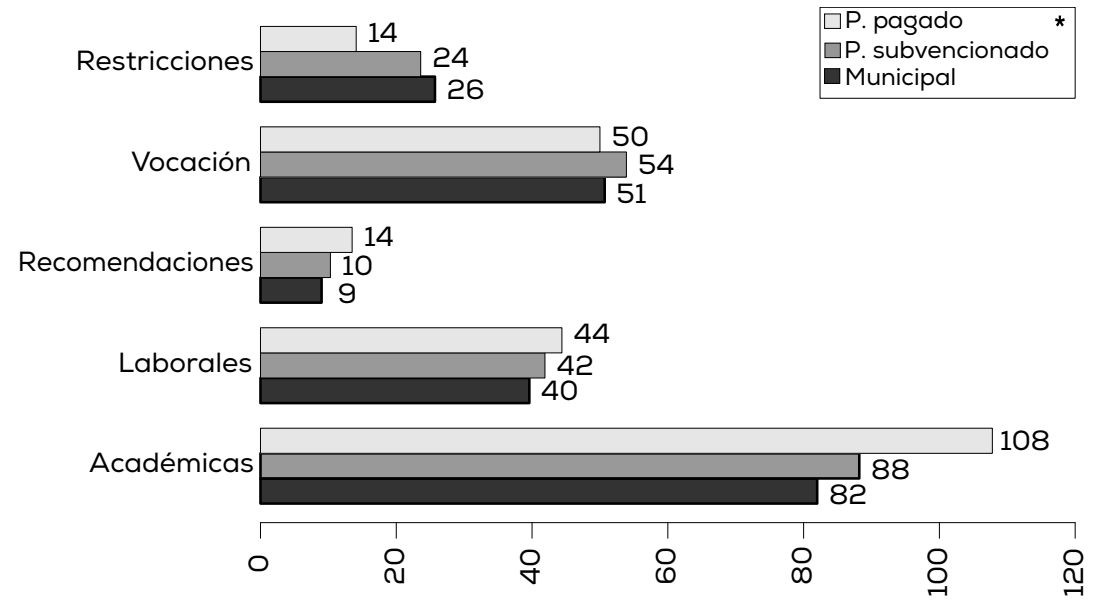

*Total de respuestas suma 230, 218 y $207 \%$, respectivamente

Los resultados, según si el estudiante es primera generación o tiene algún padre con estudios superiores, son consistentes con los resultados por dependencia (y, por lo tanto, omitimos la figura). Encontramos que los hijos de personas con estudios superiores priorizan considerablemente más lo académico, y algo más lo laboral $(90$ y 43 versus 81 y 41 por ciento), y eligen menos en función de las restricciones que quienes son primera generación en ir a la educación superior (19 versus 26 por ciento). Además, quienes son primera generación mencionan menos las recomendaciones de familiares y conocidos ( 8 versus 12 por ciento), lo que es razonable, ya que carecen de padres con una visión de la educación superior desde la experiencia personal.

Estos resultados sugieren que, al igual que con la elección de la institución de estudios, existen desigualdades socioeconómicas en la 
forma de elegir carrera: los estudiantes de origen más vulnerable escogen más restringidos.

Para terminar, la figura 5 muestra los resultados por principal fuente de financiamiento. Al igual que en el caso de la elección de institución, los estudiantes que se financian principalmente con beca son muy similares a los que lo hacen con crédito. Quienes se financian trabajando escogen menos por vocación y por razones académicas, y lo hacen más en función de restricciones, de forma similar a los que se financian con sus ahorros. Por último, los que se financian principalmente con recursos familiares se enfocan más en lo académico, consideran más las recomendaciones y eligen bajo menos restricciones.

Figura 5. FRECUENCIA DE MOTIVOS PARA ELEGIR LA CARRERA POR PRINCIPAL FUENTE DE FINANCIAMIENTO (PORCENTAJE)

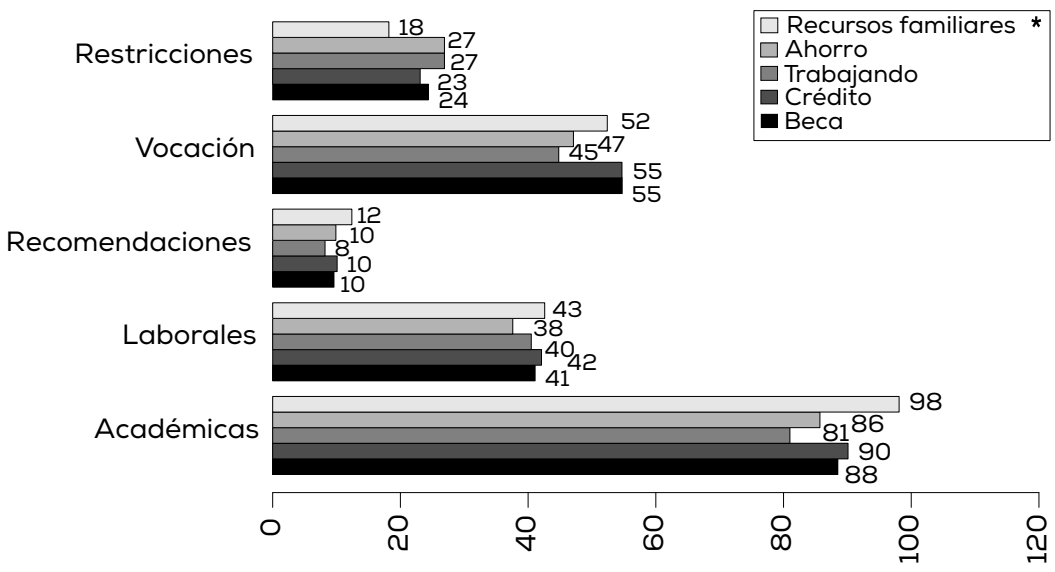

*Total de respuestas suma 223, 207, 202, 221 y 218\%, respectivamente

\subsection{Conclusión sobre la elección de institución y carrera}

En conclusión, en la elección de institución generalmente priman las razones académicas y laborales, y no tanto las restricciones como aranceles, ubicación u horarios. Parte de este resultado podría deberse al hecho de que los estudiantes para los cuales las restricciones eran muy relevantes son más propensos a no postular del todo o a desertar en parte del camino. Como nuestra muestra se compone de estudiantes que están cercanos a egresar, no se registran casos de este tipo. 
No obstante la menor importancia relativa de las restricciones en la elección de institución, existen desigualdades importantes en su peso. Por ejemplo, las personas que estudian en instituciones técnicas atribuyen mayor relevancia a los aranceles y a los horarios disponibles, a la vez que las restricciones pesan más en los egresados de colegios municipales y en quienes son primera generación en la educación superior.

Por su parte, en la elección de carrera, el motivo principal es la vocación, seguido por las oportunidades laborales de los egresados, el prestigio y los cursos. Nuevamente las restricciones - tales como el arancel y posibilidades de financiamiento, la mejor opción dado el puntaje y los horarios - resultan en general poco importantes. Sin embargo, al igual que en el caso anterior, encontramos diferencias gravitantes entre los distintos grupos. Primero, observamos que los hombres priorizan en mayor medida las razones académicas y laborales, mientras que las mujeres dan mayor peso a la vocación. Segundo, encontramos que las oportunidades laborales son más importantes en las instituciones técnicas, en desmedro de la vocación. Consistente con los resultados para la elección de institución, los estudiantes de origen más vulnerable, ya sea medido a través de dependencia escolar o de si son primera generación, escogen bajo más restricciones.

Por último, tanto para la elección de institución como la de carrera, los estudiantes que se financian, principalmente con beca, son muy similares a los que lo hacen con crédito. Quienes se financian trabajando o con ahorros propios escogen bajo mayores restricciones, al contrario de lo que sucede con quienes se financian principalmente con recursos familiares.

\section{3. ¿CÓMO EVALÚAN LOS ESTUDIANTES A SU INSTITUCIÓN DE EDUCACIÓN SUPERIOR?}

\subsection{Evaluación institucional}

En la muestra, a los estudiantes se les preguntó: "Considerando todas las cosas, ¿qué nota le pondrías a tu institución de educación superior?". La figura 6 muestra un diagrama de caja de las notas asignadas para todas las instituciones en las que contamos con más de 15 observaciones (omitimos los nombres de las instituciones para respetar 
la confidencialidad). Un primer resultado que salta a la vista es que las medias de la evaluación entre instituciones, marcadas con la barra horizontal negra, son altas y similares, ubicándose todas por sobre el cinco y mayormente en torno al seis. Segundo, llama la atención que la distribución de la evaluación sea bastante parecida entre instituciones. De hecho, los percentiles 25 y 75, marcados por los bordes superior e inferior de los rectángulos, son bastante similares, con oscilaciones máximas de poco más de un punto.

Figura 6. EVALUACIÓN A LAS INSTITUCIONES DE EDUCACIÓN SUPERIOR

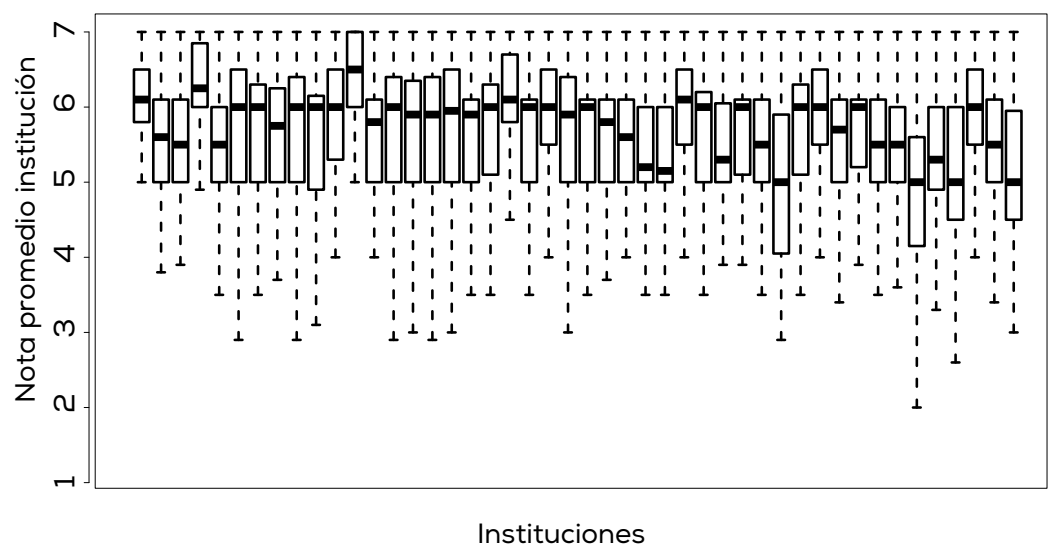

Estos resultados sugieren que, a grandes rasgos, los estudiantes de todas las instituciones están en general satisfechos con su institución. De hecho, como muestra la tabla 4, la nota promedio en la muestra es 5,6, al mismo tiempo que el percentil 20, de la distribución de notas, ya supera el nivel de suficiencia ${ }^{13}$ y el percentil 60 alcanza ya una nota de 6. En suma, resultados excelentes para las instituciones desde la perspectiva de los estudiantes. Algo muy similar sucede para la nota asignada a la carrera de estudios, con un promedio incluso algo mayor, de 5,8 (columna 3 de la tabla 4).

Es probable que, en parte, estos resultados se deban a que una vez que se ingresa a una institución —o carrera - se estaría satisfecho principalmente por falta de un punto de referencia. Para testear esto, ob-

${ }^{13}$ La escala de notas en Chile va del 1 al 7, y el nivel de suficiencia está dado por el 4. 
servamos la distribución para los estudiantes que estuvieron en otra institución o en otra carrera (en la muestra corresponden a 3.091 y 3.451 casos, respectivamente; no mostrado). Los resultados son equivalentes a los anteriores, por lo que un punto de referencia adicional, o mayor información, no pareciera marcar una diferencia importante en términos de la evaluación asignada a la institución o la carrera.

Tabla 4. DISTRIBUCIÓN DE LA NOTA ASIGNADA A INSTITUCIÓN Y CARRERA (ESCALA DE 1A 7)

\begin{tabular}{lcc}
\hline & Nota institución & Nota carrera \\
\hline $\mathrm{N}$ & 14.146 & 14.146 \\
\hline Promedio & 5,6 & 5,8 \\
Desv. Est. & 1,0 & 1,1 \\
\hline Perc. 0\% & 1,0 & 1,0 \\
Perc. 20\% & 5,0 & 5,0 \\
Perc. 40\% & 5,5 & 5,9 \\
Perc. 60\% & 6,0 & 6,1 \\
Perc. 80\% & 6,4 & 6,6 \\
Perc. 100\% & 7,0 & 7,0 \\
\hline
\end{tabular}

Otra medida de satisfacción de los estudiantes con sus estudios es la probabilidad, del 1 al 7, que ellos le asignan a volver a elegir el seguir estudios superiores, elegir su institución y su carrera. Como muestra la tabla 5, el panorama sigue siendo optimista. Más del 80 por ciento de los estudiantes le asigna probabilidad de más de 6 a seguir estudios superiores, con un promedio de 6,4. En cuanto a la institución y carrera, las probabilidades son algo menores, con promedios de 5,7 y 5,9 , respectivamente. Son muy pocos los estudiantes que se arrepienten de su elección. Si consideramos que los arrepentidos son aquellos que ponen nota roja a la probabilidad de volver a elegir su opción, menos del 4 por ciento se arrepiente de haber seguido estudios superiores, menos del 11 por ciento se arrepiente de la institución que eligió y menos del 9 por ciento se arrepiente de su carrera. En suma, nuevamente encontramos un alto nivel de satisfacción por parte de los encuestados con su decisión de educación superior, medida en términos de volver a elegir el mismo camino. 
Tabla 5. DISTRIBUCIÓN DE LA PROBABILIDAD DE VOLVER A ELEGIR... (ESCALA DE 1A 7)

\begin{tabular}{lccc}
\hline & Seguir estudios superiores & Tu institución & Tu carrera \\
\hline $\mathrm{N}$ & 14.146 & 14.146 & 14.146 \\
\hline Promedio & 6,4 & 5,7 & 5,9 \\
Desv. Est. & 1,1 & 1,6 & 1,5 \\
\hline Perc. 0\% & 1,0 & 1,0 & 1,0 \\
Perc. 20\% & 6,0 & 5,0 & 5,0 \\
Perc. 40\% & 7,0 & 6,0 & 6,0 \\
Perc. 60\% & 7,0 & 7,0 & 7,0 \\
Perc. 80\% & 7,0 & 7,0 & 7,0 \\
Perc. 100\% & 7,0 & 7,0 & 7,0 \\
\hline
\end{tabular}

En cuanto al tipo de institución, la tabla 6 nos muestra que las notas promedio son muy similares, con una diferencia máxima de tres décimas. Las universidades privadas de fuera del Cruch obtienen el mínimo, de 5,5, y las privadas dentro del Cruch, el máximo, de 5,8. Las diferencias se incrementan cuando se pregunta por la probabilidad de volver a elegir los estudios superiores. Las mayores dudas respecto de seguir estudios superiores se observan en los CFT, aunque la probabilidad sigue siendo muy alta (6,2, en escala de 1 a 7). En tanto, la probabilidad de volver a elegir la propia institución recibe un mínimo de 5,5 en las universidades privadas y un máximo de 6,1 en las privadas del Cruch.

Tabla 6. NOTA PROMEDIO Y VOLVERÍAS A ELEGIR... POR TIPO DE INSTITUCIÓN (ESCALA DE 1A 7)

\begin{tabular}{lcccc}
\hline & Nota & Seguir ests. sups. & Tu institución & Tu carrera \\
\hline CFT & 5,67 & 6,24 & 5,62 & 5,88 \\
IP & 5,68 & 6,32 & 5,66 & 5,86 \\
U. estatales & 5,59 & 6,55 & 6,01 & 5,67 \\
U. privadas & 5,52 & 6,44 & 5,51 & 6,00 \\
U. privadas Cruch & 5,83 & 6,61 & 6,11 & 5,79 \\
\hline
\end{tabular}

Respecto de la carrera, la mayor probabilidad de volverla a elegir se encuentra en las universidades privadas fuera del Cruch y, la menor, en las universidades estatales. Cabe tener en mente, no obstante, que 
todas las probabilidades son muy altas, lo que sugiere una relativa satisfacción de los encuestados con su opción de estudios superiores.

Las diferencias que se observan por área de carrera, por sexo, por principal fuente de financiamiento, por dependencia escolar y por máximo nivel de educación alcanzado por el padre o por la madre son aún menores que las observadas por tipo de institución, por lo que no las presentamos.

\subsection{Conclusión sobre la evaluación institucional}

En conclusión, pareciera que los estudiantes de los últimos años de carrera y los recién graduados están muy satisfechos con su institución y, más en general, con su elección de educación superior. Esto varía poco entre instituciones, áreas de carrera y características socioeconómicas de los estudiantes.

De esta forma, desde la perspectiva de los propios usuarios, el sistema de educación superior obtiene una buena nota, así como prácticamente todas las instituciones que lo componen (y que están en nuestra muestra). Este escenario en alguna medida contrasta con la visión más lúgubre de la educación superior que se ha apoderado del debate político. Sin embargo, y como recalcamos en otros capítulos de este estudio, cabe preguntarse si parte de la buena evaluación se debe a que - ya sea consciente o inconscientemente- los estudiantes intentan convencerse de que han tomado buenas decisiones. A la vez, la evaluación probablemente esté mediada por el nivel de información que los estudiantes manejan sobre el sistema, el que puede diferir por tipo de estudiante. En este sentido, una segunda ola de la encuesta podría dar cuenta de cambios en la evaluación una vez que los estudiantes se enfrentan al mercado laboral.

\section{4. ¿CUÁL ES LA RELACIÓN ENTRE AÑOS DE ACREDITACIÓN Y LAS PERCEPCIONES DE LOS ESTUDIANTES?}

El objetivo de la acreditación ${ }^{14}$ de las instituciones es "evaluar el cumplimiento de su proyecto corporativo y verificar la existencia

${ }^{14} \mathrm{Al}$ momento de este estudio, la acreditación institucional era un proceso voluntario para las instituciones y estaba a cargo de la Comisión Nacional de Acreditación (CNA). La CNA evaluaba la pertinencia de la acreditación y, en caso de entregarla, la otorgaba por un determinado número de años, con un máximo de siete. Habitualmente, los años de acreditación se asocian con la calidad de la institución. Este sistema fue reformado en la nueva ley de educación superior, Ley 21.091, de 2018. 
de mecanismos eficaces de autorregulación y de aseguramiento de la calidad" (Comisión Nacional de Acreditación 2017). De esta manera, esperaríamos que el fortalecimiento de la capacidad de autorregulación y el mejoramiento continuo de las instituciones tuviesen una relación con las opiniones vertidas por los estudiantes. En este capítulo mostraremos cuál es la relación entre años de acreditación y percepciones académicas y laborales de los estudiantes, además de presentar estadísticas acerca de las características de los mismos, separando por nivel de acreditación.

\subsection{Acreditación y caracteristicas individuales}

En primer lugar, a los estudiantes participantes del estudio se los dividió en cuatro tramos, según los años de acreditación de sus instituciones (de menor a mayor). Como se puede ver en la tabla 7, la mayor proporción está concentrada en instituciones en un rango de acreditación de cuatro a cinco años, con 48 por ciento de los estudiantes.

Tabla 7. RESPUESTAS POR ACREDITACIÓN DE INSTITUCIÓN (PORCENTAJE)

\begin{tabular}{lc}
\hline Años de acreditación & \% estudiantes \\
\hline 0 & 7,0 \\
$2-3$ & 14,6 \\
$4-5$ & 48,0 \\
$6-7$ & 30,4 \\
\hline
\end{tabular}

Al estudiar las características de los estudiantes que pertenecen a instituciones en los distintos tramos de acreditación, vemos que en los primeros dos tramos - cero acreditación y dos a tres años- hay una mayor proporción de mujeres que de hombres ( 69 y 55 versus 54 y 50 por ciento, respectivamente; no mostrado). Estos tramos también tienen una mayor proporción de estudiantes con 30 años o más ( 35 y 33 versus 13 y 16 por ciento, respectivamente; no mostrado) y una proporción mucho mayor de estudiantes con hijos que sus pares de instituciones con cuatro años de acreditación o más (42 y 36 versus 13 y 15 por ciento, respectivamente; no mostrado).

La tabla 8, en tanto, muestra la distribución de estudiantes por tramo de acreditación según la principal fuente de financiamiento utilizada 
para sus estudios. ${ }^{15}$ Se concluye que la principal fuente para los estudiantes de instituciones de los primeros dos tramos de acreditación es el trabajo, mientras que para los demás tramos son los recursos familiares, seguidos por el crédito.

Tabla 8. DISTRIBUCIÓN EN ACREDITACIÓN SEGÚN FUENTE PRINCIPAL DE FINANCIAMIENTO (PORCENTAJE)

\begin{tabular}{lcrrr}
\hline Años de acreditación & \multicolumn{1}{c}{0} & $2-3$ & $4-5$ & $6-7$ \\
\hline Beca & 9,2 & 16,3 & 14,9 & 22,6 \\
Crédito & 12,5 & 21,1 & 24,1 & 27,3 \\
Ahorros & 10,2 & 7,5 & 4,6 & 4,7 \\
Recursos familiares & 30,6 & 21,7 & 45,8 & 31,1 \\
Trabajando & 37,2 & 33,2 & 10,2 & 14,1 \\
\hline
\end{tabular}

Para estudiar la composición socioeconómica de los estudiantes por tramo de acreditación, relacionamos esta variable con el tipo de dependencia del establecimiento de educación media, el nivel educacional de los padres y un indicador de si el estudiante es primera generación en la educación superior o no. La figura 7 nos muestra que los estudiantes de establecimientos particulares pagados pertenecen, en una mayor proporción, a instituciones de los dos últimos tramos de acreditación que los estudiantes de establecimientos municipales y particulares subvencionados.

La figura 8, en tanto, muestra un comportamiento similar, pero en función del máximo nivel educacional alcanzado por el padre o la madre. Los estudiantes, cuyos progenitores obtuvieron educación superior técnica o universitaria completa, pertenecen, en mayor proporción, a instituciones ubicadas en los dos últimos tramos de acreditación, si se los compara con los estudiantes cuyos padres no han alcanzado - $\mathrm{O}$ sólo obtuvieron - la educación media completa.

Finalmente, lo mismo ocurre en el caso de la proporción de estudiantes que son primera generación con la educación superior. Los estudiantes que se hallan en esta situación están concentrados en instituciones situadas en los primeros dos tramos de acreditación (11 y 24 versus

${ }^{15}$ Una explicación detallada de la construcción de esta variable se encuentra en el anexo de la versión digital, sección "Glosario de cuestionario". 
Figura 7. ACREDITACIÓN Y DEPENDENCIA ESCOLAR (PORCENTAJE)

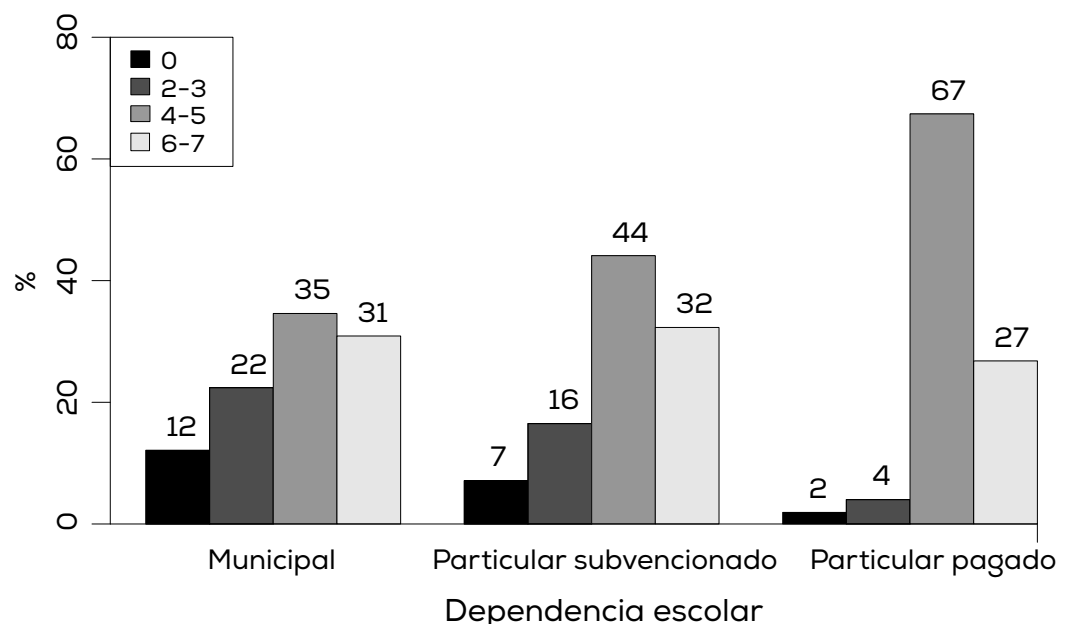

Figura 8. ACREDITACIÓN Y MÁXIMO NIVEL EDUCACIONAL DE LOS PADRES (PORCENTAJE)

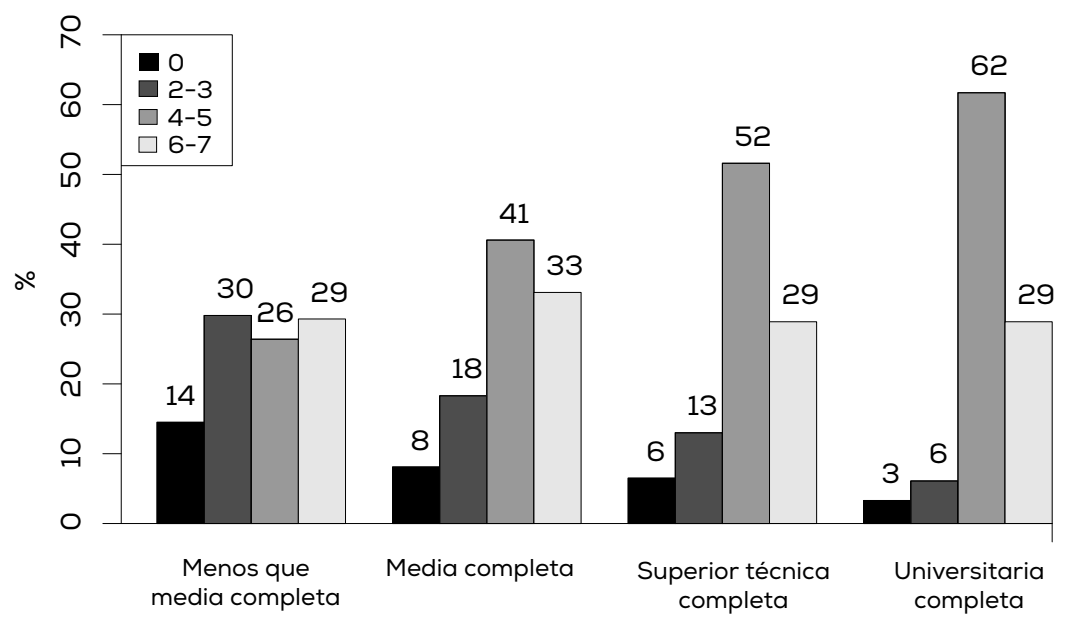

Máximo nivel educacional de los padres 
5 y 9 por ciento, respectivamente), mientras que los estudiantes que no son primera generación están concentrados en las instituciones del tramo de 4 o 5 años de acreditación (57 versus 33 por ciento).

En suma, todos los indicadores socioeconómicos muestran que las instituciones de menor nivel de acreditación tienden a educar estudiantes de menor nivel socioeconómico.

\subsection{Acreditación y percepciones académicas}

¿Cómo cambia la percepción de los estudiantes según el nivel de acreditación de su institución de educación superior? Las figuras 9 a 11 muestran la distribución de distintas opiniones en términos académi$\cos .{ }^{16}$ En la primera, tenemos, en escala de 1 a 7 , la nota que le asignan los estudiantes a su institución y a sus profesores, según los cuatro tramos de acreditación. Podemos notar que, si bien las notas a las instituciones aumentan un tanto a medida que aumenta el tramo (años de acreditación), la nota a los profesores es más alta en instituciones sin acreditación que en cualquiera de los otros grupos.

Figura 9. NOTA A LA INSTITUCIÓN Y A LOS PROFESORES POR NIVEL DE ACREDITACIÓN (ESCALA DE 1 A 7)

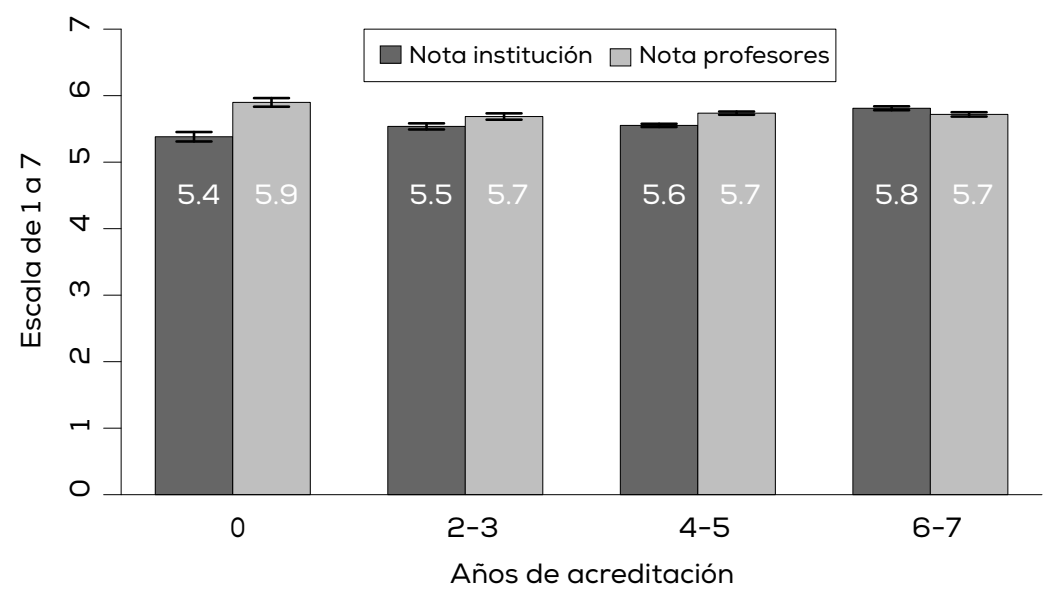

${ }^{16}$ Las figuras de este estudio que grafican promedios incluyen un intervalo de confianza del 95 por ciento, el cual indica el rango en el que se mueve el promedio de la variable estudiada. 
La figura 10 muestra la percepción de los estudiantes, en escala de 1 a 7, de la exigencia académica de su carrera, el nivel de motivación hacia el estudio de sus compañeros y el nivel académico de los mismos. Aquí podemos observar que, a medida que las instituciones logran más años de acreditación, sus estudiantes perciben que la exigencia académica es ligeramente menor. La motivación de sus compañeros hacia el estudio disminuye en la misma dirección. En términos del nivel académico de los compañeros, podemos decir que el nivel percibido aumenta con los años de acreditación, excepto en las instituciones sin acreditación, donde la percepción es tan alta como en las instituciones con más acreditación.

Figura 10. NIVEL DE EXIGENCIA PERCIBIDA, MOTIVACIÓN Y NIVEL ACADÉMICO DE LOS COMPAÑEROS POR NIVEL DE ACREDITACIÓN (ESCALA DE 1 A 7)

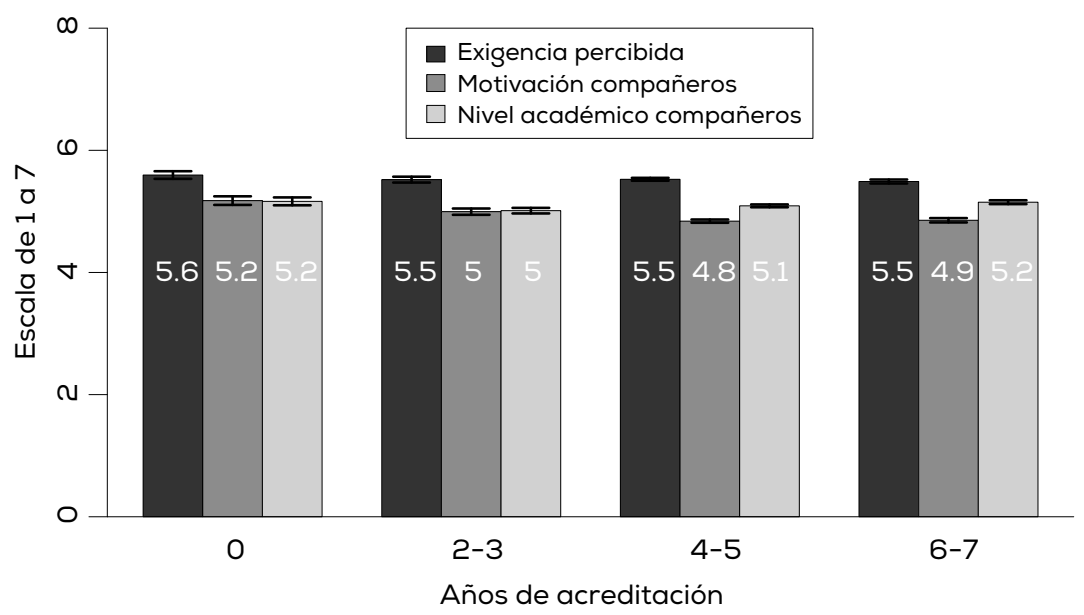

Por su parte, la proporción de estudiantes por tramo de acreditación según la percepción de dificultades académicas que presentaron al estudiar su carrera nos muestra que las instituciones de los dos primeros tramos de acreditación tienen una menor proporción de estudiantes con "muchas dificultades académicas" si se las compara con las instituciones en los dos tramos siguientes ( 3,4 y 5,2 versus 6,4 y 6,2 por ciento, respectivamente; no mostrado).

Por otro lado, la figura 11 muestra la relación entre el promedio del nivel de apoyo institucional percibido por los estudiantes con algunas 
o muchas dificultades académicas. Aquí se observa que a medida que la institución tiene más años de acreditación, el nivel de apoyo percibido disminuye. En el caso de las instituciones no acreditadas, la menor proporción de estudiantes con muchas dificultades académicas puede explicarse por el alto nivel de apoyo que impediría que esta proporción crezca mucho. Para las instituciones con más años de acreditación es preocupante que éstas cuenten, al mismo tiempo, con un menor nivel de apoyo percibido y una mayor proporción de estudiantes con dificultades académicas. ¿Estarán estableciendo exigencias académicas muy altas? ¿Desconocerán el nivel y preparación de sus estudiantes? O bien, ¿será que los estudiantes tienen mayores expectativas respecto del apoyo académico que debiera brindarles su institución?

Figura 11. NIVEL DE APOYO INSTITUCIONAL POR AÑOS DE ACREDITACIÓN (ESCALA DE 1A 7)

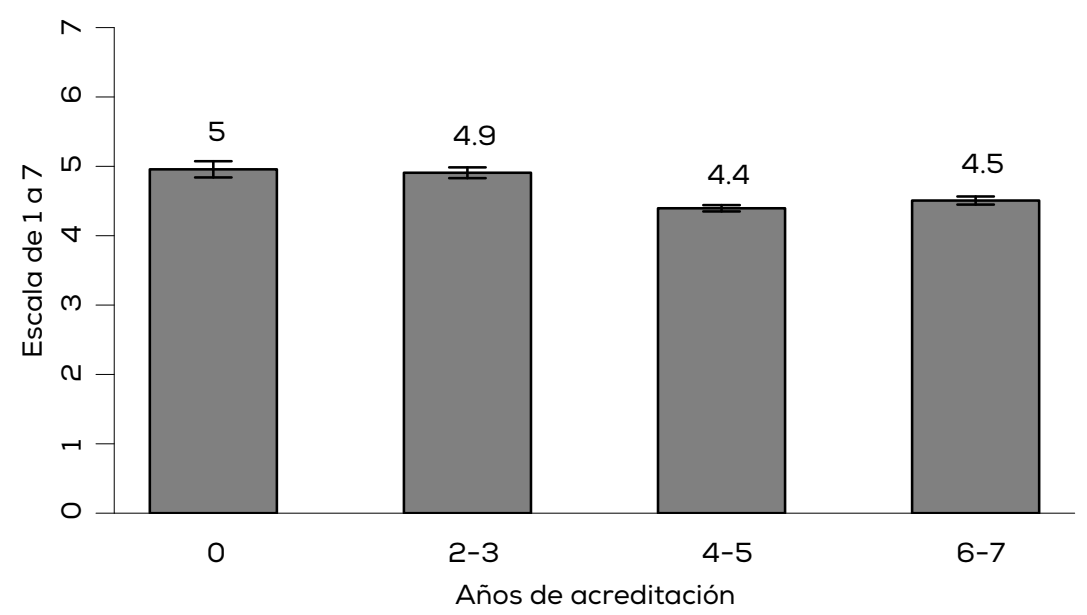

Para terminar con el análisis de las percepciones académicas, la tabla 9 revela que hay una leve correlación negativa entre los años de acreditación y la percepción de respeto dentro de la institución. ¿Qué puede significar esto? Una hipótesis es que la diferencia en respeto se debe a que las instituciones con más años de acreditación son instituciones más politizadas, medido a través del promedio de la respuesta sobre interés en la política. La politización se asociaría a mayor debate políti- 
co, el que, sabemos, suele acalorarse, pudiendo llevar a situaciones que afecten el respeto. De hecho, la correlación entre respeto y politización en la institución es de $-0,1$, por lo que ésta parece una hipótesis más plausible. ${ }^{17}$ En el capítulo 7 de este estudio investigamos más sobre la relación entre identificación con alguna tendencia política y la percepción de respeto, pero por ahora adelantamos que el porcentaje de estudiantes que se identifica con alguno de los extremos políticos en el área de estudios o institución está correlacionado negativamente con el nivel promedio de respeto percibido.

Tabla 9. PERCEPCIÓN DE RESPETO Y AÑOS DE ACREDITACIÓN (ESCALA DE 1 A 7)

\begin{tabular}{lc}
\hline Años de acreditación & Promedio \\
\hline 0 & 5,71 \\
$2-3$ & 5,67 \\
$4-5$ & 5,39 \\
$6-7$ & 5,45 \\
\hline
\end{tabular}

En definitiva, las instituciones con mayor acreditación tienen mejores notas institucionales, menos exigencia académica, menos motivación, mejor nivel académico de los compañeros y menor nivel de apoyo institucional. Sin embargo, los estudiantes de instituciones sin acreditación tienen una visión más optimista respecto de las características académicas de su institución que sus pares en otras instituciones. Específicamente, en la nota a profesores, motivación de sus compañeros, nivel académico de sus compañeros y mayor nivel de respeto percibido.

Esto podría revelar que, independientemente de si la acreditación es conocida por los estudiantes, los criterios de acreditación podrían no estar enfocados en los aspectos que son relevantes para ellos. Lo anterior estaría en línea con el que las características de los estudiantes de instituciones sin acreditación los llevarían a sentirse más satisfechos con el hecho de acceder a la educación superior, independientemente de dónde. Por ejemplo, como vimos anteriormente, una proporción impor-

${ }^{17}$ Otra hipótesis posible es que las instituciones con mayor acreditación son más despersonalizadas, pues en promedio tienen mayor tamaño; sin embargo, los datos no apoyan esta tesis. 
tante de los estudiantes de instituciones con menor nivel de acreditación es primera generación en la educación superior. Al contar con menos referencias sobre este nivel educacional, podrían ser menos exigentes con respecto a la calidad de la institución en la que estudian, o bien tener un concepto de calidad distinto.

\subsection{Acreditación y percepciones laborales}

En términos de la preparación laboral que los estudiantes sienten que su carrera e institución entregan, vemos en la tabla 10 que a medida que las instituciones tienen más años de acreditación, los estudiantes sienten que están menos preparados para el mundo laboral, en una escala de 1 a 7. Esto quiere decir que los estudiantes de instituciones sin acreditación no sólo son más optimistas con respecto a los aspectos académicos de su institución, sino también con la preparación laboral que ésta les entrega. En línea con lo planteado en la sección anterior, los criterios de acreditación podrían no contemplar con suficiente fuerza las razones por las que los estudiantes eligen sus carreras. Por ejemplo, si los estudiantes de instituciones sin acreditación están más conectados con el mundo laboral, es posible que escojan carreras que les entreguen conocimientos más específicos y que les preparen para el trabajo, estando conscientes de sus debilidades y sin necesidad de que éstas cumplan con otros criterios de calidad, tales como la investigación académica de excelencia.

Tabla 10. PERCEPCIONES LABORALES Y ACREDITACIÓN

\begin{tabular}{lcccc}
\hline & $\begin{array}{c}\text { Preparación para el mundo laboral } \\
\text { (esc. 1 a 7) }\end{array}$ & $\begin{array}{c}\text { Probabilidad de estar empleado } \\
\text { (esc. 1 a 10) }\end{array}$ \\
\hline & Promedio & Desv. Est. & Promedio & Desv. Est. \\
\hline 0 & 5,84 & 1,07 & 8,54 & 1,81 \\
$2-3$ & 5,69 & 1,16 & 8,59 & 1,72 \\
$4-5$ & 5,47 & 1,20 & 8,44 & 1,93 \\
$6-7$ & 5,40 & 1,24 & 8,64 & 1,74 \\
\hline
\end{tabular}

\subsection{Conclusión sobre relación entre acreditación y percepciones}

A modo de conclusión, podemos decir que los resultados de la primera sección nos indican que la composición de los estudiantes dentro de las instituciones es distinta según sus años de acreditación, en 
términos de dependencia escolar, educación de los padres y si son o no primera generación en asistir a la educación superior. Esto es relevante en términos de política pública, pues los estudiantes que en teoría están asistiendo a instituciones de peor calidad tienden a ser los más desaventajados (provienen de establecimientos municipales, tienen padres con menor nivel educacional y son primera generación en la educación superior). Además, los estudiantes de estas instituciones son en promedio mayores, tienen una mayor probabilidad de tener hijos y de tener que trabajar para pagar sus estudios.

El hecho de que los estudiantes de instituciones no acreditadas sean más optimistas que sus pares respecto de la motivación y el nivel académico de sus compañeros, o de la preparación para entrar al mundo laboral, además genera preguntas sobre si los objetivos de la acreditación se alinean con los criterios relevantes para los estudiantes. Esto se corresponde con otros estudios, como el de Orellana et al. (2017), donde se plantea que el rol informativo de la acreditación es distinto según el nivel socioeconómico del estudiante y sus percepciones culturales. Así, un estudiante tradicional (en base a las lógicas del sistema pre1981), de clase alta, prioriza las opiniones de contactos y cercanos, o el peso de la tradición de las instituciones, por sobre la acreditación, mientras que para un estudiante "nuevo" (distinto al tradicional), de clase baja, la acreditación representa el único factor de exclusión al momento de elegir una carrera o institución.

\section{5. ¿CUÁL ES LA PRINCIPAL FUENTE DE FINANCIAMIENTO QUE UTILIZAN LOS ESTUDIANTES Y CÓMO SE RELACIONA CON SUS PERSPECTIVAS ACADÉMICAS?}

A los estudiantes se les preguntó por la forma en que habían financiado sus estudios, pudiendo elegir entre beca, crédito, ahorros personales, recursos familiares o trabajando. Para cada una de estas fuentes, se les pidió especificar su importancia en su financiamiento, en una escala de "nada", "poco", "bastante", "mucho" o "todo". La principal fuente de financiamiento es la que se indicó como más importante según la escala anterior. ${ }^{18}$ Cabe destacar que dentro de las opciones de financia-

${ }^{18}$ De haber empate entre dos o más fuentes de financiamiento, la proporción se dividió en partes equivalentes. El 0,2 por ciento de los estudiantes no reportaron haber utilizado alguno de estos tipos de financiamiento. 
miento no se considera la gratuidad universitaria, pues, al haberse instaurado en 2016, no forma parte de las fuentes relevantes para el grupo de estudiantes cercanos a egresar ese mismo año.

La tabla 11 muestra la distribución de los estudiantes según la clasificación anterior. Se puede ver que más de un tercio de los estudiantes utiliza los recursos familiares como la principal fuente para financiar sus estudios de educación superior y que, poco menos de un cuarto, utiliza crédito. Sólo el 5,5 por ciento de los estudiantes utiliza ahorros propios.

Tabla 11. PROPORCIÓN DE ESTUDIANTES POR PRINCIPAL FUENTE DE FINANCIAMIENTO (PORCENTAJE)

\begin{tabular}{lc}
\hline & Promedio \\
\hline Beca & 17,0 \\
Crédito & 23,8 \\
Ahorros & 5,5 \\
Recursos familiares & 36,8 \\
Trabajando & 16,6 \\
\hline
\end{tabular}

\subsection{Principal fuente de financiamiento y características personales}

Las figuras 12 a 14 muestran la distribución de estudiantes por principal fuente de financiamiento: según el tipo de institución, el tipo de dependencia escolar y el nivel educacional de los padres, respectivamente. De la figura 12 se puede extraer que la mayoría de estudiantes de CFT e IP financian sus estudios principalmente trabajando, mientras que en las universidades privadas (tanto dentro como fuera del Cruch) hay una mayor proporción de estudiantes que utilizan los recursos familiares como fuente principal. En las universidades estatales, en tanto, la mayor proporción la tienen los estudiantes que utilizan las becas como principal fuente de financiamiento.

La figura 13 muestra que para estudiantes de establecimientos municipales la principal fuente de financiamiento es, en mayor proporción, el crédito, seguido de los recursos del trabajo. Para estudiantes de establecimientos particulares subvencionados, también existe una alta proporción de estudiantes que utiliza el crédito como principal fuente 
de financiamiento, pero el segundo lugar lo ocupan los recursos familiares. La gran diferencia está en los estudiantes de establecimientos particulares pagados, donde casi el 70 por ciento de los estudiantes utiliza recursos familiares para financiar sus estudios.

Figura 12. PRINCIPAL FUENTE DE FINANCIAMIENTO Y TIPO DE INSTITUCIÓN (PORCENTAJE)

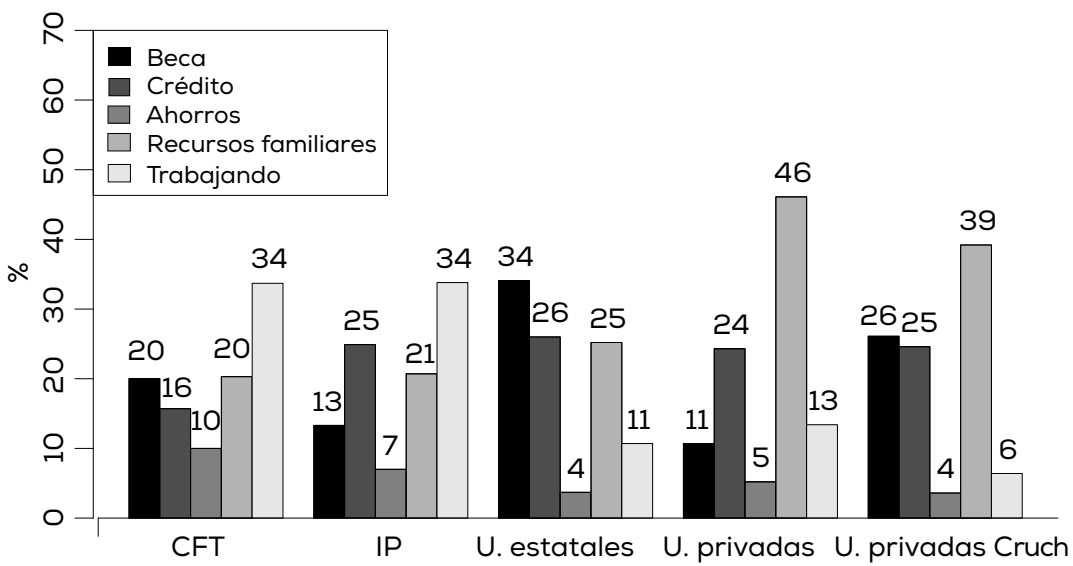

Figura 13. PRINCIPAL FUENTE DE FINANCIAMIENTO Y DEPENDENCIA ESCOLAR (PORCENTAJE)

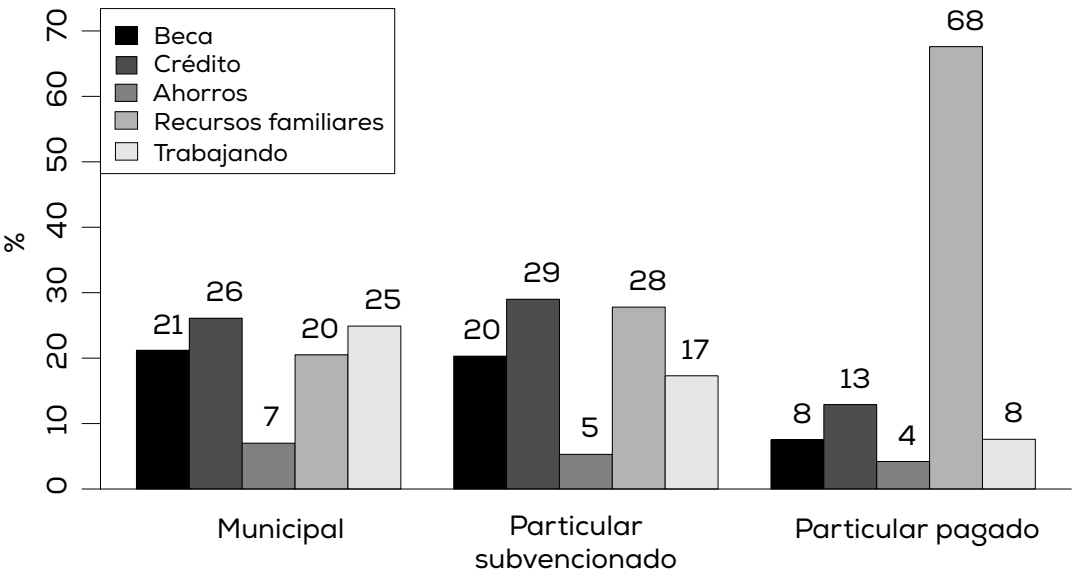


Finalmente, vemos en la figura 14 que a medida que aumenta el nivel educacional de los padres hay una mayor proporción de estudiantes que utiliza los recursos familiares como principal fuente de financiamiento, y una menor proporción que utiliza los recursos del trabajo y los ahorros personales. La proporción de estudiantes que utiliza crédito también aumenta en esta dirección, con excepción de los estudiantes que poseen, al menos, uno de sus padres con educación universitaria completa. De manera similar, la proporción de estudiantes que utiliza beca como principal fuente disminuye a medida que aumenta el nivel educacional de los padres, excepto para estudiantes cuyos padres tienen menos que educación media completa.

Figura 14. PRINCIPAL FUENTE DE FINANCIAMIENTO Y MÁXIMO NIVEL EDUCACIONAL DE LOS PADRES (PORCENTAJE)

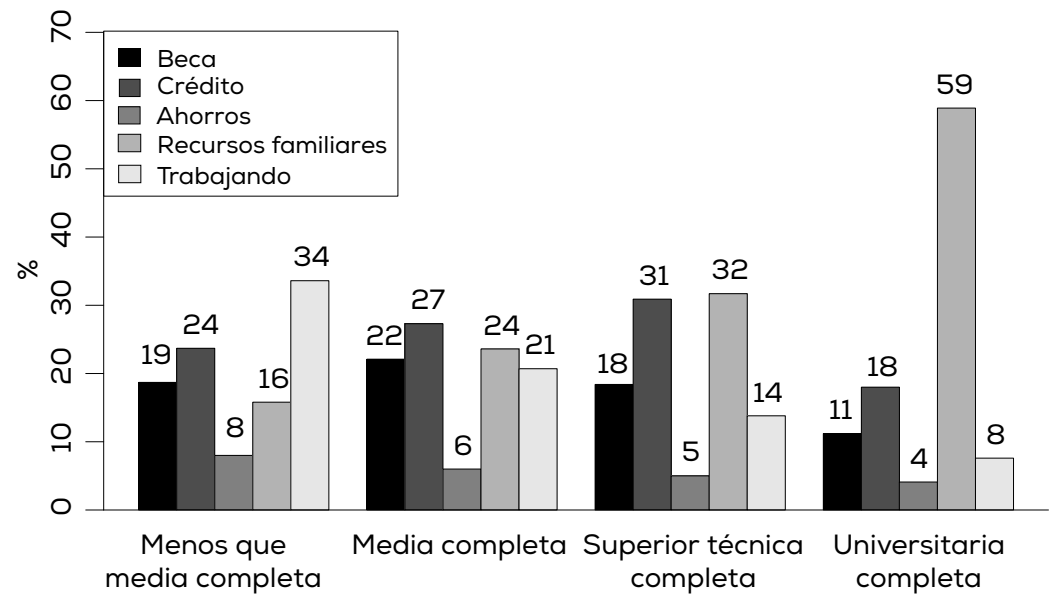

Los resultados anteriores nos muestran que - considerando las fuentes de financiamiento existentes hasta antes de 2016- hay un fuerte uso de los recursos privados (crédito y recursos familiares) para financiar la educación superior en todas las clasificaciones. Este tipo de recursos son especialmente relevantes en universidades, siendo los recursos familiares más predominantes en estudiantes de establecimientos particulares pagados y con padres con educación superior completa.

A continuación, analizaremos las perspectivas académicas de los estudiantes según su principal fuente de financiamiento. 


\subsection{Principal fuente de financiamiento y perspectivas académicas}

La figura 15 muestra la proporción de estudiantes que tienen algunas dificultades y muchas dificultades académicas, según principal fuente de financiamiento. ${ }^{19}$ La primera columna de cada grupo indica que los estudiantes con "algunas dificultades" están más concentrados entre los estudiantes que utilizan principalmente crédito. En tanto, los que no tienen dificultades académicas se concentran mayormente entre los que estudian con beca (no mostrado). Estos resultados son consistentes con el hecho de que, para un mismo nivel socioeconómico, el acceso a beca exige un mayor puntaje PSU, por lo que en promedio quienes estudian con becas tienen mejor rendimiento académico que quienes estudian con crédito.

Figura 15. DIFICULTADES ACADÉMICAS POR PRINCIPAL FUENTE DE FINANCIAMIENTO (PORCENTAJE)

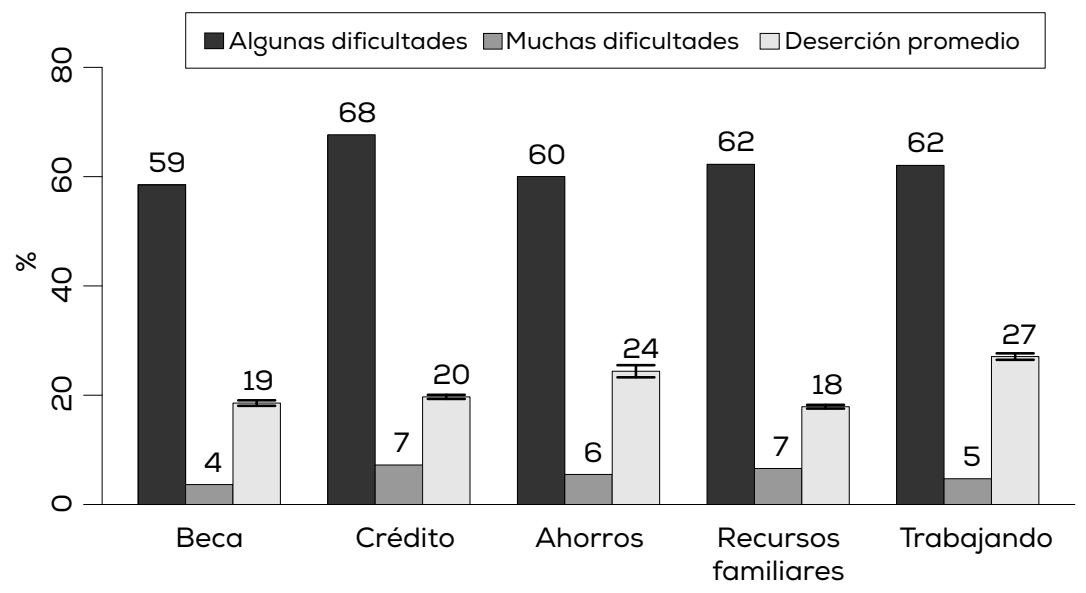

Fuente para deserción: mifuturo.cl

Esta figura también muestra el promedio del porcentaje de deserción al primer año por carrera e institución obtenido de mifuturo.

${ }^{19}$ Para calcular los promedios de la figura 15 se consideró solamente a los estudiantes que declararon que cada una de estas fuentes es la única principal fuente de financiamiento, o una de dos principales fuentes de financiamiento. Es decir, se excluyen tres o más fuentes de financiamiento principal. 
$\mathrm{cl}^{20}$ según las distintas fuentes de financiamiento. Aquí podemos ver que los estudiantes que utilizan ahorros o recursos del trabajo como principal fuente de financiamiento tienden a encontrarse en carreras con una mayor deserción. Si bien esta relación requiere de mayor estudio, es posible que la mayor deserción se deba, al menos en parte, a que los estudiantes que se financian trabajando tienen dificultades para compatibilizar trabajo y estudios. Otra hipótesis es que, precisamente porque estos estudiantes están trabajando, cursan sus estudios de manera menos definitiva, entrando y saliendo de la educación superior con más frecuencia. En otras palabras, la deserción, puede ser transitoria. Es también relevante notar que la deserción en las carreras donde estudian quienes se financian sobre todo con crédito es muy similar a la de las donde estudian quienes se financian sobre todo con beca, en línea con otros estudios (Intelis y Verde 2012), pese a que los estudiantes con crédito tienen mayores dificultades académicas.

\subsection{Conclusión sobre la principal fuente de financiamiento}

Como conclusión, podemos observar que la mayoría de los estudiantes utilizan crédito o recursos familiares a modo de principal medio para financiar su educación superior, y que este tipo de financiamiento está asociado a mayores dificultades académicas. En general, hay una relación positiva entre nivel socioeconómico (aproximado por tipo de dependencia escolar y nivel educacional de los padres) y uso de crédito, y una relación negativa entre nivel socioeconómico y uso de beca. Esto último está en línea con los criterios y requisitos de nivel socioeconómico para acceder a becas y créditos, previos a la incorporación de la gratuidad universitaria.

Por otro lado, pese a que los estudiantes que utilizan principalmente crédito para financiar sus estudios tienen mayores dificultades académicas que los estudiantes que utilizan principalmente beca, no hay grandes diferencias en términos del nivel de deserción de sus carreras.

Dado que una proporción no menor de estudiantes financia sus estudios trabajando, y que éstos son los alumnos que se encuentran en

${ }^{20}$ Mifuturo.cl es una página web desarrollada por el Ministerio de Educación que entrega información de empleabilidad, ingresos y costos de las distintas carreras del sistema de educación superior, entre otras cosas. 
carreras con mayor porcentaje de deserción, resulta interesante analizar cuáles son las posibles dificultades que este tipo de estudiantes enfrenta. En el capítulo 4 de este estudio se puede ver que la mayoría estudia en instituciones no acreditadas o con pocos años de acreditación. Dentro de los CFT e IP, son el mayor grupo de estudiantes y, generalmente, provienen de establecimientos municipales o tienen padres con un nivel educacional menor. Como información adicional, podemos decir que el promedio de edad de estos estudiantes es mayor, que una proporción más grande de ellos tiene hijos y que casi el 70 por ciento ya se encontraba trabajando a tiempo completo al momento de contestar la encuesta.

Con estos antecedentes, cabe cuestionarse las políticas enfocadas a este grupo, al que generalmente no se lo considera en los análisis. ¿Qué espacio hay para la educación continua ${ }^{21}$ dentro de la educación superior? ¿Cómo se elabora un sistema de apoyo institucional más efectivo para reducir los niveles de deserción? ¿Cómo se integra a estudiantes mayores, los con familia y aquellos que deben cumplir horarios diferentes? Un buen diseño de la política de educación superior debiera considerar de mejor manera a quienes estudian bajo esta alternativa de financiamiento y las características de los estudiantes que la utilizan para alcanzar un mayor nivel de equidad.

\section{6. ¿QUIÉNES SON LOS ESTUDIANTES CON DIFICULTADES ACADÉMICAS Y CUÁNTO APOYO RECIBEN?}

A los estudiantes de la muestra se les preguntó: “¿Cuántas dificultades de rendimiento académico has tenido durante tus estudios?", pudiendo elegir entre: Ninguna dificultad, algunas dificultades o muchas dificultades. La tabla 12 muestra la proporción de respuestas para cada una de estas categorías, donde se evidencia que poco más de dos tercios de los estudiantes tienen algún tipo de dificultad académica y casi seis por ciento dice tener muchas dificultades académicas.

${ }^{21}$ Sobre la educación continua actualmente no existen definiciones y las prácticas varían entre las instituciones en extensión, mecanismos de ingreso, etcétera. 
Tabla 12. PROPORCIÓN DE ESTUDIANTES POR NIVEL DE DIFICULTADES ACADÉMICAS (PORCENTAJE)

\begin{tabular}{lc}
\hline & Porcentaje \\
\hline Ninguna dificultad académica & 31,4 \\
Algunas dificultades académicas & 62,6 \\
Muchas dificultades académicas & 5,9 \\
\hline
\end{tabular}

¿Quiénes son los estudiantes con muchas dificultades académicas? La tabla 13 muestra que los hombres dicen tener más dificultades que las mujeres. Por su parte, la figura 16 muestra que los estudiantes que cursaron su enseñanza media en un establecimiento particular pagado tienen menores dificultades, mientras que aquellos que estudiaron en establecimientos municipales o particulares subvencionados muestran mayores dificultades.

Tabla 13. DIFICULTADES ACADÉMICAS POR SEXO (PORCENTAJE)

\begin{tabular}{lcc}
\hline & Hombre & Mujer \\
\hline Ninguna dificultad académica & 43,8 & 56,2 \\
Algunas dificultades académicas & 46,2 & 53,8 \\
Muchas dificultades académicas & 52,2 & 47,8 \\
\hline
\end{tabular}

Figura 16. DIFICULTADES ACADÉMICAS Y DEPENDENCIA ESCOLAR (PORCENTAJE)

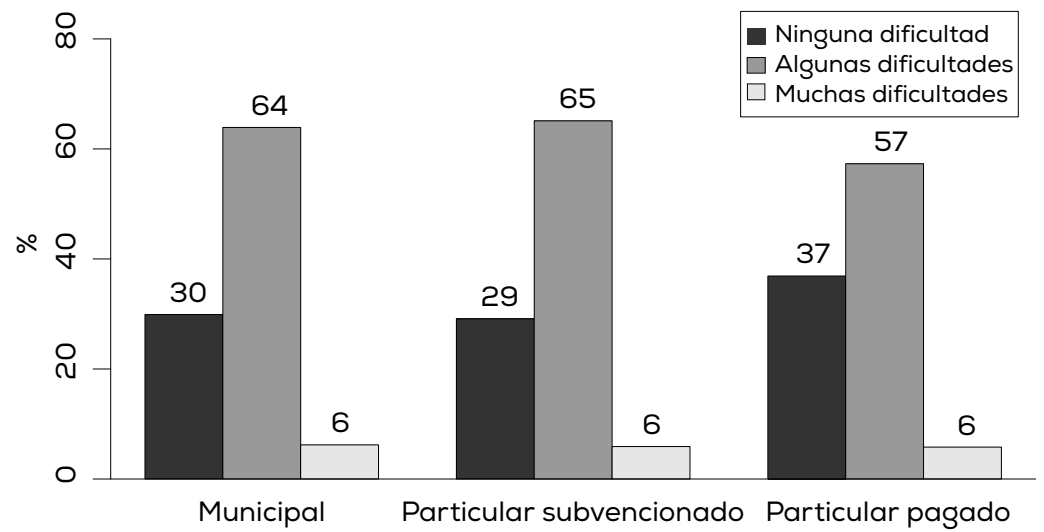




\subsection{Dificultades académicas y percepciones académicas}

Con el fin de entender mejor los motivos tras las dificultades académicas, estudiamos la relación entre éstas y dos variables académicas: por una parte, la percepción de preparación académica previa a ingresar a estudiar su carrera y, por la otra, la percepción de la exigencia académica de su carrera. En la figura 17 se puede apreciar que, en la medida en que aumenta el nivel de dificultades académicas percibidas, aumenta la exigencia académica, mientras que la percepción de la preparación previa disminuye, tal como era de esperar. No obstante, pareciera que la relación entre dificultades académicas y preparación previa es más fuerte que la que aparece entre dificultades y exigencia académica, sugiriendo que la preparación previa es un factor más relevante para las dificultades académicas que el nivel de exigencia, al menos desde la percepción de los propios estudiantes.

Figura 17. PREPARACIÓN PREVIA Y EXIGENCIA PERCIBIDA POR DIFICULTADES ACADÉMICAS (ESCALA DE 1 A 7)

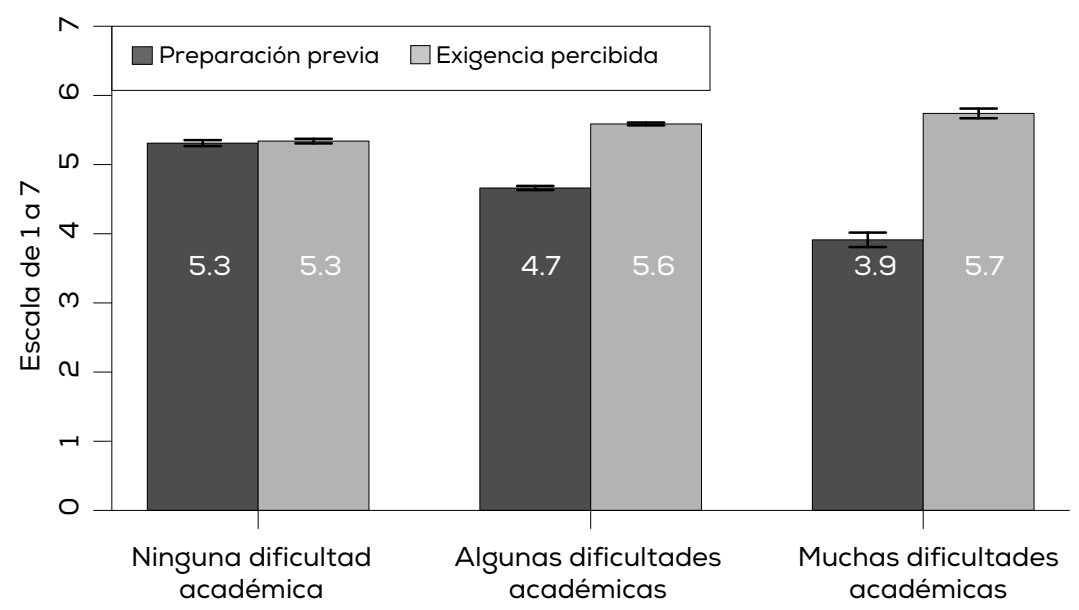

Para profundizar en esto, en la tabla 14 mostramos los promedios de estas dos variables por tipo de dependencia escolar. Podemos observar aquí que la evaluación de la preparación previa percibida muestra una diferencia de casi 0,4 puntos entre estudiantes de establecimientos municipales y particulares pagados, mientras que la diferencia en el 
nivel de exigencia académica percibida es de cerca de 0,1 puntos para los mismos grupos. Usando otro indicador de nivel socioeconómico, el máximo nivel educacional alcanzado por el padre o por la madre, vemos que los resultados se repiten. En efecto, la diferencia en preparación previa percibida entre estudiantes cuyos padres tienen al menos educación universitaria completa y menos que media completa es de casi 4 décimas (5,01 versus 4,61), mientras que la diferencia en exigencia académica percibida es de -1 décima $(5,48$ versus 5,57$)$.

Lo anterior es consistente con lo reportado por las pruebas Simce, ${ }^{22}$ que consistentemente han mostrado que la preparación académica es de un menor nivel de logro en los establecimientos municipales, algo mayor en los particulares subvencionados, y bastante superior en los particulares pagados. En efecto, el Simce 2016 muestra que la brecha entre establecimientos particulares subvencionados y municipales (considerando que la brecha con particulares pagados es mayor) es de 15,6 puntos para Lectura y 18,9 puntos para Matemáticas en cuarto básico; y de 21,8 puntos en Ciencias Naturales, 21,1 puntos en Lectura y 38,7 puntos en Matemáticas para segundo medio. ${ }^{23}$

Tabla 14. PREPARACIÓN PREVIA Y EXIGENCIA ACADÉMICA SEGÚN DEPENDENCIA ESCOLAR (ESCALA DE 1A 7)

\begin{tabular}{lcccc}
\hline & \multicolumn{2}{c}{ Preparación previa } & \multicolumn{2}{c}{ Exigencia académica } \\
\hline & Promedio & Desv. Est. & Promedio & Desv. Est. \\
\hline Municipal & 4,72 & 1,53 & 5,57 & 1,03 \\
Particular subvencionado & 4,72 & 1,51 & 5,53 & 1,05 \\
Particular pagado & 5,09 & 1,47 & 5,46 & 1,04 \\
\hline
\end{tabular}

Los resultados indicarían que el tipo de establecimiento educacional afectaría el nivel de las dificultades académicas de los estudiantes a través de la preparación previa. Esto es relevante desde el punto de vis-

22 El Simce es una batería de pruebas que desde 1988 se aplica al universo de estudiantes del sistema escolar chileno, con el fin de medir la calidad de la educación.

${ }^{23}$ Aunque una vez que se controla por nivel socioeconómico las brechas entre puntajes Simce se vuelven más pequeñas o desaparecen. Para estos efectos, lo relevante es que existan diferencias absolutas en rendimiento académico por dependencia escolar. 
ta de políticas públicas, pues los estudiantes que egresaron de establecimientos con preparación más deficiente, que suelen provenir de sectores más vulnerables, enfrentarían condiciones académicas más difíciles al entrar en la educación superior.

Un segundo resultado relevante respecto de las percepciones académicas es la relación negativa que existe entre las dificultades académicas y las evaluaciones que los estudiantes hacen de sus instituciones. Como se puede ver en el capítulo 3 de este estudio, la evaluación de las instituciones y carreras es relativamente estable y alta entre los diferentes grupos de estudiantes. Sin embargo, en la tabla 15 se puede ver que los estudiantes con muchas dificultades académicas evalúan, en promedio, con 3,1 décimas menos a su institución y con 3,4 décimas menos a sus profesores que los estudiantes sin dificultades.

Tabla 15. NOTA A INSTITUCIÓN Y PROFESORES POR DIFICULTADES ACADÉMICAS (ESCALA DE 1 A 7)

\begin{tabular}{lcccc}
\hline & \multicolumn{2}{c}{ Nota institución } & \multicolumn{2}{c}{ Nota profesores } \\
\hline & Promedio & Desv. Est. & Promedio & Desv. Est. \\
\hline Ninguna dificultad académica & 5,69 & 1,03 & 5,79 & 1,06 \\
Algunas dificultades académicas & 5,60 & 1,03 & 5,73 & 1,02 \\
Muchas dificultades académicas & 5,38 & 1,07 & 5,45 & 1,22 \\
\hline
\end{tabular}

6.2. Dificultades académicas y percepciones laborales, políticas, de satisfacción con la vida y respeto

Teniendo en cuenta lo anterior, un ejercicio interesante es estudiar cómo las dificultades académicas permean otras áreas de la vida de los estudiantes. Por ejemplo, la tabla 16 muestra que los estudiantes con muchas dificultades académicas sienten que están 7,4 décimas menos preparados para el mundo laboral (en una escala de 1 a 7) que sus compañeros sin dificultades. Al mismo tiempo, estos estudiantes perciben que tienen 8,5 décimas menos de probabilidad de estar empleados una vez que terminen su carrera (en una escala de 1 a 10) que sus pares sin ninguna dificultad.

Las dificultades académicas, además, tienen una asociación importante con cómo los estudiantes evalúan (en una escala de 1 a 7) a instituciones como la democracia y el sistema económico. En particular, 
la diferencia entre los estudiantes que tienen muchas dificultades y ninguna dificultad es de 3,8 décimas para el sistema económico y de casi 4,6 décimas para la democracia ( 3,3 versus 3,7 y 3,2 versus 3,6 , respectivamente; no mostrado).

Tabla 16. PERCEPCIONES LABORALES Y DIFICULTADES ACADÉMICAS

\begin{tabular}{lcccc}
\hline & \multicolumn{2}{c}{$\begin{array}{c}\text { Preparación para el } \\
\text { mundo laboral (esc. 1 a 7) }\end{array}$} & \multicolumn{2}{c}{$\begin{array}{l}\text { Probabilidad de estar } \\
\text { empleado (esc. 1 a 10) }\end{array}$} \\
\hline & Promedio & Desv. Est. & Promedio & Desv. Est. \\
\hline $\begin{array}{l}\text { Ninguna dificultad } \\
\text { académica }\end{array}$ & 5,72 & 1,15 & 8,82 & 1,62 \\
$\begin{array}{l}\text { Algunas dificultades } \\
\text { académicas }\end{array}$ & 5,45 & 1,19 & 8,44 & 1,86 \\
$\begin{array}{l}\text { Muchas dificultades } \\
\text { académicas }\end{array}$ & 4,98 & 1,44 & 7,97 & 2,33 \\
\hline
\end{tabular}

Vemos que tener dificultades académicas también se relaciona con el nivel de satisfacción con la vida en una escala de 1 a 10. Los estudiantes con muchas dificultades académicas tienen un promedio de 6,89 de satisfacción, mientras que sus compañeros con algunas dificultades tienen un promedio de 7,52 y quienes no tienen dificultades, un promedio de 7,84. La diferencia entre los grupos extremos es, por tanto, de casi un punto, equivalente a 57 por ciento de desviación estándar de satisfacción con la vida (no mostrado).

Finalmente, el nivel de respeto percibido, en una escala de 1 a 7 , hacia personas $u$ opiniones diferentes en el ambiente de la institución superior también disminuye con la existencia de dificultades académicas. En efecto, el promedio de respeto percibido para los estudiantes que no tienen dificultades académicas es de 5,55, mientras que para los con muchas dificultades es de 5,12.

Estos resultados muestran que, además de existir diferencias según la preparación previa de los estudiantes, las dificultades académicas están asociadas a visiones más pesimistas respecto de la evaluación institucional, las perspectivas laborales, las opiniones políticas, la satisfacción con la vida y la percepción en el nivel de respeto. Si bien se requiere más estudio para determinar la causalidad, todo parece indicar que experimentar dificultades académicas pareciera ser una experiencia muy determinante para los estudiantes. 


\subsection{Apoyo institucional}

A los estudiantes que mostraban algún tipo de dificultad académica se les preguntó: "¿Qué tanto apoyo has recibido por parte de tu institución con tus dificultades de rendimiento académico?", en una escala de 1 a 7. Si los estudiantes presentan algunas dificultades académicas, el promedio de esta variable es de 4,61, mientras que si tienen muchas dificultades, el promedio es de 3,82. La tabla 17 muestra cómo se distribuye esta medida de apoyo según el tipo de institución, siendo las universidades del Cruch (estatales y privadas) las con peor promedio en el nivel de apoyo, en tanto que los CFT e IP tienen los promedios más altos. Como se puede apreciar, las notas entregadas para el nivel de apoyo son relativamente bajas con respecto a otras características institucionales evaluadas, especialmente para el grupo de estudiantes con muchas dificultades académicas. De hecho, el apoyo percibido por los estudiantes que dicen tener muchas dificultades, correspondientemente ponderado, obtiene promedio rojo. Este fuerte contraste entre la evaluación de las instituciones y de su nivel de apoyo ante dificultades académicas sugiere que ésta es una dimensión en la cual las instituciones están haciendo un mal trabajo.

Tabla 17. APOYO INSTITUCIONAL Y DIFICULTADES ACADÉMICAS, POR TIPO DE INSTITUCIÓN (ESCALA DE 1A 7)

\begin{tabular}{lcccc}
\hline & \multicolumn{2}{c}{ Algunas dificultades } & \multicolumn{2}{c}{ Muchas dificultades } \\
\hline & Promedio & Desv. Est. & Promedio & Desv. Est. \\
\hline CFT & 5,07 & 1,58 & 4,26 & 1,56 \\
IP & 5,00 & 1,44 & 4,44 & 1,66 \\
U. estatales & 4,45 & 1,58 & 3,89 & 1,80 \\
U. privadas & 4,51 & 1,57 & 3,66 & 1,71 \\
U. privadas Cruch & 4,43 & 1,54 & 3,79 & 1,70 \\
\hline
\end{tabular}

Las figuras 18 y 19, por su parte, muestran cuál es el nivel de apoyo entregado según los tramos de deserción al primer año, separando entre estudiantes con algunas y muchas dificultades. A medida que aumenta el nivel de deserción, hay ligeramente un mayor apoyo entregado por parte de la institución a los estudiantes con algunas dificultades académicas, pero menor apoyo a los con muchas dificultades. La ex- 
cepción está en el tramo de más de 30 por ciento de deserción, donde el promedio de apoyo percibido es el mayor entre los estudiantes con muchas dificultades académicas.

Figura 18. APOYO POR NIVEL DE DESERCIÓN Y DIFICULTADES ACADÉMICAS (ESCALA DE 1A 7)

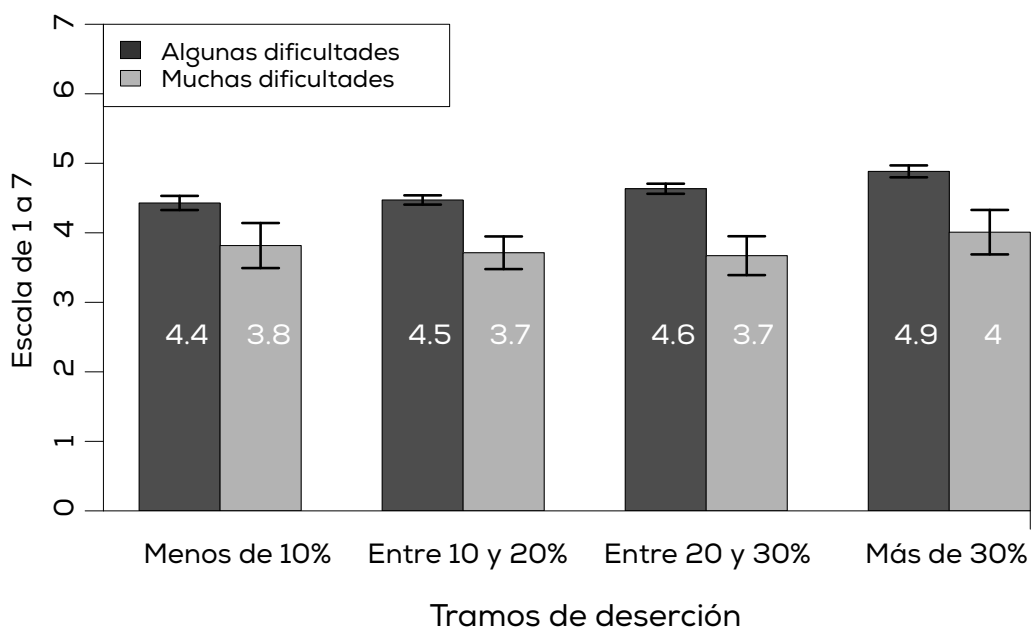

Figura 19. APOYO POR NIVEL DE DESERCIÓN Y DIFICULTADES ACADÉMICAS

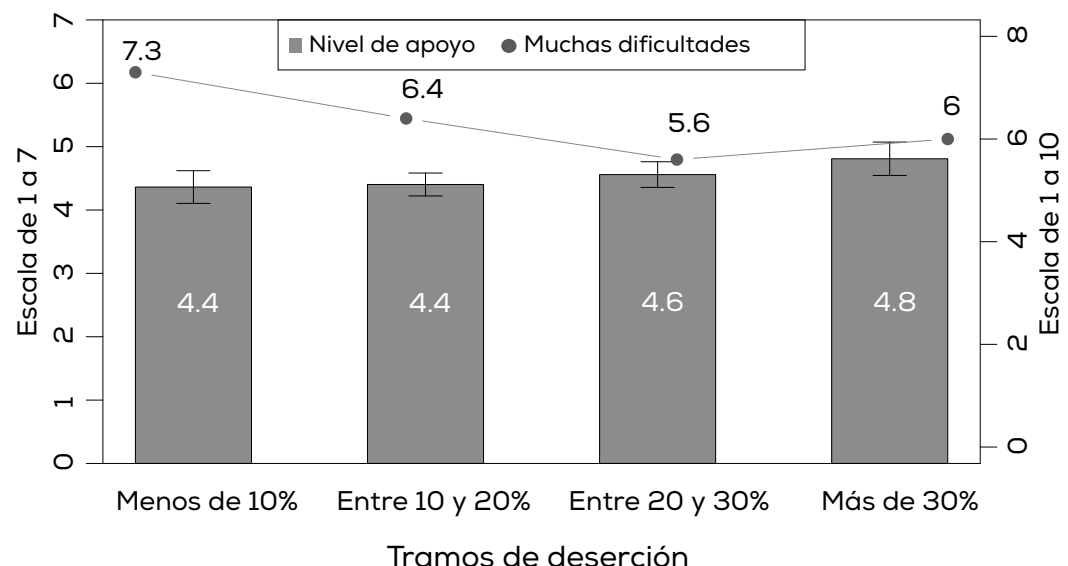

Tramos de deserción 
Cabe destacar que estos resultados no muestran una relación causal entre apoyo institucional y dificultades académicas o deserción. Si bien una institución puede brindar un mayor apoyo cuando una mayor proporción de sus estudiantes tiene dificultades académicas, también puede ocurrir que los estudiantes tengan menores dificultades académicas porque tienen mayor apoyo de su institución. Asimismo, las exigencias que tienen los estudiantes con respecto al nivel de apoyo institucional y el conocimiento que tienen las instituciones sobre la preparación de sus estudiantes también influirían en la relación entre estas dos variables.

\subsection{Análisis multivariado para dificultades académicas}

Para analizar más directamente la relación que tienen algunas de las variables estudiadas con la percepción de dificultades académicas, realizamos el análisis multivariado presentado en la tabla 18. El objetivo de esta regresión, así como de todas las de este trabajo, es simplemente describir las relaciones empíricas entre las variables de interés. En ningún sentido pretendemos mostrar relaciones de causalidad.

La primera columna muestra los resultados cuando la variable dependiente es una dicotómica que toma valor 1 si el o la estudiante dice haber tenido muchas dificultades académicas y 0 si dice tener algunas o ninguna. La segunda columna contiene los resultados para una variable dependiente dicotómica que toma valor 1 si el o la estudiante tuvo muchas o algunas dificultades académicas y 0 si no tuvo dificultades. Por simplicidad, se utiliza una regresión lineal en lugar de un modelo Probit/Logit, ya que los resultados son virtualmente los mismos. Los coeficientes de la regresión lineal se pueden interpretar como los efectos marginales del cambio en las variables explicativas en modelos no lineales (Angrist y Pischke 2009).

Las variables de control son la edad, la edad al cuadrado, el sexo, si el o la estudiante tiene hijos, el tipo de dependencia escolar (con municipal como base), el nivel educacional de los padres (con menos que media completa como base), el nivel de percepción de preparación previa (en desviaciones estándar), el nivel de exigencia académica (en desviaciones estándar), el área de conocimiento de la carrera cursada (con administración y comercio como base) y el nivel de dificultades económicas que enfrentó el o la estudiante al estudiar su carrera (con ninguna dificultad como base). En ambas estimaciones se controla por efectos fijos a nivel de la institución. 
Los resultados de la tabla 18 muestran que las dificultades académicas están asociadas a estudiantes mayores en edad, pero a tasas decrecientes; es decir, a estudiantes que tienen apenas un par de años más que sus compañeros. Los hombres enfrentan mayores dificultades académicas que las mujeres y tener o no hijos está asociado sólo en el caso en que el o la estudiante tiene algunas dificultades, pero no muchas.

No existe correlación significativa por tipos de dependencia escolar, ni por nivel educacional de los padres, una vez que se controla por preparación previa. En este sentido, una desviación estándar en preparación previa está asociada a una mayor disminución en la probabilidad de tener dificultades académicas que una desviación estándar de exigencia académica, confirmando que los niveles de educación anteriores tienen mayor relevancia en este aspecto que la exigencia propia de la institución. Por su parte, el tipo de carrera está correlacionado con las dificultades académicas, en tanto las carreras clasificadas dentro de las categorías agropecuaria, salud y tecnología se asocian a mayores dificultades que las de administración y comercio, y las carreras dentro de arte y arquitectura y ciencias sociales se asocian a menores dificultades. Finalmente, hay una correlación positiva entre dificultades económicas y dificultades académicas.

Tabla 18. REGRESIÓN PARA DIFICULTADES ACADÉMICAS

\begin{tabular}{lcc}
\hline & \multicolumn{2}{c}{ Variable dependiente } \\
\hline & $(1)$ & $\begin{array}{c}\text { Muchas y algunas dif. } \\
\text { académicas }\end{array}$ \\
\hline Mujer & $-0,015^{* * *}$ & $-0,027^{* * *}$ \\
& $(0,004)$ & $(0,008)$ \\
\hline Edad & $0,008^{* * *}$ & $0,021^{* * *}$ \\
\hline Edad ${ }^{*}$ & $(0,002)$ & $(0,004)$ \\
\hline Hijos & $-0,0001^{* * *}$ & $-0,0003^{* * *}$ \\
& $(0,00004)$ & $(0,0001)$ \\
\hline Part. subvencionado & $-0,008$ & $-0,023^{* *}$ \\
& $(0,006)$ & $(0,011)$ \\
\hline Part. pagado & $-0,005$ & $-0,004$ \\
& $(0,005)$ & $(0,009)$ \\
\hline Educ. padres media & 0,004 & $-0,014$ \\
& $(0,007)$ & $(0,013)$ \\
\hline & $-0,007$ & $-0,001$ \\
& $(0,006)$ & $(0,012)$ \\
\hline
\end{tabular}


L. COX, A. HERNANDO y A. REBOLLEDO / Una evaluación de la educación superior 55

\begin{tabular}{|c|c|c|}
\hline \multirow[t]{2}{*}{ Educ. padres técnica } & 0,009 & $-0,017$ \\
\hline & $(0,008)$ & $(0,015)$ \\
\hline \multirow[t]{2}{*}{ Educ. padres universitaria } & 0,009 & $-0,011$ \\
\hline & $(0,008)$ & $(0,014)$ \\
\hline \multirow[t]{2}{*}{ Preparación previa } & $-0,111 * * *$ & $-0,296^{* * *}$ \\
\hline & $(0,007)$ & $(0,012)$ \\
\hline \multirow[t]{2}{*}{ Exigencia } & $0,064^{* * *}$ & 0,281 *** \\
\hline & $(0,011)$ & $(0,021)$ \\
\hline \multirow[t]{2}{*}{ Agropecuaria } & $0,061^{* * *}$ & $0,090^{* * *}$ \\
\hline & $(0,019)$ & $(0,026)$ \\
\hline \multirow[t]{2}{*}{ Arte y arquitectura } & $-0,019 *$ & $-0,011$ \\
\hline & $(0,010)$ & $(0,023)$ \\
\hline \multirow[t]{2}{*}{ Ciencias básicas } & $-0,003$ & 0,037 \\
\hline & $(0,019)$ & $(0,028)$ \\
\hline \multirow[t]{2}{*}{ Ciencias sociales } & $-0,015^{* *}$ & $-0,068^{* * *}$ \\
\hline & $(0,006)$ & $(0,015)$ \\
\hline \multirow[t]{2}{*}{ Derecho } & 0,014 & 0,022 \\
\hline & $(0,011)$ & $(0,018)$ \\
\hline \multirow[t]{2}{*}{ Educación } & $-0,006$ & $-0,089^{* * *}$ \\
\hline & $(0,007)$ & $(0,016)$ \\
\hline \multirow[t]{2}{*}{ Humanidades } & 0,021 & $-0,035$ \\
\hline & $(0,027)$ & $(0,046)$ \\
\hline \multirow[t]{2}{*}{ Salud } & $0,020^{* * *}$ & 0,020 \\
\hline & $(0,007)$ & $(0,014)$ \\
\hline \multirow[t]{2}{*}{ Tecnología } & $0,019^{* \star \star}$ & $0,033^{* * *}$ \\
\hline & $(0,006)$ & $(0,011)$ \\
\hline \multirow[t]{2}{*}{ Algunas dif. eco. } & $0,023^{* * *}$ & $0,134^{* * *}$ \\
\hline & $(0,004)$ & $(0,010)$ \\
\hline \multirow[t]{2}{*}{ Muchas dif. eco. } & $0,074^{* * *}$ & $0,187^{* * *}$ \\
\hline & $(0,007)$ & $(0,011)$ \\
\hline \multirow[t]{2}{*}{ Constante } & $-0,069 *$ & $-0,148$ * \\
\hline & $(0,040)$ & $(0,076)$ \\
\hline Efecto fijo por IES & Sí & Si \\
\hline N & 14.128 & 14.128 \\
\hline $\mathrm{R} 2$ & 0,050 & 0,114 \\
\hline R2 Ajustado & 0,050 & 0,110 \\
\hline
\end{tabular}

Nota: ${ }^{*} p<0,1 ;{ }^{* *} p<0,05 ;{ }^{* * *} p<0,01$. Errores robustos. 


\subsection{Conclusión sobre las dificultades académicas \\ y el apoyo institucional}

En definitiva, vemos que las dificultades académicas están fuertemente asociadas a un menor nivel de preparación previa percibida, el cual se relaciona con el tipo de dependencia escolar y, en particular, con el nivel socioeconómico de los estudiantes.

Sabemos, también, que el tener dificultades académicas está asociado a visiones más pesimistas respecto de las características de la institución de educación superior, de las perspectivas laborales e incluso de la satisfacción con la vida. Sin embargo, pese a que las dificultades afectan en mayor medida a los estudiantes más vulnerables y a que sufrirlas se asocia a aspectos tan graves como una menor satisfacción con la vida, las instituciones parecieran no estar entregando suficiente apoyo a quienes enfrentan dificultades. Éste es, especialmente, el caso de quienes enfrentan muchas dificultades, quienes ponen nota roja al apoyo recibido.

La falta de apoyo ante dificultades académicas nos parece un problema importante de nuestro sistema de educación superior y la política de educación debiera hacerse cargo. Por un lado, es necesario mejorar la preparación previa de los estudiantes de menor nivel socioeconómico - una tarea de largo aliento - y, por otro, hay que promover que las instituciones tengan mecanismos de apoyo más robustos y, es más, que establezcan una cultura de apoyo a sus estudiantes. Esto requiere que las instituciones conozcan a sus estudiantes y ayuden prioritariamente a los más vulnerables.

\section{7. ¿HAY RESPETO HACIA LAS PERSONAS U OPINIONES DIFERENTES EN LA EDUCACIÓN SUPERIOR?}

El respeto es importante per se. A todos nos gusta que se nos respete y se nos trate bien, con independencia de nuestro origen, apariencia, condiciones, opciones u opiniones. Como plantea el libro del PNUD, "la igualdad en dignidad se concreta en gran medida en la igualdad del trato" $(2017,199)$, por lo que vivir en un ambiente de poco respeto puede afectar fuertemente la calidad de vida. De hecho, nuestra encuesta muestra que los estudiantes que perciben un bajo nivel de respeto (menor a 4 en escala de 1 a 7) están alrededor de un punto menos satisfechos con su vida (en una escala de 1 a 10) que aquellos que perciben 
un alto nivel de respeto (de más de 6). Pero cuando hablamos de un ambiente educativo, el respeto es todavía más importante, puesto que su ausencia dificulta la sana interacción con los profesores y entre estudiantes, dificultando a su vez el aprendizaje.

En este capítulo analizamos la percepción de respeto de los encuestados, distinguiendo por tipo de instituciones y por tipo de estudiantes, intentando capturar la diversidad de personas y opiniones que existe en la educación superior. Luego, analizamos cómo varía el nivel de respeto percibido según si se es mayoría o minoría en términos de algunas características relevantes. Los análisis se basan en la pregunta: "En general, ¿qué tanto respeto hay en el ambiente de tu institución hacia las personas o las opiniones diferentes?", la que se contestó en una escala de 1 a 7 .

\subsection{Respeto por tipo de institución}

La tabla 19 muestra que el promedio general en la percepción de respeto es 5,5, una nota razonable, muy por sobre el nivel de suficiencia. Menos de un 8 por ciento de los encuestados manifiesta una nota roja en el nivel de respeto. En cuanto a las diferencias por tipo de institución, el nivel de respeto es mayor en las instituciones técnicas y algo menor en las universidades privadas del Cruch.

Tabla 19. PERCEPCIÓN DE RESPETO POR TIPO DE INSTITUCIÓN (ESCALA DE 1 A 7)

\begin{tabular}{lc}
\hline & Respeto \\
\hline CFT & 5,72 \\
IP & 5,74 \\
U. estatales & 5,46 \\
U. privadas & 5,42 \\
U. privadas Cruch & 5,25 \\
\hline Total & 5,47 \\
\hline
\end{tabular}

7.2. Respeto y sexo

Como muestra la tabla 20, las mujeres perciben un nivel de respeto prácticamente igual al percibido por los hombres. La brecha de género en percepción de respeto es algo mayor en los CFT y en las universidades privadas del Cruch, pero todavía se encuentra por debajo de una décima. 
Tabla 20. RESPETO POR SEXO Y TIPO DE INSTITUCIÓN (ESCALA DE 1 A 7)

\begin{tabular}{lccc}
\hline & Hombre & Mujer & Diferencia \\
\hline CFT & 5,77 & 5,68 & 0,09 \\
IP & 5,73 & 5,74 & $-0,01$ \\
U. estatales & 5,45 & 5,47 & $-0,02$ \\
U. privadas & 5,43 & 5,42 & 0,01 \\
U. privadas Cruch & 5,28 & 5,21 & 0,07 \\
\hline Total & 5,48 & 5,46 & 0,02 \\
\hline
\end{tabular}

Si observamos las brechas de género en respeto según el área de conocimiento de la carrera cursada (tabla 21), encontramos mayores diferencias. Primero, cabe notar que la percepción de respeto, en el total, es considerablemente más baja en derecho y algo menor en ciencias sociales. En cuanto a las brechas, encontramos más de una décima a favor de los hombres en humanidades y en agropecuaria, y una a favor de las mujeres en ciencias sociales y en educación. El análisis que sigue sugiere que parte de estas brechas probablemente se deban a una diferencia en la composición de género de estas áreas de estudio.

Tabla 21. RESPETO POR ÁREA DE CONOCIMIENTO Y SEXO (ESCALA DE 1 A 7)

\begin{tabular}{lrccc}
\hline & Total & Hombre & Mujer & Diferencia \\
\hline Administración y comercio & 5,58 & 5,59 & 5,57 & 0,02 \\
Agropecuaria & 5,37 & 5,46 & 5,31 & 0,15 \\
Arte y arquitectura & 5,43 & 5,44 & 5,42 & 0,02 \\
Ciencias básicas & 5,3 & 5,27 & 5,32 & $-0,05$ \\
Ciencias sociales & 5,2 & 5,11 & 5,24 & $-0,13$ \\
Derecho & 4,96 & 5,02 & 4,91 & 0,11 \\
Educación & 5,6 & 5,5 & 5,64 & $-0,14$ \\
Humanidades & 5,65 & 5,97 & 5,48 & 0,49 \\
Salud & 5,45 & 5,42 & 5,46 & $-0,04$ \\
Tecnología & 5,58 & 5,58 & 5,57 & 0,01 \\
\hline Total & 5,47 & 5,48 & 5,46 & 0,02 \\
\hline
\end{tabular}

Para evaluar la relación entre percepción de respeto y la composición de género, nos enfocamos en las combinaciones de área de conocimiento-institución, considerando sólo aquéllas para las que tenemos 
al menos diez observaciones. ${ }^{24}$ El porcentaje de mujeres en la combinación área-institución se correlaciona positivamente con el nivel de respeto que perciben las mujeres (4,6 por ciento) y negativamente con el percibido por los hombres (-5 por ciento), lo que sugiere que mientras un estudiante tenga más compañeros de su mismo género, siente un mayor nivel de respeto.

Figura 20. RESPETO Y COMPOSICIÓN DE GÉNERO (ESCALA DE 1 A 7)

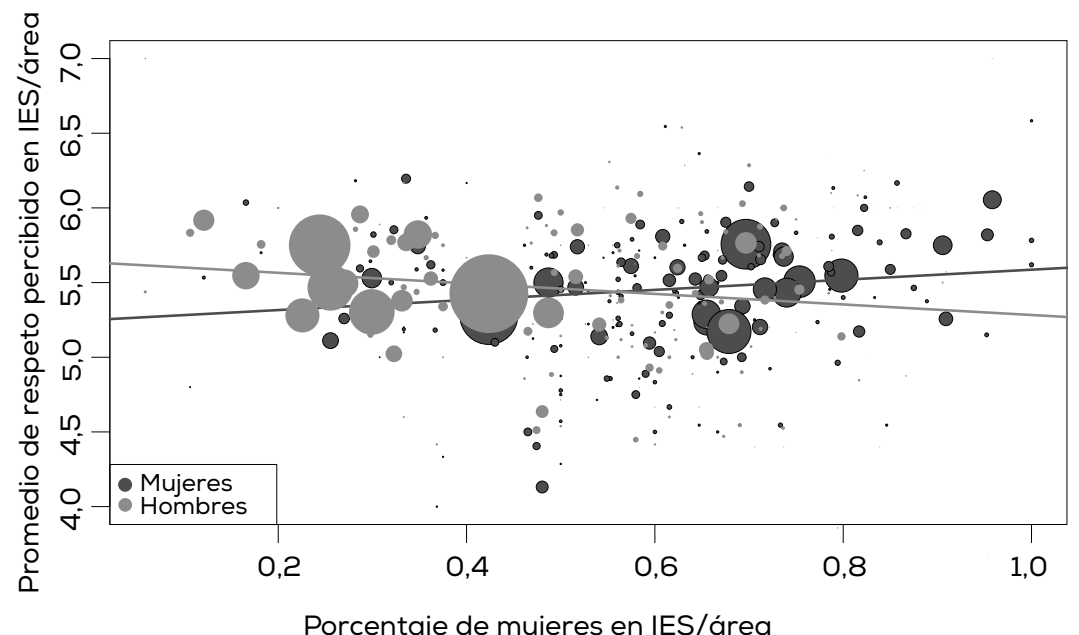

Nota: Las curvas de tendencia ponderan por número de observaciones

Este mismo resultado se presenta en la figura 20. El eje horizontal muestra el porcentaje de mujeres en la combinación área-institución y el eje vertical, el nivel de respeto promedio en la combinación. Los resultados se presentan separadamente para mujeres (gris oscuro) y hombres (gris claro), y el tamaño de cada punto refleja la cantidad de estudiantes a los que el punto representa. Las líneas representan, para cada caso, el ajuste de una regresión lineal, a nivel de combinación, entre respeto promedio y porcentaje de mujeres, ponderada por la cantidad de observaciones incluidas en cada combinación. Tal como mostraban las correlaciones, a medida que el porcentaje de mujeres aumenta, las mujeres perciben mayor respeto y los hombres, lo contrario. Es interesante

${ }^{24}$ Esto reduce la muestra a un total de 13.562 observaciones, correspondientes a 185 combinaciones área-institución, distribuidas en 45 instituciones. 
que la intersección de estas dos curvas se encuentra más allá del 50 por ciento de mujeres, lo que implica que para que las mujeres perciban el mismo nivel de respeto que los hombres, se requiere que sean más de la mitad.

\subsection{Respeto y dificultades académicas}

Los estudiantes que tienen dificultades académicas perciben un menor nivel de respeto, y en una magnitud importante: 4,4 décimas menos. Esta brecha es especialmente grande en las universidades privadas del Cruch y en los CFT, y es insignificante en los IP (tabla 22). Por su parte, en todas las áreas de estudios el respeto que perciben los estudiantes con dificultades académicas es menor. La brecha es especialmente grande en educación y es menor en ciencias sociales y en administración y comercio (no mostrado).

Tabla 22. RESPETO POR PERCEPCIÓN DE DIFICULTADES ACADÉMICAS Y TIPO DE INSTITUCIÓN (ESCALA DE 1 A 7)

\begin{tabular}{lcccc}
\hline & Ninguna & Algunas & Muchas & Dif. Ninguna-Muchas \\
\hline CFT & 5,72 & 5,75 & 5,19 & 0,53 \\
IP & 5,78 & 5,72 & 5,71 & 0,07 \\
U. estatales & 5,52 & 5,45 & 5,28 & 0,24 \\
U. privadas & 5,51 & 5,41 & 5,14 & 0,38 \\
U. privadas Cruch & 5,36 & 5,26 & 4,69 & 0,67 \\
\hline Total & 5,55 & 5,46 & 5,12 & 0,44 \\
\hline
\end{tabular}

Ahora, ¿cómo varía el nivel de respeto percibido según la cantidad de compañeros con dificultades académicas? Primero, es interesante notar que el nivel de respeto percibido promedio cae a mayor proporción de estudiantes con muchas dificultades (correlación: -5 por ciento). Como era de esperar, esta correlación es más fuerte para los estudiantes con muchas dificultades ( -9 por ciento) y similar para aquellos con ninguna o alguna dificultad académica $(-4,2$ y $-3,7$ por ciento, respectivamente). Como muestra la figura 21, a diferencia del caso del género, donde los estudiantes percibían menor respeto cuando su género era minoría, todos los grupos según nivel de dificultades académicas perciben menor respeto a medida que aumenta el porcentaje de estudiantes con 
muchas dificultades. De esta forma, un ambiente académico donde una proporción importante enfrenta muchas dificultades académicas resulta perjudicial para todos en términos del respeto percibido, incluso para aquellos que no enfrentan dificultades.

Figura 21. RESPETO Y COMPOSICIÓN SEGÚN DIFICULTADES ACADÉMICAS (ESCALA DE 1 A 7)

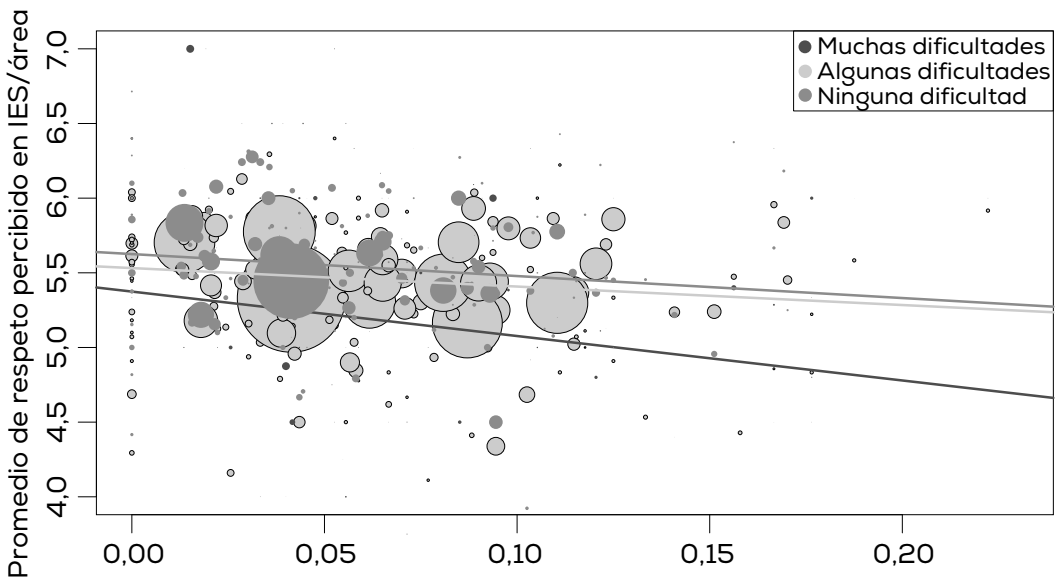

Porcentaje con muchas dificultades académicas en IES/área Nota: Las curvas de tendencia ponderan por número de observaciones

\subsection{Respeto y dependencia escolar}

Ahora, analizamos la relación entre respeto y dependencia escolar, la que, como sabemos, está bastante correlacionada con el nivel socioeconómico. Por una parte, es posible que estudiantes provenientes de distintos niveles socioeconómicos sean tratados de formas diferentes. Por otra, es posible que en sus hogares ellos experimenten niveles de respeto distintos y que, como la percepción de respeto es posiblemente relativa, evalúen de forma distinta ambientes que son en realidad similares. De cualquier forma, la tabla 23 muestra que en todos los tipos de instituciones el respeto percibido por los estudiantes egresados de establecimientos municipales es mayor al percibido por los egresados de establecimientos particulares pagados, mientras que los egresados de establecimientos particulares subvencionados se encuentran en un nivel 
similar al de los de municipales. ${ }^{25}$ Esta brecha a favor de los estudiantes de establecimientos municipales es especialmente relevante en las universidades estatales y en los IP, y es casi inexistente en las universidades privadas del Cruch.

Tabla 23. RESPETO PERCIBIDO POR DEPENDENCIA ESCOLAR Y TIPO DE INSTITUCIÓN (ESCALA DE 1A 7)

\begin{tabular}{lcccc}
\hline & Municipal & P. subvencionado & P. pagado & Dif. Muni-P. pagado \\
\hline CFT & 5,69 & 5,78 & 5,42 & 0,27 \\
IP & 5,79 & 5,74 & 5,40 & 0,39 \\
U. estatales & 5,50 & 5,54 & 5,09 & 0,41 \\
U. privadas & 5,55 & 5,47 & 5,30 & 0,25 \\
U. privadas Cruch & 5,25 & 5,27 & 5,22 & 0,03 \\
\hline Total & 5,57 & 5,52 & 5,28 & 0,29 \\
\hline
\end{tabular}

¿Cuál es la relación entre la composición de estudiantes según dependencia socioeconómica y la percepción de respeto? En lo global, el nivel de respeto está correlacionado positivamente con la proporción de estudiantes de establecimientos municipales (10,6 por ciento) y negativamente con la de egresados de establecimientos particulares pagados (-9,6 por ciento). Pero estas correlaciones se deben principalmente a las percepciones de respeto de los estudiantes provenientes de establecimientos municipales y particulares subvencionados, quienes perciben más respeto a medida que hay más estudiantes de establecimientos municipales (correlaciones de 10 por ciento y 8 por ciento, respectivamente) y menor respeto cuando hay más estudiantes de establecimientos particulares pagados (correlaciones de -9 por ciento y -7 por ciento, respectivamente). En tanto, los estudiantes de establecimientos particulares pagados apenas varían su percepción de respeto en función de la composición de su ambiente por dependencia escolar, con una correla-

${ }^{25}$ Resultados similares se obtienen al realizar este análisis para la variable del nivel de educación de los padres, otro proxy de nivel socioeconómico: el nivel de respeto percibido es siempre menor para los estudiantes con algún padre con educación universitaria completa que para los con padres con educación media incompleta. En cuanto a área de conocimiento, la mayor brecha se observa en derecho, y se ve una diferencia a favor de los estudiantes de establecimientos particulares pagados en arte y arquitectura, ciencias básicas y ciencias sociales (no mostrado). 
ción de 3 por ciento con la proporción de estudiantes de establecimientos municipales y de -2 por ciento con la de estudiantes de particulares pagados. Estos resultados se grafican en la figura 22.

Figura 22. RESPETO Y COMPOSICIÓN SEGÚN DEPENDENCIA ESCOLAR (ESCALA DE 1A7)

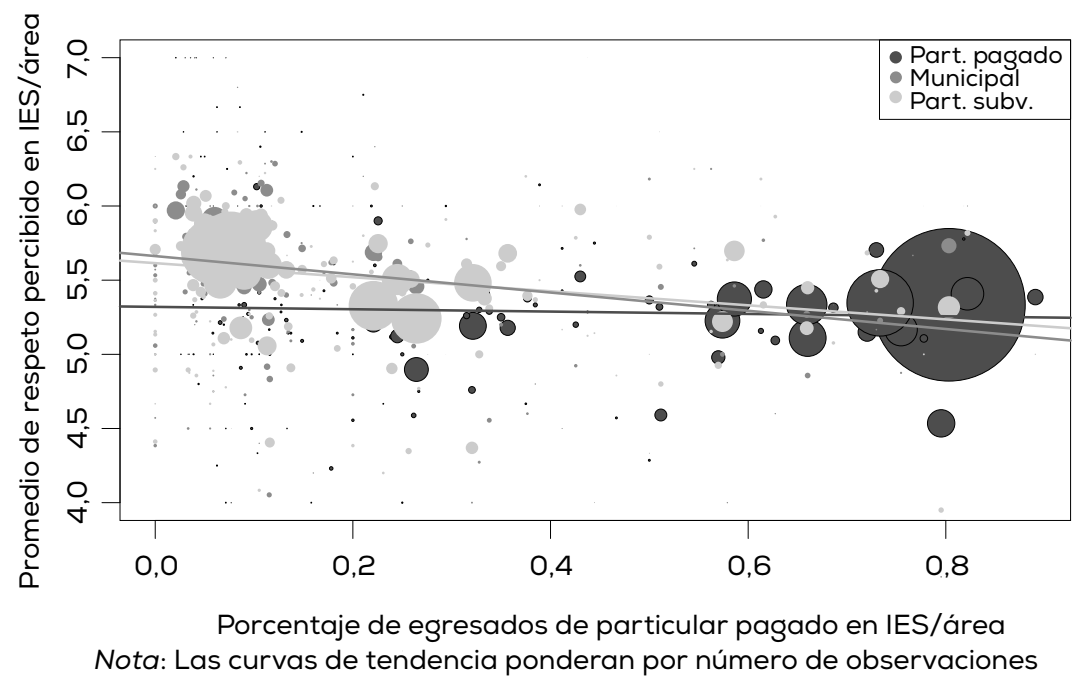

Así, el respeto en el ambiente pareciera verse mermado cuando la composición incluye muchos estudiantes de establecimientos particulares pagados, especialmente para los estudiantes que no provienen de esos establecimientos. Este resultado, por cierto, puede deberse a otros factores correlacionados con la composición por dependencia, ya que sabemos que, por ejemplo, las instituciones con más años de acreditación concentran a más estudiantes de establecimientos particulares pagados, y poseen, además, un conjunto de características distintas. Estos resultados sugieren un desafío para la integración social en nuestras instituciones de educación superior.

\subsection{Respeto e identificación política}

Analicemos, ahora, la relación entre respeto e identificación política. En general, los estudiantes que se identifican con la izquierda perciben menor respeto que los que se identifican con la derecha (dife- 
rencia de 2,7 décimas). Quienes no se identifican con ninguna posición política son los que perciben el mayor nivel de respeto, lo que sugiere, nuevamente, que la politización se asocia a una menor percepción de respeto.

Como muestra la tabla 24, la mayor brecha de respeto, a favor de la derecha, se observa en las universidades privadas del Cruch, mientras que en las universidades estatales se observa una brecha a favor de la izquierda. En cuanto al área de conocimiento, las mayores brechas a favor de la derecha se presentan en educación, mientras que las menores están en arte y arquitectura y en administración y comercio (no mostrado).

Tabla 24. RESPETO POR POSICIÓN POLÍTICA Y TIPO DE INSTITUCIÓN (ESCALA DE 1 A 7)

\begin{tabular}{lcccccccc}
\hline & Izq. & $\begin{array}{c}\text { Cen. } \\
\text { izq. }\end{array}$ & $\begin{array}{c}\text { Cen- } \\
\text { tro }\end{array}$ & $\begin{array}{c}\text { Cen. } \\
\text { der. }\end{array}$ & Der. & Indep. & $\begin{array}{c}\text { Nin- } \\
\text { guna }\end{array}$ & $\begin{array}{c}\text { Dif. Izq- } \\
\text { Der. }\end{array}$ \\
\hline CFT & 5,44 & 5,87 & 5,36 & 5,96 & 5,78 & 5,83 & 5,70 & $-0,34$ \\
IP & 5,84 & 5,68 & 5,59 & 5,71 & 5,79 & 5,62 & 5,77 & 0,05 \\
U. estatales & 5,35 & 5,41 & 5,21 & 5,29 & 5,11 & 5,58 & 5,60 & 0,24 \\
U. privadas & 5,20 & 5,29 & 5,36 & 5,46 & 5,53 & 5,30 & 5,50 & $-0,33$ \\
U. privadas & 5,04 & 5,21 & 5,17 & 5,35 & 5,41 & 5,24 & 5,27 & $-0,37$ \\
Cruch & & & & & & & & \\
\hline Total & 5,27 & 5,35 & 5,33 & 5,47 & 5,54 & 5,42 & 5,56 & $-0,27$ \\
\hline
\end{tabular}

La tabla 25 muestra las correlaciones entre el porcentaje de estudiantes con identificación de extremos —izquierda; izquierda y centro izquierda; derecha y centro derecha; y derecha (en el eje vertical) - y el respeto percibido promedio para los estudiantes que se identifican con cada posición (en el eje horizontal). Como se observa, el nivel de respeto promedio de todos los estudiantes cae al aumentar la proporción de cualquiera de estos grupos, pero especialmente de la izquierda y centro izquierda. En tanto, los estudiantes de izquierda o centro izquierda perciben considerablemente menos respeto cuando aumenta el porcentaje de derecha o centro derecha, y lo contrario es cierto para los estudiantes de derecha. En otras palabras, el respeto percibido cae cuando en el propio ambiente hay más personas de la posición política contraria. A 
su vez, los estudiantes de centro perciben menos respeto cuando en el ambiente prima la izquierda, pero los independientes sienten menor respeto cuando prima la derecha.

Tabla 25. CORRELACIONES ENTRE PORCENTAJE DE ESTUDIANTES CON IDENTIFICACIÓN DE EXTREMOS Y EL RESPETO PERCIBIDO POR ESTUDIANTES QUE SE IDENTIFICAN CON CADA POSICIÓN (PORCENTAJE)

\begin{tabular}{lcccccccc}
\hline & Total & Izq. & $\begin{array}{l}\text { Cen. } \\
\text { izq. }\end{array}$ & Centro & $\begin{array}{l}\text { Cen. } \\
\text { der. }\end{array}$ & Der. & Indep. & Ninguna \\
\hline \% Izq. y & $-7,6$ & $-2,5$ & $-3,1$ & $-9,0$ & $-10,4$ & $-6,0$ & $-2,4$ & $-7,0$ \\
Cen. izq. & & & & & & & & \\
\% Izq. & $-5,9$ & $-2,2$ & $-2,7$ & $-7,0$ & $-10,2$ & $-5,9$ & 0,3 & $-4,4$ \\
\% Der. y & $-5,7$ & $-13,1$ & $-10,3$ & $-2,7$ & $-2,6$ & $-3,7$ & $-11,2$ & $-6,3$ \\
Cen. der. & & & & & & & & \\
\% Der. & $-2,6$ & $-8,8$ & $-6,5$ & $-1,0$ & $-0,2$ & $-3,0$ & $-7,6$ & $-3,0$ \\
\hline
\end{tabular}

La figura 23 muestra gráficamente estos resultados en relación con el porcentaje de estudiantes que se identifican con la derecha o centro derecha (panel superior) y a los que se identifican con la izquierda o centro izquierda (panel inferior). En ambos casos se observa que los grupos políticos no varían mucho su percepción de respeto en función de cuántos piensan como ellos, pero su percepción de respeto sí cae a medida que aumenta la proporción de estudiantes con la posición contraria. Los de centro, independientes o que no se identifican con ninguna posición, en tanto, perciben menos respeto a medida que cualquiera de los extremos se torna muy preponderante. Esto sugiere que los grupos más de centro o menos politizados perciben menor respeto cuando se encuentran en un ambiente más politizado.

\subsection{Análisis multivariado para respeto}

Hasta ahora, nos hemos enfocado en la relación entre respeto y género, dificultades académicas, dependencia escolar e identificación política, pero siempre de a una variable a la vez. Ahora, mediante el uso de regresiones, evaluaremos estas relaciones, pero controlando por varias variables a la vez. Por supuesto, estas regresiones no buscan establecer 
Figura 23. RESPETO Y COMPOSICIÓN SEGÚN IDENTIFICACIÓN POLÍTICA (ESCALA DE 1A 7)

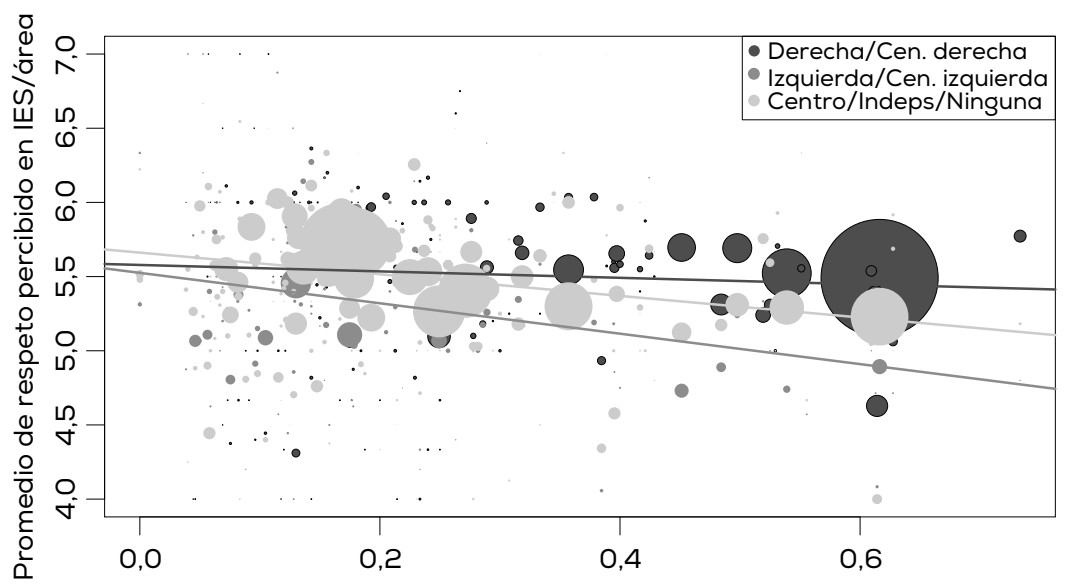

Porcentaje que se identifica con derecha o centro derecha en IES/área Nota: Las curvas de tendencia ponderan por número de observaciones

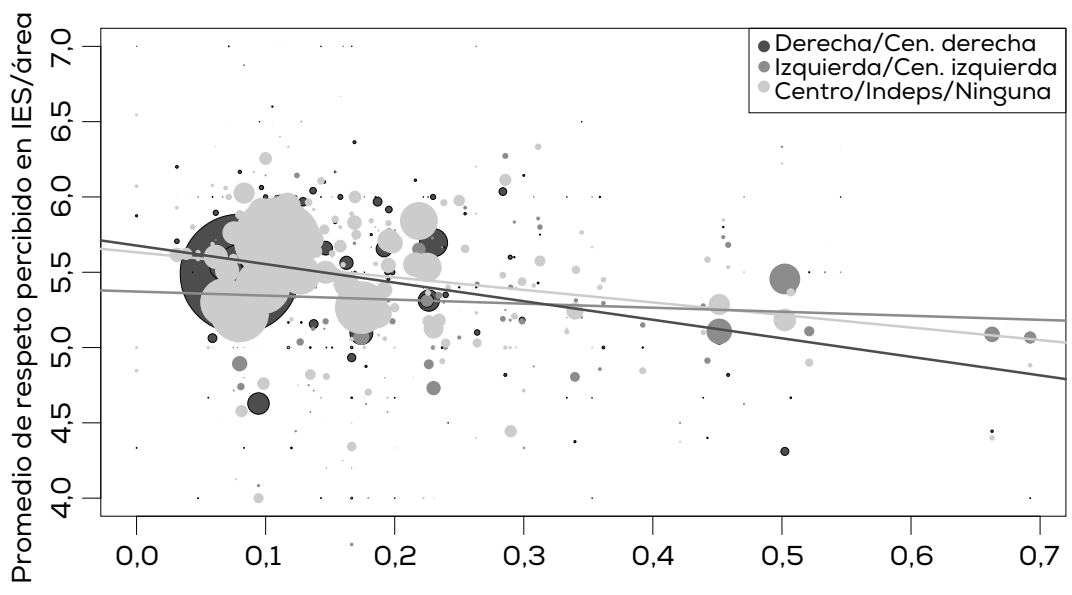

Porcentaje que se identifica con izquierda o centro izquierda en IES/área Nota: Las curvas de tendencia ponderan por número de observaciones

relaciones de causalidad, ya que presentan muchas fuentes de endogeneidad; lo que se busca es describir el mejor ajuste de los datos, con el fin de mostrar las asociaciones empíricas que éstos presentan.

La tabla 26 muestra el resultado de regresiones para el respeto percibido, sin considerar las variables de composición del ambiente acadé- 
mico en que cada estudiante se desenvuelve. Ambas columnas incluyen efectos fijos de área de conocimiento. La primera columna incluye variables relativas a la institución (tipo de institución, años de acreditación), y la segunda no lo hace, ya que incluye efectos fijos de institución. Las variables incluidas son sexo, edad, dificultades académicas (la base es "sin dificultades académicas"), tipo de institución (la base es CFT), años de acreditación, dependencia escolar (la base es municipal), máximo nivel de educación alcanzado por el padre o la madre (la base es media incompleta), identificación con la derecha o centro derecha e identificación con la izquierda o centro izquierda. Los errores estándar son robustos.

Los resultados muestran que no hay una diferencia significativa en respeto por sexo. Las dificultades académicas están asociadas a una caída importante en la percepción de respeto. Las universidades privadas $y$, en particular, las privadas del Cruch presentan menores niveles de respeto. Los estudiantes provenientes de establecimientos particulares pagados experimentan un menor nivel de respeto, a la vez que el respeto es decreciente en la educación de los padres. Finalmente, la identificación con la derecha se asocia a un mayor nivel de respeto percibido, mientras que lo contrario sucede con la identificación con la izquierda.

A continuación, incorporamos al análisis las variables de composición del ambiente académico del estudiante (combinación área-institución). Para ello, sólo se incluyen observaciones para las que hay más de diez individuos en la combinación. Aunque no todos se muestran, las regresiones incluyen todos los controles usados en las regresiones anteriores.

Los resultados que incorporan la composición por sexo (columnas 1 y 5, tabla 27) muestran que ser mujer se asocia a una percepción de respeto significativamente menor, y que el nivel de respeto aumenta considerablemente cuando la proporción de mujeres en el ambiente académico aumenta. Respecto de las dificultades académicas (columnas 2 y 5), se mantiene que éstas se asocian a una menor percepción de respeto y se observa que esto es así sobre todo en ambientes con proporciones relativamente altas de estudiantes con muchas dificul- 
tades. Las regresiones muestran que los estudiantes que provienen de establecimientos particulares pagados perciben significativamente menos respeto (columnas 3 y 5), aunque ahora la percepción de respeto no varía significativamente de acuerdo a la proporción de estudiantes de establecimientos particulares pagados. Finalmente, las columnas que consideran la composición del ambiente de acuerdo a posición política (columnas 4 y 5) no muestran diferencias en el nivel de respeto según identificación con la derecha o la izquierda, pero sí muestran que la composición importa: los estudiantes de derecha sienten considerablemente mayor respeto cuando la proporción de estudiantes de derecha aumenta y, de manera aún más fuerte, los estudiantes de izquierda perciben menor respeto cuando están en un ambiente de derecha.

Tabla 26. REGRESIÓN PARA RESPETO PERCIBIDO

\begin{tabular}{lcc}
\hline & \multicolumn{2}{c}{ Variable dependiente } \\
& $(1)$ & $(2)$ \\
\hline Mujer & 0,004 & $-0,006$ \\
& $(0,024)$ & $(0,023)$ \\
\hline Edad & $0,012^{* * *}$ & $0,010^{* * *}$ \\
\hline Algunas dificultades académicas & $(0,002)$ & $(0,002)$ \\
\hline Muchas dificultades académicas & $-0,099^{* * *}$ & $-0,090^{* * *}$ \\
\hline IP & $(0,023)$ & $(0,023)$ \\
\hline U. estatal & $-0,418^{* * *}$ & $-0,404{ }^{* * *}$ \\
& $(0,055)$ & $(0,054)$ \\
\hline U. privada & 0,028 & \\
\hline U. privada Cruch & $(0,045)$ & \\
\hline Años acreditación & $-0,069$ & \\
\hline & $(0,051)$ & \\
\hline & $-0,112^{* * *}$ & \\
\hline
\end{tabular}




\begin{tabular}{|c|c|c|}
\hline \multirow[t]{2}{*}{ Part. subvencionado } & 0,025 & 0,025 \\
\hline & $(0,027)$ & $(0,027)$ \\
\hline \multirow[t]{2}{*}{ Part. pagado } & $-0,089 * *$ & $-0,108$ *** \\
\hline & $(0,037)$ & $(0,038)$ \\
\hline \multirow[t]{2}{*}{ Educ. padres media } & $-0,078^{* *}$ & $-0,068^{* *}$ \\
\hline & $(0,033)$ & $(0,033)$ \\
\hline \multirow[t]{2}{*}{ Educ. padres técnica } & $-0,116^{* * *}$ & $-0,114^{* * *}$ \\
\hline & $(0,042)$ & $(0,042)$ \\
\hline \multirow[t]{2}{*}{ Educ. padres universitaria } & $-0,200^{* * *}$ & $-0,193^{* * *}$ \\
\hline & $(0,039)$ & $(0,039)$ \\
\hline \multirow[t]{2}{*}{ Derecha o centro derecha } & $0,105^{\text {*** }}$ & $0,114^{* * *}$ \\
\hline & $(0,038)$ & $(0,038)$ \\
\hline \multirow[t]{2}{*}{ Izquierda o centro izquierda } & $-0,147^{* * *}$ & $-0,156$ *** \\
\hline & $(0,042)$ & $(0,042)$ \\
\hline \multirow[t]{2}{*}{ Constante } & $5,574^{* * *}$ & $3249^{* * *}$ \\
\hline & $(0,084)$ & $(0,083)$ \\
\hline Efecto fijo por IES & No & Si \\
\hline Efecto fijo por área de conocimiento & Si & Si \\
\hline $\mathrm{N}$ & 14.128 & 14.128 \\
\hline $\mathrm{R} 2$ & 0,043 & 0,055 \\
\hline R2 ajustado & 0,041 & 0,05 \\
\hline Error estd. residuos & $\begin{array}{r}1.281(\mathrm{df}= \\
14102)\end{array}$ & $\begin{array}{r}1.275(\mathrm{df}= \\
14059)\end{array}$ \\
\hline $\mathrm{F}$ & $\begin{array}{r}25.063^{* * *}(\mathrm{df}= \\
25 ; 14102)\end{array}$ & $\begin{array}{r}11.985^{\star * *}(\mathrm{df}= \\
68 ; 14059)\end{array}$ \\
\hline
\end{tabular}

Nota: ${ }^{*} p<0,1 ;{ }^{* *} p<0,05 ;{ }^{* *} p<0,01$. Errores robustos.

\subsection{Conclusión sobre nivel de respeto}

En términos generales, los estudiantes perciben un nivel relativamente alto de respeto en su ambiente académico (promedio de 5,5). El respeto percibido, a nivel global, es menor entre las mujeres, aunque esto sólo se observa al controlar por otras variables observables, como muestran las últimas especificaciones del análisis multilineal. El respeto también cae considerablemente con el nivel de dificultades percibidas y es menor entre los egresados de establecimientos particulares pagados. 
Tabla 27. REGRESIÓN PARA RESPETO PERCIBIDO Y COMPOSICIÓN

\begin{tabular}{|c|c|c|c|c|c|}
\hline & \multicolumn{5}{|c|}{$\begin{array}{c}\text { Variable dependiente } \\
\text { Respeto }\end{array}$} \\
\hline & (1) & (2) & (3) & (4) & (5) \\
\hline \multirow[t]{2}{*}{ Mujer } & $-0,135^{\star}$ & $-0,003$ & $-0,006$ & $-0,005$ & $-0,136^{*}$ \\
\hline & $(0,072)$ & $(0,024)$ & $(0,024)$ & $(0,024)$ & $(0,072)$ \\
\hline \multirow[t]{2}{*}{ Mujeres \% } & 0,244 & & & & 0,255 \\
\hline & $(0,169)$ & & & & $(0,179)$ \\
\hline \multirow[t]{2}{*}{$\begin{array}{l}\text { Algunas dificultades } \\
\text { académicas }\end{array}$} & $-0,092^{* * *}$ & $-0,096^{* *}$ & $-0,092^{* * *}$ & $-0,094^{* * *}$ & $-0,099^{* *}$ \\
\hline & $(0,024)$ & $(0,042)$ & $(0,024)$ & $(0,024)$ & $(0,042)$ \\
\hline \multirow[t]{2}{*}{$\begin{array}{l}\text { Muchas dificultades } \\
\text { académicas }\end{array}$} & $-0,401^{* * *}$ & $-0,174$ & $-0,400^{* * *}$ & $-0,397^{* * *}$ & $-0,185$ \\
\hline & $(0,055)$ & $(0,117)$ & $(0,055)$ & $(0,055)$ & $(0,116)$ \\
\hline \multirow[t]{2}{*}{$\begin{array}{l}\text { Muchas dificultades } \\
\text { académicas \% }\end{array}$} & & 0,326 & & & 0,355 \\
\hline & & $(0,631)$ & & & $(0,640)$ \\
\hline \multirow[t]{2}{*}{ Part. subvencionado } & 0,032 & 0,033 & 0,019 & 0,032 & 0,018 \\
\hline & $(0,028)$ & $(0,028)$ & $(0,037)$ & $(0,028)$ & $(0,037)$ \\
\hline \multirow[t]{2}{*}{ Part. pagado } & $-0,095^{\star *}$ & $-0,096^{\star *}$ & $-0,149^{* *}$ & $-0,101^{\star \star *}$ & $-0,150^{* *}$ \\
\hline & $(0,039)$ & $(0,039)$ & $(0,063)$ & $(0,039)$ & $(0,063)$ \\
\hline \multirow[t]{2}{*}{ Part. pagado \% } & & & $-0,244$ & & $-0,072$ \\
\hline & & & $(0,226)$ & & $(0,238)$ \\
\hline \multirow[t]{2}{*}{ Derecha } & $0,131^{* * *}$ & $0,130^{* \star *}$ & $0,129^{* * *}$ & $-0,016$ & $-0,017$ \\
\hline & $(0,038)$ & $(0,038)$ & $(0,038)$ & $(0,121)$ & $(0,121)$ \\
\hline \multirow[t]{2}{*}{ Izquierda } & $-0,151^{* * *}$ & $-0,154^{* * *}$ & $-0,152^{* * *}$ & $-0,025$ & $-0,024$ \\
\hline & $(0,043)$ & $(0,043)$ & $(0,043)$ & $(0,131)$ & $(0,131)$ \\
\hline \multirow[t]{2}{*}{ Derecha \% } & & & & $-0,429^{*}$ & $-0,234$ \\
\hline & & & & $(0,245)$ & $(0,262)$ \\
\hline \multirow[t]{2}{*}{ Izquierda \% } & & & & 0,236 & 0,362 \\
\hline & & & & $(0,250)$ & $(0,255)$ \\
\hline \multirow[t]{2}{*}{ Mujer* \% Mujeres } & $0,227^{*}$ & & & & $0,232^{*}$ \\
\hline & $(0,129)$ & & & & $(0,129)$ \\
\hline \multirow{2}{*}{$\begin{array}{l}\text { Algunas dif. acad. * \% } \\
\text { Muchas dif. acad. }\end{array}$} & & 0,044 & & & 0,050 \\
\hline & & $(0,631)$ & & & $(0,629)$ \\
\hline \multirow{2}{*}{$\begin{array}{l}\text { Muchas dif. acad. *\% } \\
\text { Muchas dif. acad. }\end{array}$} & & $-2,688^{* *}$ & & & $-2,571^{\star *}$ \\
\hline & & $(1,280)$ & & & $(1,277)$ \\
\hline
\end{tabular}




\begin{tabular}{|c|c|c|c|c|c|}
\hline Part.Subv. \% Part. pag. & & \multicolumn{3}{|c|}{0,090} & \multirow{2}{*}{$\begin{array}{l}0,069 \\
(0,151)\end{array}$} \\
\hline & & & & & \\
\hline \multirow[t]{2}{*}{ Part.Pag. * \% Part. pag. } & & & 0,180 & & 0,157 \\
\hline & & & $(0,159)$ & & $(0,160)$ \\
\hline \multirow[t]{2}{*}{ Derecha* \% Derecha } & & & & $0,388^{*}$ & $0,403^{*}$ \\
\hline & & & & $(0,223)$ & $(0,224)$ \\
\hline \multirow[t]{2}{*}{ Derecha* \% Izquierda } & & & & 0,078 & 0,054 \\
\hline & & & & $(0,510)$ & $(0,511)$ \\
\hline \multirow[t]{2}{*}{ Izquierda* \% Derecha } & & & & $-1,127^{\star \star *}$ & $-1,126^{\star \star *}$ \\
\hline & & & & $(0,382)$ & $(0,382)$ \\
\hline \multirow[t]{2}{*}{ Izquierda* \% Izquierda } & & & & 0,336 & 0,326 \\
\hline & & & & $(0,298)$ & $(0,299)$ \\
\hline \multirow[t]{2}{*}{ Constante } & $5,693^{* * *}$ & $5,816^{* * *}$ & $5,811^{\star \star \star}$ & $5,858^{* * *}$ & $5,717^{* \star *}$ \\
\hline & $(0,290)$ & $(0,282)$ & $(0,280)$ & $(0,280)$ & $(0,296)$ \\
\hline Controles & $\mathrm{Si}$ & Si & Sí & Sí & Si \\
\hline $\mathrm{N}$ & 13.562 & 13.562 & 13.562 & 13.562 & 13.562 \\
\hline $\mathrm{R} 2$ & 0,0550 & 0,0550 & 0,0540 & 0,0570 & 0,0580 \\
\hline R2 Ajustado & 0,0500 & 0,0500 & 0,0500 & 0,0520 & 0,0530 \\
\hline
\end{tabular}

Nota: ${ }^{*} p<0,1 ;{ }^{* *} p<0,05 ;{ }^{* * *} p<0,01$. Errores robustos.

En cuanto a la composición de estudiantes en la misma institución y área de carrera, encontramos que el respeto percibido por hombres y mujeres aumenta a medida que hay más estudiantes de su mismo sexo en su ambiente académico. Esto sugiere que ser minoría en términos de género se asocia a una percepción de menor respeto. Por su parte, cuando la composición de estudiantes presenta mayores dificultades académicas, el nivel de respeto percibido es menor para todos los estudiantes, incluidos los sin dificultades.

Por último, desde el punto de vista de la posición política, encontramos que, para quienes se identifican con la izquierda o la derecha, la percepción de respeto cae importantemente en función de la proporción de estudiantes con la posición política contraria. En tanto, los de centro, independientes o que no se identifican con ninguna posición perciben menos respeto a medida que cualquiera de los extremos se torna muy preponderante. Esto sugiere que los grupos moderados o bien menos politizados perciben menor respeto cuando se encuentran en un ambiente más politizado. 


\section{CONCLUSIONES GENERALES}

A modo de conclusión, queremos plantear una serie de preguntas para la política pública que surgen a partir de este artículo. En general éstas se enmarcan dentro de dos principales desafíos: el rol de la información en las elecciones y evaluaciones de los estudiantes que deciden terminar una carrera en educación superior y la importancia del nivel socioeconómico en las diferencias en percepción que éstos tienen. Esperamos que este estudio y las preguntas planteadas puedan dar luces sobre cómo enfrentar estos desafíos.

Primero, respecto de cómo los estudiantes escogen su institución y carrera, aprendimos que lo principal son las razones académicas y laborales, y aprendimos también que los estudiantes de menor nivel socioeconómico escogen bajo más restricciones, como horarios, ubicación, puntaje o aranceles. ¿Cómo podemos hacer para ir reduciendo estas restricciones? Es importante notar que varias de estas restricciones no se resuelven automáticamente por la vía de eliminar los aranceles, ya que, por ejemplo, las personas pueden necesitar igualmente trabajar, lo que restringe su horario y ubicación, y también al momento de enfrentarse a la educación superior ya hay déficits académicos que les impiden acceder a sus opciones favoritas. Por otro lado, la información aquí presentada puede ser útil para el diseño de las políticas comunicacionales durante su proceso de admisión, pudiendo enfocarlas a los factores que los estudiantes consideran más importantes.

En cuanto a cómo los estudiantes evalúan su institución, aprendimos que en general pareciera haber un alto grado de satisfacción con la elección de educación superior. ¿Es que los estudiantes son poco exigentes en su forma de evaluar o que se autoconvencen para no arrepentirse? ¿O significa más bien que el sistema es mejor de lo que a veces se cree? Es importante avanzar en un sistema más profundo de evaluación de nuestras instituciones, que nos permita dilucidar estos asuntos.

En una línea similar, en el capítulo de acreditación vimos que no siempre la percepción de los estudiantes mejora con los años de acreditación. Tal es el caso, por ejemplo, de la percepción del nivel académico de los compañeros o de la preparación para entrar al mundo laboral. Aquí, nuevamente nos preguntamos, ¿es que los estudiantes de instituciones de menor acreditación se contentan con poco o es que nuestro 
sistema de acreditación no contempla en la correcta medida los factores que son relevantes para los propios estudiantes? En otras palabras, ¿están equivocados los estudiantes - en cuyo caso debiera entregarse mejor información, para que corrijan su error-o está equivocado, o al menos incompleto, el sistema de acreditación —en cuyo caso debe adaptarse para estar más en línea con lo que es importante para los propios estudiantes-?

Respecto de la principal fuente de financiamiento, vimos que hay un grupo importante de estudiantes que se financia con su propio trabajo, los que suelen ser también de origen más vulnerable y se educan en instituciones con menor acreditación. De ellos, poco se habla en el debate de educación superior. ¿De qué manera nuestro sistema facilita la educación continua? ¿Cómo se puede permitir de mejor manera un tránsito bidireccional fluido entre el mundo del trabajo y el sistema educativo?

En cuanto a dificultades académicas, aprendimos que ellas tienen también una dimensión socioeconómica, pues quienes las sufren suelen ser quienes tuvieron una peor preparación previa, lo que se correlaciona con el nivel socioeconómico. También aprendimos que las dificultades académicas parecen afectar negativamente toda la experiencia en educación superior, e incluso la satisfacción con la vida. Por último, aprendimos que las instituciones de educación superior parecen no entregar los apoyos suficientes a quienes sufren dificultades académicas. ¿Cuáles son las políticas más adecuadas para promover un adecuado apoyo académico a los estudiantes que lo necesitan?

Por último, en el capítulo sobre el respeto en las instituciones, aprendimos que en general el respeto percibido se ve mermado cuando se es minoría (de género, de identificación política). ¿Cómo podemos promover un mejor manejo de la diversidad en nuestras instituciones, para que todos los estudiantes se sientan respetados?

Si bien este trabajo aporta gran cantidad de información al debate sobre educación superior, existen aún otras áreas por explorar. En particular, sería interesante a futuro poder contar con información de estudiantes de primer año para ver cómo cambian preferencias y percepciones a lo largo de su carrera. Asimismo, de contar con información sobre los estudiantes que desertan de la educación superior, podríamos ampliar el análisis de preferencias a un grupo poco estudiado, pero que representa una parte importante del sistema. 


\section{REFERENCIAS}

Agencia de Calidad de la Educación. 2016. "Presentación de la Conferencia de Prensa Simce 2016". http://archivos.agenciaeducacion.cl/Resultados Nacionales2016_.pdf/.

Angrist, Joshua D. \& Jörn-Steffen Pischke. 2009. Mostly Harmless Econometrics. An Empiricist's Companion. Princeton: Princeton University Press.

Comisión Nacional de Acreditación de Chile. 2015. "Misión”. https://www. cnachile.cl/Paginas/ Acreditacion-institucional.aspx.

Intelis, Centro \& Consultora Verde. 2012. "Evaluación de impacto de las becas de educación superior del Mineduc". Dipres, Gobierno de Chile. http://www. dipres.gob.cl/597/articles-141157_informe_final.pdf/.

Ministerio de Desarrollo Social de Chile. 2015. Encuesta Casen 2015.

OECD. 2017. OECD Employment Outlook 2017. París: OECD Publishing. http:// dx.doi.org/10.1787/empl_outlook-2017-en/.

Orellana, Víctor, Carolina Guzmán, Cristián Bellei, Benjamín Gareca \& Francisca Torres. "Elección de carrera y universidad en Chile: sentido y utilidad de la acreditación". Cuadernos de Investigación en Aseguramiento de la Calidad 7, Comisión Nacional de Acreditación. https://www.cnachile.cl/Biblioteca\%20 Documentos\%20de\%20Interes/Cuaderno_Orellana.pdf/.

PNUD. 2017. Desiguales. Orígenes, cambios y desafios de la brecha social en Chile. Santiago: Uqbar.

Solís, Alex. 2012. "Does Higher Education Cause Political Participation?: Evidence From a Regression Discontinuity Design". Working Paper Series 2013:13, Uppsala University, Department of Economics. 


\section{ANEXO}

\subsection{Glosario de cuestionario}

- Acreditación: Según los años de acreditación por institución de la Comisión Nacional de Acreditación para 2016.

- Apoyo institucional frente a dificultades académicas: Para aquellos estudiantes que reportaron tener algunas o muchas dificultades académicas, se les preguntó: “¿Qué tanto apoyo has recibido por parte de tu institución con tus dificultades de rendimiento académico?" en una escala de 1 a 7 .

- Área de conocimiento: Clasificación que entrega el Ministerio de Educación para 2016 para las carreras de educación superior.

- Dependencia escolar: Se separa a los estudiantes según si su establecimiento de educación media era municipal, particular subvencionado (o de administración delegada) o particular pagado.

- Deserción: Deserción al primer año en base a las tasas entregadas por carrera e institución en MiFuturo.cl para 2016.

- Dificultades académicas: A los estudiantes se les preguntó: "¿Cuántas dificultades de rendimiento académico has tenido durante tus estudios?", pudiendo elegir entre: ninguna dificultad, algunas dificultades o muchas dificultades.

- Dificultades económicas: A los estudiantes se les preguntó: “¿Cuántas dificultades económicas has tenido durante tus estudios?", pudiendo elegir entre ninguna dificultad, algunas dificultades o muchas dificultades.

- Edad: Calculada en base al año de nacimiento que reportan los estudiantes.

- Estudios superiores previos: Se les preguntó a los estudiantes si habían realizado estudios superiores previos a los estudios de los cuales está egresando, dando la posibilidad de especificar si estos fueron en la misma carrera, en la misma institución o en otra institución.

- Exigencia académica percibida: Se les preguntó a los estudiantes: “¿Cómo evalúas el nivel de exigencia académica de tu carrera?”, en escala de 1 a 7.

- Factores para elegir institución: Se les preguntó a los estudiantes, en una lista cerrada: “¿Cuáles de los siguientes factores fueron los 
más importantes al momento de elegir tu institución de educación superior?", pudiendo elegir a lo más tres opciones.

- Factores para elegir carrera: Se les preguntó a los estudiantes, en una lista cerrada: “¿Cuáles de los siguientes factores fueron los más importantes al momento de elegir tu carrera?", pudiendo elegir a lo más tres opciones.

- Funcionamiento de la democracia: Se les preguntó a los estudiantes: "¿Qué tan mal o qué tan bien crees que funcionan las siguientes instituciones en Chile?", específicamente la democracia, donde 1 es "muy mal" y 7 es "muy bien".

- Funcionamiento del sistema económico: Se les preguntó a los estudiantes: "¿Qué tan mal o qué tan bien crees que funcionan las siguientes instituciones en Chile?", específicamente el sistema económico, donde 1 es "muy mal" y 7 es "muy bien".

- Hijos: Se les preguntó a los estudiantes si tienen hijos o no.

- Identificación política: Se les preguntó a los estudiantes: "Como sabes, tradicionalmente en nuestro país la gente define las posiciones políticas como más cercanas a la izquierda, al centro o a la derecha. ¿Con cuál posición te identificas o simpatizas más?”.

- Interés en la política: A los estudiantes se les preguntó sobre su interés en la política, pudiendo responder: nada interesado, algo interesado, bastante interesado o muy interesado.

- Matrícula total: En base a la información entregada por carrera e institución por el Ministerio de Educación para 2016.

- MiFuturo.cl: Información recolectada por el Ministerio de Educación sobre ingresos al cuarto año y empleabilidad al primer año para una serie de combinaciones carrera/institución.

- Motivación de los compañeros: Se les preguntó a los estudiantes: "En general, ¿qué tanta motivación hacia el estudio tienen tus compañeros?", en escala de 1 a 7.

- Nivel académico de los compañeros: Se les preguntó a los estudiantes: "En general, ¿qué nivel académico tienen tus compañeros?", en escala de 1 a 7 .

- Nivel educacional de los padres: Se separa a los estudiantes según el máximo nivel educacional alcanzado por el padre o la madre, los cuales pueden ser menos que educación media completa, educación media completa, superior técnica completa o universitaria completa. 
- Nota carrera: Se les pidió a los estudiantes que evaluaran a su carrera en una escala de 1 a 7.

- Nota institucional: Se les pidió a los estudiantes que evaluaran a su institución de educación superior en una escala de 1 a 7.

- Nota profesores: Se les pidió a los estudiantes que evaluaran a los profesores de su institución de educación superior en una escala de 1 a 7.

- Preparación académica previa: Se les preguntó a los estudiantes: “¿Qué tan preparado/a sientes que estabas, académicamente, para estudiar tu carrera en el momento que ingresaste a ella?", en una escala de 1 a 7.

- Preparación para enfrentar el mundo laboral: A los estudiantes se les preguntó: "¿Qué tan preparado te sientes para enfrentar el mundo laboral?", en una escala de 1 a 7.

- Primera generación en educación superior: En base a las respuestas de la variable de nivel educacional de los padres se elaboró este indicador en función de que ni el padre ni la madre tengan más que educación media completa.

- Principal fuente de financiamiento: A los estudiantes se les preguntó por la forma en que habían financiado sus estudios, pudiendo elegir entre beca, crédito, ahorros personales, recursos familiares o trabajando. Para cada una de estas fuentes, se les pidió especificar su importancia en su financiamiento, indicando nada, poco, bastante, mucho o todo. La principal fuente es la que los estudiantes indicaron que es la más importante, en función de esta escala. De haber empate entre dos o más fuentes de financiamiento, la proporción se dividió en partes equivalentes.

- Probabilidad de volver a elegir...: Se les preguntó a los estudiantes: "Si pudieras volver atrás en el tiempo, del 1 al 7, ¿qué tan probable sería que volvieras a elegir...?", dando como opciones estudiar nuevamente una carrera de educación superior, la propia institución o la propia carrera.

- Respeto percibido: Se les preguntó a los estudiantes: "En general, ¿qué tanto respeto hay en el ambiente de tu institución hacia las personas o las opiniones diferentes?", en escala de 1 a 7.

- Satisfacción con la vida: Se les preguntó a los estudiantes: "Considerando todas las cosas, ¿cuán satisfecho estás con tu vida en este momento? En una escala en que 1 significa "estar totalmente insa- 
tisfecho" y 10 significa "totalmente satisfecho", ¿dónde te ubicarías?”. Esta pregunta está contenida también en la encuesta CEP.

- Sexo: Se separa a los estudiantes entre hombres y mujeres.

- Situación laboral: Se les dio a elegir una combinación de las opciones: trabajando tiempo completo, trabajando tiempo parcial, buscando trabajo, tengo experiencia laboral en algo relacionado a mi carrera y he trabajado tiempo completo alguna vez por al menos 6 meses.

- Tipo de institución: Se consideran Centros de Formación Técnica, Institutos Profesionales, Universidades estatales del Consejo de Rectores (Cruch), Universidades privadas y Universidades Privadas dentro del Cruch.

\subsection{Muestra}

\subsubsection{Instituciones participantes}

A continuación se presenta una comparación entre la proporción de instituciones participantes y el universo total de instituciones del país, según diferentes criterios de clasificación. Para ello, se usan datos provenientes de las bases de matrícula del Sistema de Ingreso a la Educación Superior, del Ministerio de Educación, para el año 2016.

\subsubsection{Proporción de instituciones por tipo}

En la tabla 28 se muestra el porcentaje de instituciones según la clasificación por tipo, tanto en la muestra de este estudio (primera columna, "Muestra"), como con respecto del total de instituciones del país (segunda columna, "Total"). Se puede ver que la proporción de centros de formación técnica (CFT) e institutos profesionales (IP) participantes es menor a la proporción total. Esto se debe a que un criterio para contactar a este tipo de instituciones es que estuvieran acreditadas o que tuvieran más de 1.000 estudiantes. Por ello, en la tercera columna se muestran las proporciones respecto del total de las instituciones contactadas ("Total contactado"). Vemos que la proporción de CFT es un poco mayor a la proporción total contactada, y que la muestra de universidades, tanto privadas como del Consejo de Rectores, es representativa a nivel país. 
Tabla 28. PROPORCIÓN DE INSTITUCIONES POR TIPO (PORCENTAJE)

\begin{tabular}{lccc}
\hline & Muestra & Total & Total contactado \\
\hline Centros de formación técnica & 24,5 & 32,7 & 19,4 \\
Institutos profesionales & 18,4 & 28,0 & 23,3 \\
Universidades estatales Cruch & 12,2 & 10,7 & 15,5 \\
Universidades privadas & 32,7 & 22,7 & 33,0 \\
Universidades privadas Cruch & 12,2 & 6,0 & 8,7 \\
\hline
\end{tabular}

\subsubsection{Proporción de instituciones por tramo de matrícula}

En la tabla 29 se observa que la muestra no contiene instituciones de menos de 100 estudiantes matriculados, y sólo muy pocas con menos de 1.000 estudiantes matriculados. Sin embargo, la proporción de instituciones con matrícula media y alta es mayor que la muestra total. Nuevamente, si ajustamos según los CFT e IP contactados, tal como se muestra en la tercera columna, la proporción de instituciones de la muestra se acerca más a la proporción total contactada, con una mayor representación de las instituciones de matrícula alta (15.001 - 100.000).

Tabla 29. PROPORCIÓN DE INSTITUCIONES POR TRAMO DE MATRÍCULA (PORCENTAJE)

\begin{tabular}{lccc}
\hline & Muestra & Total & Total contactado \\
\hline $0-100$ & 0,0 & 10,7 & 0,0 \\
$101-1.000$ & 4,1 & 24,7 & 5,8 \\
$1.001-5.000$ & 30,6 & 25,3 & 36,9 \\
$5.001-15.000$ & 20,4 & 23,3 & 34,0 \\
$15.001-100.000$ & 44,9 & 16,0 & 23,3 \\
\hline
\end{tabular}

\subsubsection{Proporción de instituciones según región}

Para clasificar las instituciones según si pertenecen a la Región Metropolitana ${ }^{1} \mathrm{o}$ a otra de las regiones del país, se consideró, en primer

${ }^{1}$ La Región Metropolitana, donde se encuentra la capital Santiago, es la más populosa de Chile, abarcando alrededor del 40 por ciento de la población nacional. Debido al alto grado de centralización del país, en general se habla de "regiones" para referirse a todas las regiones distintas a la Metropolitana. 
lugar, la matrícula por región de cada una. Si no contaban con estudiantes matriculados en la Región Metropolitana se les consideró como "regional". Por el contrario, si sólo contaban con estudiantes matriculados en la Región Metropolitana, se les clasificó en ese grupo. Si la institución contaba con estudiantes matriculados en más de una región, se consideró para la clasificación la ubicación de la casa central o la región donde se concentra el mayor número de estudiantes matriculados. Como se aprecia en la tabla 30, la proporción entre instituciones con sede central en la Región Metropolitana es muy similar a la proporción de la muestra total.

Tabla 30. PROPORCIÓN DE INSTITUCIONES SEGÚN REGIÓN (PORCENTAJE)

\begin{tabular}{lccc}
\hline & Muestra & Total & Total contactado \\
\hline Región Metropolitana & 65,3 & 62,0 & 62,1 \\
Regional & 34,7 & 38,0 & 37,9 \\
\hline
\end{tabular}

Tabla 31. PROPORCIÓN DE INSTITUCIONES POR NIVEL DE ACREDITACIÓN (PORCENTAJE)

\begin{tabular}{lccc}
\hline & Muestra & Total & Total contactado \\
\hline No acreditada & 12,2 & 50,0 & 27,2 \\
2 años & 8,2 & 4,7 & 6,8 \\
3 años & 22,4 & 14,7 & 21,4 \\
4 años & 14,3 & 10,7 & 15,5 \\
5 años & 22,4 & 12,7 & 18,4 \\
6 años & 12,2 & 4,7 & 6,8 \\
7 años & 8,2 & 2,7 & 3,9 \\
\hline
\end{tabular}

10.2.1.4. Proporción de instituciones por nivel de acreditación

La tabla 31 muestra que la proporción de instituciones acreditadas en cualquier tramo es mayor que en la proporción total, pues cerca del 50 por ciento del universo de instituciones no está acreditada. Si en cambio, consideramos nuevamente sólo a los CFT e IP acreditados o con más de 1.000 estudiantes como parte del universo de instituciones contactadas, vemos que la proporción de instituciones contactadas no acreditadas cae a 27 por ciento. La tercera columna indica, por tanto, 
que la muestra utilizada para este estudio representa en mayor medida a las instituciones acreditadas, especialmente las con más de cinco años de acreditación.

\subsubsection{Estudiantes}

En esta sección se presentan las tasas de respuesta totales de los estudiantes que participaron del estudio en su primera ronda. En primera instancia, la tasa de respuesta se mide en función de la cantidad de correos enviados para contactar a los estudiantes de último año que cada institución reportó (40 de las 49 instituciones entregaron información sobre los correos enviados a sus estudiantes; sin embargo, la precisión de estos datos difiere entre instituciones). ${ }^{2}$ Considerando la heterogeneidad de la información del envío de correos, se presenta como segunda medida la tasa de respuesta sobre el total de matrícula de estudiantes de primer año, según la información entregada por el Ministerio de Educación para el año 2016. Lo que se intenta capturar es el tamaño de una cohorte similar a la de los estudiantes considerados en esta encuesta.

Las siguientes tablas (32) consideran la muestra total de 14.146 estudiantes para el total de instituciones participantes. ${ }^{3}$ Las dos primeras columnas muestran la tasa de respuesta medida como porcentaje de respuesta sobre correos enviados o matrícula para cada categoría ("Tasa de respuesta"), y porcentaje de encuestas respondidas por categoría sobre total de encuestas ("Muestra"). Se incluyen dos columnas como punto de comparación. La primera contiene la proporción de matrícula de las instituciones participantes en el estudio. La segunda, replica los resultados de la sección anterior y corresponde a la proporción de matrícula según clasificación para el total de instituciones del país. La razón de incluir estos dos puntos de comparación es para mostrar separadamente dos fuentes de sesgo que presenta este estudio. La primera es la que surge de tener una muestra de instituciones participantes con proporciones diferentes a la población, tal como se vio en la sección anterior. La segunda fuente de sesgo surge de que la fracción de estudiantes contacta-

${ }^{2}$ En algunos casos, la información reportada indicaba que se envió una cantidad de correos considerablemente superior a la matrícula total de la institución.

${ }^{3}$ Cerca del 0,6 por ciento de las 14.230 encuestas totales corresponden a instituciones no participantes. 
dos que contestaron la encuesta al interior de este grupo de instituciones participantes no es necesariamente pareja por institución. ${ }^{4}$

\subsubsection{Proporción de estudiantes por tipo de institución}

La siguiente tabla muestra que casi la mitad de los estudiantes que contestaron la encuesta provienen de universidades privadas. Si contrastamos con que un 30 por ciento de la matrícula total corresponde a este grupo, vemos que los estudiantes de este tipo de instituciones se encuentran sobre representados en la muestra. Si bien las universidades del Cruch tienen una proporción más representativa, los IP se encuentran subrepresentados.

Tabla 32. PROPORCIÓN DE ESTUDIANTES POR TIPO DE INSTITUCIÓN (PORCENTAJE)

\begin{tabular}{lccccc}
\hline & $\begin{array}{c}\text { Tasa } \\
\text { de resp. } \\
\text { (correos) }\end{array}$ & $\begin{array}{c}\text { Tasa } \\
\text { de resp. } \\
\text { (matrícula) }\end{array}$ & Muestra & $\begin{array}{c}\text { Matrícula } \\
\text { IES } \\
\text { participantes }\end{array}$ & $\begin{array}{c}\text { Matrícula } \\
\text { total }\end{array}$ \\
\hline $\begin{array}{l}\text { Centros de formación } \\
\text { técnica }\end{array}$ & 0,2 & 2,3 & 9,1 & 12,6 & 11,4 \\
$\begin{array}{l}\text { Institutos } \\
\text { profesionales }\end{array}$ & 0,4 & 2,4 & 14,0 & 29,4 & 30,8 \\
$\begin{array}{l}\text { Universidades } \\
\text { estatales Cruch }\end{array}$ & 8,7 & 6,0 & 10,9 & 11,5 & 15,4 \\
$\begin{array}{l}\text { Universidades } \\
\text { privadas }\end{array}$ & 1,0 & 9,5 & 49,3 & 33,1 & 30,1 \\
$\begin{array}{l}\text { Universidades } \\
\text { privadas Cruch }\end{array}$ & 14,5 & 8,1 & 16,7 & 13,3 & 12,3 \\
\hline
\end{tabular}

10.2.2.2. Proporción de estudiantes por tramo de matrícula

En la tabla 33 vemos que en términos de la proporción de estudiantes que pertenecen a instituciones según los siguientes tramos de matrícula, la muestra sería representativa.

${ }^{4}$ En este caso se considera el total de instituciones para las cuales se cuenta con información de matrícula en 2016, sin dejar fuera CFT e IP con menos de 1.000 estudiantes sin acreditación. 
Tabla 33. PROPORCIÓN DE ESTUDIANTES POR TRAMO DE MATRÍCULA (PORCENTAJE)

\begin{tabular}{lccccc}
\hline & $\begin{array}{c}\text { Tasa de } \\
\text { resp. } \\
\text { (correos) }\end{array}$ & $\begin{array}{c}\text { Tasa de } \\
\text { resp. } \\
\text { (matrícula) }\end{array}$ & Muestra & $\begin{array}{c}\text { Matricula } \\
\text { IES } \\
\text { participantes }\end{array}$ & $\begin{array}{c}\text { Matrícula } \\
\text { total }\end{array}$ \\
\hline 0-100 & 0,0 & 0,0 & 0,0 & 0,0 & 0,1 \\
$101-1.000$ & 5,0 & 11,6 & 0,5 & 0,1 & 1,3 \\
$1.001-5.000$ & 2,2 & 7,3 & 8,3 & 4,5 & 8,5 \\
$5.001-15.000$ & 4,6 & 12,4 & 24,0 & 10,8 & 25,8 \\
$15.001-100.000$ & 0,6 & 4,4 & 67,2 & 84,5 & 64,4 \\
\hline
\end{tabular}

10.2.2.3. Proporción de estudiantes según región

La tabla 34, de proporción de estudiantes según si la institución a la que pertenece es considerada de la Región Metropolitana o regional, indica que los estudiantes de la Región Metropolitana están ligeramente menos representados, según lo que indicaría la proporción de matrícula de las instituciones que participaron del estudio.

Tabla 34. PROPORCIÓN DE ESTUDIANTES POR REGIÓN (PORCENTAJE)

\begin{tabular}{lccccc}
\hline & $\begin{array}{c}\text { Tasa } \\
\text { de resp. } \\
\text { (correos) }\end{array}$ & $\begin{array}{c}\text { Tasa } \\
\text { de resp. } \\
\text { (matricula) }\end{array}$ & Muestra & $\begin{array}{c}\text { Matricula } \\
\text { IES } \\
\text { participantes }\end{array}$ & $\begin{array}{c}\text { Matricula } \\
\text { total }\end{array}$ \\
\hline Región Metropolitana & 0,7 & 5,1 & 79,5 & 83,5 & 75,4 \\
Regional & 2,9 & 7,0 & 20,5 & 16,5 & 24,6 \\
\hline
\end{tabular}

10.2.2.4. Proporción de estudiantes por nivel de acreditación

La tabla 35 indica que los estudiantes que pertenecen a instituciones con cinco años de acreditación están sobrerrepresentados, pues son una fracción de la muestra casi dos veces mayor que la fracción a la que corresponden sobre el total de instituciones. Los estudiantes de instituciones con tres años de acreditación, en cambio, se encuentran subrepresentados. 
Tabla 35. PROPORCIÓN DE ESTUDIANTES POR NIVEL DE ACREDITACIÓN (PORCENTAJE)

\begin{tabular}{lccccc}
\hline & $\begin{array}{c}\text { Tasa } \\
\text { de resp. } \\
\text { (correos) }\end{array}$ & $\begin{array}{c}\text { Tasa } \\
\text { de resp. } \\
\text { (matricula) }\end{array}$ & Muestra & $\begin{array}{c}\text { Matricula } \\
\text { IES } \\
\text { participantes }\end{array}$ & $\begin{array}{c}\text { Matrícula } \\
\text { total }\end{array}$ \\
\hline No acreditada & 1,6 & 18,7 & 7,0 & 2,3 & 11,0 \\
2 años & 0,2 & 4,9 & 3,4 & 4,5 & 4,0 \\
3 años & 1,2 & 2,0 & 11,2 & 27,5 & 23,7 \\
4 años & 0,8 & 7,9 & 17,3 & 12,6 & 15,7 \\
5 años & 7,1 & 11,2 & 30,7 & 17,0 & 18,4 \\
6 años & 0,3 & 3,6 & 11,7 & 14,8 & 11,8 \\
7 años & 1,2 & 5,1 & 18,8 & 21,3 & 15,4 \\
\hline
\end{tabular}

\subsubsection{Proporción de estudiantes por sexo}

El análisis de representatividad en términos de género, mostrado en la tabla 36, se realizó comparando la proporción de estudiantes que contestaron "Hombre" o "Mujer" en la pregunta de sexo de la encuesta, y la proporción en la matrícula total entre hombres y mujeres de las instituciones participantes del estudio y la matrícula total. Aquí podemos observar que la proporción entre hombres y mujeres es representativa a nivel nacional.

Tabla 36. PROPORCIÓN DE ESTUDIANTES POR SEXO (PORCENTAJE)

\begin{tabular}{lccc}
\hline & Muestra & Matricula participantes & Matricula total \\
\hline Proporción de mujeres & 54,2 & 50,7 & 52,2 \\
\hline
\end{tabular}

\subsubsection{Proporción de estudiantes por dependencia escolar}

Finalmente, se analiza la composición de estudiantes según si cursaron su enseñanza media en un establecimiento municipal, particular subvencionado (o de administración delegada) o particular pagado. En este caso, la matrícula que se utiliza como punto de comparación es la que entrega el Ministerio de Educación para el año 2016 para estos tres tipos de establecimientos. Cabe destacar que en los datos del Ministerio sólo el 85,7 por ciento de la matrícula total de las instituciones está 
considerada en alguna de estas tres categorías. Según lo que muestra la tabla 37 , la muestra tendría, frente al total nacional, una menor proporción de estudiantes de establecimientos municipales y particulares subvencionados y una mucho mayor proporción de estudiantes de establecimientos particulares pagados.

Tabla 37. PROPORCIÓN DE ESTUDIANTES POR DEPENDENCIA ESCOLAR (PORCENTAJE)

\begin{tabular}{lccc}
\hline & Muestra & Matrícula participantes & Matrícula total \\
\hline Municipal & 25,9 & 30,3 & 31,7 \\
Particular subvencionado & 46,8 & 55,6 & 55,7 \\
Particular pagado & 27,3 & 14,1 & 12,6 \\
\hline
\end{tabular}

\section{CUESTIONARIO}

\subsection{Diseño}

El cuestionario de la primera ola incluyó principalmente tres módulos (además de un módulo de preguntas para una caracterización demográfica básica):

1. Un módulo sobre la experiencia del estudiante en la educación superior, incluyendo preguntas sobre su satisfacción con distintas dimensiones de su institución, percepción sobre la existencia de apoyos, de aprendizaje, etcétera.

2. Un módulo sobre expectativas de inserción laboral, destinado a conocer el tipo de trabajo que el estudiante espera obtener en un año más.

3. Un módulo sobre la visión de los estudiantes respecto del país, incluyendo preguntas sobre cómo ven a Chile y sobre comportamiento político.

La segunda encuesta, a aplicarse, transcurrido un año desde la primera, incluirá un módulo sobre el proceso de inserción laboral y otro, nuevamente, sobre visión de mundo. La elaboración de ambos cuestionarios estuvo a cargo de un equipo académico experto y bajo la supervisión de expertos internacionales. Además, ambos fueron y serán testeados previamente para asegurar su pertinencia. 


\subsection{Cuestionario Estudio de educación superior}

Te hemos contactado gracias a la colaboración de tu institución de educación superior, para invitarte a participar en un estudio académico dirigido por un equipo de investigadores del Centro de Estudios Públicos (CEP) y del Instituto Tecnológico de Massachusetts (MIT).

El objetivo del estudio es comprender cómo los propios estudiantes de la educación superior evalúan su paso por ella, cuáles son sus expectativas laborales y conocer algunas de sus ideas sobre la sociedad.

Para ello te pedimos que nos ayudes contestando una encuesta de menos de 15 minutos. Por completar la encuesta podrás participar del sorteo ${ }^{5}$ de:

-5 mini Ipads 2

-10 entradas para Lollapalooza 2017

-40 giftcards de $\$ 15.000$ en Cencosud (París, Jumbo y otros)

Tu participación es muy importante para comprender cómo funciona nuestra educación superior y los cambios sociales, culturales y políticos asociados a ella. Esperamos que este estudio contribuya a mejorar la educación superior en Chile.

\section{Indicaciones}

Esta encuesta es voluntaria y debes ser mayor de 18 años para contestarla. Sólo nos interesa analizar datos anónima y confidencialmente, y sólo con fines de investigación. Los datos se analizarán de manera agregada, impidiendo la identificación de las personas y de las instituciones de educación superior. Puedes contestar esta encuesta una sola vez.

Si tienes cualquier pregunta, escríbenos a estudio.ed.superior@ cepchile.cl. Al continuar accedes voluntariamente a contestar esta encuesta.

-Acepto participar

P1. Considerando todas las cosas, ¿cuán satisfecho estás con tu vida en este momento? En una escala en que 1 significa estar "totalmente insatisfecho" y 10 significa que "totalmente satisfecho". ¿Dónde te ubicarías?

\footnotetext{
${ }^{5}$ Los resultados del sorteo serán publicados en enero en www.cepchile.cl.
} 
P2. Tu institución de educación superior es:

-Universidad

-Instituto Profesional (IP)

-Centro de Formación Técnica (CFT)

(Si la opción "Universidad" es elegida)

P2.1. Tus estudios corresponden a:

-Carrera profesional Carrera técnica Postítulo

-Magíster

-Doctorado

(Si las opciones "Postítulo" o "Doctorado" son elegidas)

Lo sentimos, pero no eres elegible para esta encuesta. Muchas gracias.

P3. ¿En qué etapa de tus estudios de educación superior te encuentras? (Entenderemos que finalizar estudios significa estar listo para ingresar de lleno al mundo laboral).

-Espero finalizar mis estudios este año (2016)

-Espero finalizar mis estudios el próximo semestre

-Ya finalicé mis estudios

(Si opción "Espero finalizar mis estudios el próximo semestre" es elegida)

P3.1. ¿Cuándo esperas finalizar tus estudios? Marca tu mejor estimación.

-Primer semestre de 2017

-Segundo semestre de 2017

-Primer semestre de 2018

-Segundo semestre de 2018 o después

(Si opción "Ya finalicé mis estudios" es elegida)

P3.2. ¿Cuándo finalizaste tus estudios?

-Primer semestre de 2016

-Segundo semestre de 2015

-Primer semestre de 2015

-En 2014 o antes 
P4. ¿Cuál es el tipo de jornada que más se adecúa a tus estudios? Puedes marcar más de una, si correspondiera.

-Diurno

-Vespertino

-A Distancia

-Semipresencial

- Otro

P5. Llena los siguientes datos sobre tus estudios: (Elige la carrera que mejor se ajuste a tu plan de estudios).

-Tipo de institución

-Institución

-Carrera

P6. Si tu carrera no aparece o aparece con un nombre distinto, escríbela aquí:

En adelante, cuando nos refiramos a "tu institución de educación superior" y a "tu carrera", piensa en los datos que recién seleccionaste.

P7. Considerando todas las cosas, ¿qué nota le pondrías a tu institución de educación superior?

(Escala 1 a 7).

P8. ¿Y qué nota le pondrías a tu carrera?

(Escala 1 a 7).

P9. ¿Cuáles de los siguientes factores fueron los más importantes al momento de elegir tu institución de educación superior? Puedes marcar hasta 3 alternativas.

-Ubicación

-Arancel y posibilidades de financiamiento

-El tipo de estudiantes

-Su nivel académico y prestigio

-Orientación o áreas de especialización en mi carrera

-Oportunidades laborales de los egresados de la institución

-Me la recomendaron familiares o conocidos

-Era la mejor opción dado mi puntaje 
-Horarios disponibles

-Su acreditación

P10. ¿Cuáles de los siguientes factores fueron los más importantes al momento de elegir tu carrera? Puedes marcar hasta 3 alternativas.

-Vocación

-Oportunidades laborales de los egresados de la carrera

-Arancel y posibilidades de financiamiento

-Prestigio de la carrera

-Sus asignaturas o cursos

-Me la recomendaron familiares o conocidos

-Era la mejor opción dado mi puntaje

-Su nivel académico

-Horarios disponibles

P11. ¿Qué tan preparado/a sientes que estabas, académicamente, para estudiar tu carrera en el momento que ingresaste a ella?

Nada preparado 1234567 Muy preparado

P12. ¿Cómo evalúas el nivel de exigencia académica de tu carrera? Nada exigente 1234567 Muy exigente

P13. ¿Cuántas dificultades económicas has tenido durante tus estudios?

-Ninguna dificultad

-Algunas dificultades

-Muchas dificultades

P14. ¿Cuántas dificultades de rendimiento académico has tenido durante tus estudios?

-Ninguna dificultad

-Algunas dificultades

-Muchas dificultades

(Si las opciones "Algunas dificultades" o "Muchas dificultades" son elegidas)

P14.1. ¿Qué tanto apoyo has recibido por parte de tu institución con tus dificultades de rendimiento académico? 
Nada de apoyo 1234567 Mucho apoyo

P15. ¿Qué tan preparado te sientes para enfrentar el mundo laboral? Nada preparado 1234567 Muy preparado

P16. En general, ¿qué tanta motivación hacia el estudio tienen tus compañeros?

Nada motivados 1234567 Muy motivados

P17. En general, ¿qué nivel académico tienen tus compañeros?

Pésimo nivel 1234567 Excelente nivel

P18. En general, ¿qué tanto respeto hay en el ambiente de tu institución hacia las personas o las opiniones diferentes?

Nada de respeto 1234567 Mucho respeto

P19. ¿Qué nota le pondrías a tu institución de educación superior en términos de?:

- ¿Infraestructura y equipamiento? (escala 1 a 7 )

$-i$ Sus profesores? (escala 1 a 7 )

P20. Si pudieras volver atrás en el tiempo, del 1 al 7, ¿qué tan probable sería que volvieras a elegir...?

-Seguir estudios superiores

Nada probable 1234567 Muy probable

-Ingresar a tu carrera

Nada probable 1234567 Muy probable

-Ingresar a tu institución de educación superior

Nada probable 1234567 Muy probable

P21. Pensando en un año más, ¿te gustaría estar trabajando o estudiando?

-Me gustaría estar trabajando

-Me gustaría estar estudiando (Pase a P34)

-Me gustaría estar trabajando y estudiando

-No me gustaría estar trabajando ni estudiando 
(Si la opción "No me gustaría estar trabajando ni estudiando" es elegida)

P21.1. ¿Qué esperas estar haciendo en un año más? (Pase a P34)

P22. Pensando en un año más: ¿qué tan probable ves que estés trabajando?

Nada probable 12345678910 Muy probable

P23. En el caso que estés trabajando, ¿cuál jornada de trabajo ves más probable que tengas en un año más?

-Jornada completa

-Jornada parcial correspondiente a más que medio tiempo

- Jornada parcial correspondiente a medio tiempo

-Jornada parcial correspondiente a menos que medio tiempo.

P24. En el caso que estés trabajando en un año más, ¿aproximadamente qué sueldo líquido mensual esperas estar ganando?

(Por "sueldo líquido" entendemos el que llega efectivamente a tu bolsillo)

P25. Y pensando en cuando lleves cuatro años trabajando, ¿aproximadamente qué sueldo líquido mensual esperas estar ganando?

P26. ¿Cuán seguro te sientes sobre las expectativas de sueldo que elegiste?

Nada seguro 1234567 Muy seguro

P27. Si en un año más estás trabajando, ¿qué tan relacionado crees que estará tu trabajo con lo que estudiaste?

Nada relacionado 1234567 Muy relacionado

P28. ¿Y qué tanto crees que te gustará tu trabajo?

Nada 1234567 Mucho

P29. Imagina que quisieras buscar trabajo ahora, ¿cuánto tiempo crees que te demorarías en encontrar? 
- Menos de 1 mes

-Entre 1 y 2 meses

-Entre 3 y 6 meses

-Entre 6 meses y un año

-Más de un año

P30. Pensando en tus compañeros de carrera, ¿crees que tendrás más, menos o similares oportunidades laborales que ellos?

-Más oportunidades laborales que mis compañeros

-Menos oportunidades laborales que mis compañeros

-Similares oportunidades laborales que mis compañeros

P31. El sitio web www.MiFuturo.cl, del Ministerio de Educación, entrega información sobre empleabilidad e ingresos esperados para varias combinaciones de carrera e institución de educación superior. ¿Estabas al tanto de esto? ¿Te has metido alguna vez a MiFuturo.cl?

-Sí, estaba al tanto y he ingresado a MiFuturo.cl

-Sí, estaba al tanto, pero no he ingresado

-No estaba al tanto

P32. De acuerdo a los datos de MiFuturo.cl, los titulados de (Carrera) en (Institución) después de un año de titulados tienen $\mathrm{X} \%$ de probabilidad de tener empleo y después de cuatro años de titulados tienen un sueldo líquido mensual promedio $\$ X X X$. De lo que tú conoces o has escuchado, ¿cuán bien se ajustan estos datos a la realidad de las oportunidades laborales de tu carrera?

Hay peores oportunidades laborales 1234567 Hay mejores oportunidades laborales

P33. Si tienes algún comentario sobre los datos de MiFuturo.cl, escríbelo aquí:

Ahora queremos saber tu opinión sobre algunas cosas.

P34. ¿Qué tan mal o qué tan bien crees que funcionan las siguientes instituciones en Chile?

-La democracia: Muy mal 1234567 Muy bien

-El sistema económico: Muy mal 1234567 Muy bien 
P35. En tu opinión, ¿los ingresos deberían hacerse más iguales o debería premiarse el esfuerzo individual? ¿Dónde te ubicarías en esta escala?

Ingresos más iguales, aunque no se premie el esfuerzo individual 12345678910 Premio al esfuerzo individual, aunque ingresos sean más desiguales

P36. Ahora, respecto quién debería tener la principal responsabilidad por el sustento económico de las personas, ¿dónde te ubicarías en esta escala?

En el Estado 12345678910 En las personas mismas

P37. ¿Cuán responsable crees que es el Estado de los ingresos y oportunidades laborales que tienen los titulados de la educación superior?

Nada responsable 1234567 Muy responsable

P38. ¿Qué tan de acuerdo estás con las siguientes afirmaciones?

-“Toda persona que esté dispuesta a trabajar tiene bastantes posibilidades de que le vaya bien económicamente" (Escala 1 a 7)

-"La mayoría de la gente a la que le va mal económicamente no debiera culpar al sistema, sino a sí misma” (Escala 1 a 7)

P39. ¿Dónde ubicarías a Chile en una escala del 1 al 7 entre los siguientes polos?

-Nada desigual 1234567 Muy desigual

-Sin divisiones políticas 1234567 Muy dividido políticamente

-Con mal futuro 1234567 Con un buen futuro

-Nada discriminador 1234567 Muy discriminador

-Anticuado 1234567 Moderno

P40. Como sabes, tradicionalmente en nuestro país, la gente define las posiciones políticas como más cercanas a la izquierda, al centro o a la derecha. ¿Con cuál posición te identificas o simpatizas más?

-Derecha

-Centro derecha

- Centro 
-Centro izquierda

-Izquierda

-Independiente

-Ninguna

P41. Desde que Chile recobró la democracia en 1990, han gobernado tres coaliciones. ¿Qué nota le pondrías a cada una de ellas?

-Concertación (1990-2010; Aylwin, Frei, Lagos, Bachelet I) (Escala 1 a 7$)$

-Alianza por Chile (2010-2014; Piñera; actual Chile Vamos) (Escala 1 a 7 )

-Nueva Mayoría (gobierno actual, desde 2014, Bachelet II) (Escala 1 a 7$)$

P42. ¿Y qué nota le pondrías al movimiento estudiantil?

(Escala 1 a 7 )

P43. ¿Cuán interesado estás en la política?

-Muy interesado

-Bastante interesado

-Algo interesado

-Nada interesado

P44. Para cada una de las siguientes actividades, indica si las realizas frecuentemente, a veces o nunca.

-Leer noticias sobre política

-Oír o ver programas políticos en la radio o TV

-Conversar con otras personas sobre política

- Tratar de convencer a alguien de lo que piensas políticamente

-Expresar tu opinión política en internet

-Asistir a marchas o manifestaciones

P45. Como sabes, en Chile, el voto es voluntario, es decir, cada persona puede decidir si votar o abstenerse. De hecho, la mayoría de la gente se abstuvo en las últimas elecciones municipales. ¿Votaste en las elecciones municipales de octubre pasado?

- Sí

$-\mathrm{No}$ 
Para terminar, queremos preguntarte algunas cosas sobre ti.

P46. ¿Cómo has financiado tus estudios? Para cada fuente de financiamiento, marca la alternativa que corresponda según cuán importante ha sido para financiar tus estudios.

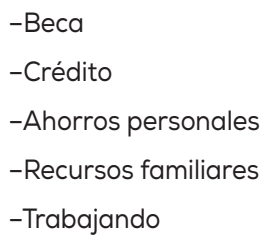

\begin{tabular}{|l|l|l|l|l} 
Nada & Poco & Bastante & Mucho & Todo \\
\hline & & & & \\
\hline & & & & \\
\hline & & & & \\
\hline & & & & \\
\hline & & & & \\
\hline
\end{tabular}

(Si la opción "Beca" fue elegida con más que "Nada" de importancia)

P46.1. ¿Cuál o cuáles beca tienes o tenías? Marca todas las que correspondan.

-Beca Bicentenario

-Beca Juan Gómez Millas

-Beca Nuevo Milenio

-Beca Excelencia Académica

-Beca Vocación de Profesor

-Beca Reparación Valech

-Beca Hijos de Profesores

-Beca de Articulación

-Beca Nivelación Académica

-Beca de mi institución de educación superior

-Otra beca

(Si la opción "Crédito" fue elegida con más que "Nada" de importancia)

P46.2. ¿Cuál o cuáles créditos tienes o tenías? Marca todos los que correspondan.

-Crédito con Aval del Estado

-Fondo Solidario de Crédito Universitario

-Crédito otorgado por banco o institución financiera

-Otro crédito 
P47. ¿Tienes estudios superiores previos a los de tu actual carrera e institución?

- No

-Sí, la misma carrera en otra institución

-Sí, otra carrera en la misma institución

-Sí, otra carrera en otra institución

P48. De las siguientes alternativas, marca todas las que correspondan:

-Actualmente estoy trabajando tiempo completo

-He trabajado tiempo completo alguna vez por al menos 6 meses

-Actualmente estoy trabajando tiempo parcial

-Tengo experiencia laboral en algo relacionado a mi carrera (excluyendo prácticas o pasantías)

-Actualmente estoy buscando trabajo

P49. ¿Cuál es tu sexo?

-Mujer

-Hombre

P50. ¿Qué año naciste?

P51. ¿En qué región y comuna vives?

- Región

-Comuna

P52. ¿En qué región y comuna estudias (o estudiaste) tu carrera?

-Región

-Comuna

P53. ¿Tienes hijos?

- Sí

$-\mathrm{No}$

P54. Pensado en el establecimiento en el que terminaste la educación media, ¿cuál era su dependencia administrativa?

-Municipal 
-Particular subvencionado

- Particular pagado

-De administración delegada

P55. ¿Y cuál era su modalidad de estudios?

-Científico-Humanista

-Técnico-Profesional

P56. ¿Cuál es el máximo nivel educacional alcanzado por tu madre?

-No estudió

-Educación básica incompleta

-Educación básica completa

-Educación media incompleta

-Educación media completa

-Educación superior no universitaria incompleta

-Educación superior no universitaria completa

-Educación universitaria incompleta

-Educación universitaria completa

-Estudios de postgrado, máster, doctorado

- No sé

P57. ¿Y cuál es el máximo nivel educacional alcanzado por tu padre?

-No estudió

-Educación básica incompleta

-Educación básica completa

-Educación media incompleta

-Educación media completa

-Educación superior no universitaria incompleta

-Educación superior no universitaria completa

-Educación universitaria incompleta

-Educación universitaria completa

-Estudios de postgrado, máster, doctorado

-No sé 
Con el fin de poder contactarte en caso que seas ganador de uno de los 5 Ipads, 10 entradas a Lollapalooza o 40 giftcards, danos tu correo electrónico.

(No compartiremos tu correo con nadie ni lo usaremos para nada más que para lo que te hemos informado. Guardaremos tu correo en un servidor seguro y lo eliminaremos una vez que el estudio haya finalizado).

¿Nos autorizas a volver a contactarte dentro de un año para solicitarte tu participación en una nueva encuesta para ver si tus expectativas laborales se cumplieron, entre otras cosas? En esa ocasión, te recordaremos cuáles eran tus expectativas hoy y nuevamente sortearemos premios. Por supuesto, siempre puedes negarte a contestar la nueva encuesta. ¡Sortearemos un iPad adicional entre los que nos permitan volver a contactarlos!

- Sí

$-\mathrm{No}$

Finalmente, queremos pedirte tu rut, con el solo fin de poder cruzar tus respuestas con datos oficiales. No lo compartiremos con nadie ni lo usaremos para nada más que para lo que te hemos informado. Guardaremos tu rut en un servidor seguro y lo eliminaremos una vez que el estudio haya finalizado. ¡Sortearemos otro iPad adicional entre los que nos entreguen su rut! Si accedes, escribe tu rut sin puntos ni guiones:

¡Muchas gracias por tu participación! El sorteo de los premios se realizará en enero próximo. Te contactaremos si sales elegido. 